\author{
UNIVERSIDADE DE SÃO PAULO \\ FACULDADE DE MEDICINA DE RIBEIRÃO PRETO
}

Nutroterapia parenteral, crescimento de biofilmes

e fatores associados à infecção do cateter venoso

central

Juliana de Carvalho Machado

RIBEIRÃO PRETO

Maio 2010 

Nutroterapia parenteral, crescimento de biofilmes

e fatores associados à infecção do cateter venoso central

Tese apresentada à Faculdade de Medicina de Ribeirão Preto, Universidade de São Paulo para obtenção de título de Doutor em Clínica Médica

Área de Investigação Clínica

Orientador: Prof. Dr. Júlio Sérgio Marchini

Ribeirão Preto 
Autorizo a reprodução e divulgação total ou parcial deste trabalho, por qualquer meio convencional ou eletrônico, para fins de estudo e pesquisa, desde que citada a fonte.

Ficha Catalográfica elaborada pela Biblioteca Central Campus USP- Ribeirão Preto

Machado, Juliana de Carvalho

Nutroterapia parenteral, crescimento de biofilmes e fatores associados à infecção do cateter venoso central. Ribeirão Preto, 2010.

122 p. .il.; $30 \mathrm{~cm}$

Tese de Doutorado - Programa de Pós Graduação em Clínica Médica - Área de Investigação Clínica - Faculdade de Medicina de Ribeirão Preto.

Orientador: Marchini, Júlio Sérgio

1. Nutroterapia Parenteral; 2.Cateter Venoso Central;

3. Biofilmes; 4. Infecção sanguínea 
Dedicatória e Agradecimentos 



\section{Dedicatória}

Ao Universo, por me permitir ser um SER em constante transformação sempre em contato com o novo

Ao Prof. Dr. José Fernando de Castro Figueiredo, in memoriam, pelos ensinamentos e contribuição a mim doados 


\section{Agradecimento Especial}

Ao CNPq pelo processo número 305551, que nos auxiliou a concretizar etapas deste projeto, que de algum modo poderá ser útil para àqueles que prescrevem ou que necessitam da nutroterapia parenteral. 


\section{Por ISSO...}

Vivo e canto sem a vergonha

De ser uma eterna aprendiza

POR ISSO...

AGRADEÇO...

A todos que me ajudaram e

Permitiram-me a concretizar sonhos

RECONHEÇO...

Todo o amor incondicional

Sempre doado por meus pais

CONHEÇO...

Pessoas maravilhosas que não temem

E que compartilham o conhecimento

REFORÇO...

A fé todos os dias em DEUS

$\mathrm{O}$ apoio da minha família e amigos

ESQUEÇO...

Os intempéries e obstáculos no meu caminho

Mas que são imprescindíveis para o meu crescimento

PORTANTO...

ESCUTO...

Aqueles que mesmo em momentos de dor

Permitem-se doar e compartilhar

LUTO...

Para apaziguar e reduzir o sofrimento

Daqueles com dor, mas que têm esperança

INVENTO...

Técnicas, desafios ou estratégias

Para uma transformação sem temer o novo

ESTIMO...

A divulgação e compartilhamento mais humano

Do conhecimento e das informações

PERMITO...

Pois sei que tudo que é bom,

Dura o tempo necessário para ser inesquecível

ENFIM...

CANTO...

"É a vida, é bonita e é bonita!

Viver, e não ter a vergonha de ser feliz

Cantar e cantar e cantar

A beleza de ser um eterno aprendiz

Ah meu Deus eu sei, eu sei

Que a vida devia ser bem melhor e será

Mas isso não impede que eu repita

É bonita, é bonita e é bonita ! (Gonzaguinha)" 

Banca Examinadora 

Nome: Machado, Juliana de Carvalho

Título:Nutroterapia parenteral, crescimento de biofilmes e fatores relacionados à infecção do cateter venoso central

Tese apresentada à Faculdade de Medicina de Ribeirão Preto, Universidade de São Paulo para obtenção de título de Doutor em Clínica Médica

Área de Investigação Clínica

Aprovado em

\section{Banca Examinadora}

\section{Titulares}

Prof Dr. Júlio Sérgio Marchini (FMRP-USP):

Parecer:

Profa. Dra. Alcyone Artioli Machado (FMRP-USP):

Parecer:

Profa. Dra. Vivian Marques Miguel Suen (FMRP-USP):

Parecer:

Profa. Dra. Ana Lúcia da Costa Darin (FCFRP-USP):

Parecer:

Prof. Dr. José Renan da Cunha Melo (UFMG):

Parecer: 
Nome: Machado, Juliana de Carvalho

Título:Nutroterapia Parenteral, Crescimento de Biofilmes e Fatores Relacionados à Infecção do Cateter Venoso Central

Tese apresentada à Faculdade de Medicina de Ribeirão Preto, Universidade de São Paulo para obtenção de título de Doutor em Clínica Médica Área de Investigação Clínica

Aprovado em 24 de maio de 2010

\section{Banca Examinadora}

\section{Titulares}

Prof Dr. Júlio Sérgio Marchini

Profa. Dra. Alcyone Artioli Machado

Profa. Dra. Vivian Marques Miguel Suen

Profa. Dra. Ana Lúcia da Costa Darini

Prof. Dr. José Renan da Cunha Melo

\section{Suplentes}

Prof. Dr. Hélio Vannucchi

Prof. Dr. Roberto Martinez

Profa. Dra. Selma Freire de Carvalho da Cunha

Prof. Dr. Fernando Bellíssimo Rodrigues

Prof. Dr. Henrique Oswaldo da Gama Torres 
1

Resumo 



\section{RESUMO}

A introdução da nutroterapia parenteral (NTP) contribuiu para redução da morbimortalidade de pacientes com contraindicação de uso do trato gastrointestinal. Porém, está relacionada a complicações clínicas, destacando-se a infecção associada ao uso de cateteres venosos centrais (CVCs) e a formação de biofilmes, que podem contribuir para piora clínica daqueles que necessita da NTP. O objetivo deste estudo foi avaliar a presença de biofilmes, a infecção sanguínea secundária ao uso de CVC utilizados em nutroterapia e os fatores de riscos associados ao processo infeccioso. Por meio de estudo clínico prospectivo, durante janeiro a junho de 2008, avaliou-se clinicamente por meio de registros médicos e de enfermagem todos pacientes em uso de parenteral internados no Hospital das Clínicas da Faculdade de Medicina de Ribeirão Preto, assim como os cateteres utilizados pelos mesmos, por meio de técnicas de cultura semiquantitativas e de hemoculturas. Aleatoriamente, algumas amostras dos CVCs utilizados foram enviadas para microscopia eletrônica de varredura e de alguns pacientes e de alguns profissionais da saúde foram coletados amostras se swab de pele. Foram avaliados 145 pacientes com idade média de $53 \pm 16$ anos, destes $46 \%$ cursaram com infecção associada ao uso de CVC, ocorrendo óbito em $43 \%$ dos casos. A mortalidade foi associada ao maior risco de infecção (0.007), a complicações metabólicas como hiperglicemia $(p<0.001)$ e distúrbio hidroeletrolítico $(p=0.036)$ e à desnutrição $(p=0.03)$. Com relação ao CVC, foram analisados um total de 179 CVCs, desses 49\% estavam colonizados por micro-organismos e 34\% foram relacionados à infecção sanguínea, não foram observadas diferenças clínicas quanto ao risco de colonização ou infecção sistêmica relacionada aos CVCs. Observou-se o risco de infecção cruzada em $21 \%$ do swabs auriculares coletados da equipe de saúde que assitia ao paciente. O risco da migração de micro-organismo da própria pele do paciente foi observado em $45 \%$ dos swabs coletados da mão e da região auricular do paciente. Quanto ao biofilme, foi observado a formação em $62 \%$ das amostras analisadas, sendo cocos mais comuns e Staphylococcus spp (39\%) e Candida spp (19\%) os micro-organismos mais frequentes. Conclui-se que a presença de biofilmes e infecção associada ao CVC utilizado para NTP é frequente e está relacionada ao aumento da mortalidade dos pacientes que necessitam desta nutroterapia

Unitermos: Nutroterapia Parenteral, Cateter Venoso Central, Biofilmes, Infeção sanguínea 


\begin{abstract}
The introduction of parenteral nutrition therapy (PNT) has helped to reduce morbidity and mortality of patients with contraindications for use of the gastrointestinal tract. However, is related to clinical complications, especially infection associated with the use of central venous catheters (CVCs) and the formation of biofilms, which may contribute to clinical worsening of those who need the PNT. The aim of this study was to evaluate the presence of biofilms, the risk of infection related to the use of CVC used in parenteral nutrition, as well as risk factors associated with infection. Through a prospective study during January to June 2008 were evaluated clinically by means of medical records and nursing all patients who needed parenteral nutrition support at Hospital das Clinicas da Faculdade de Medicina de Ribeirao Preto, as well as catheters used by them, by means of semiquantitative culture techniques and blood cultures. Randomly, some samples of CVCs used were sent for scanning electron microscopy. Also, some samples of skin's swabs were collected from, some patients and some health professionals. We evaluated 145 patients with mean age $53 \pm 16$ years, $46 \%$ of those presenting with infection associated with the use of CVC, death occurring in $43 \%$ of cases. Mortality was associated with increased risk of infection (0.007), hyperglycemia $(p<0.001)$, electrolyte disturbance $(p=$ 0.036 ) and malnutrition $(p=0.03)$. Regarding the CVC were analyzed a total of 179 CVCs, $49 \%$ of these were colonized by micro-organisms and $34 \%$ were related to bloodstream infection, there were no clinical differences between the risk of colonization or bloodstream infection related to CVCs. It was noted the risk of cross infection in $21 \%$ of ear swabs collected from the health team whom attended to the patient. The risk of migration of micro-organism of the patient's own skin was observed in $45 \%$ of the swabs collected from the hand and around patient's ear. Biofilm formation was observed in $62 \%$ of samples, being more common cocci. Staphylococcus spp (39\%) and Candida spp (19\%) were the most frequent micro-organisms. The presence of biofilms and infection related to CVC used for NTP is frequent and is associated with increased mortality of patients who need this nutritional support.
\end{abstract}

Key words: Parenteral Nutrition, Central Venous Catheter, Biofilms, Blood-stream Infection. 
Listas e Sumário 



\section{LISTA DE ABREVIATURAS E SIGLAS}

\section{A. baumanni: Acinetobacter baumanni}

BHI: Brain Hearth Infusion

C. albicans: Candida albicans

C. parapsilosis: Candida parapsilosis

CDC: Centers for Disease Control and Prevention

CIM: Concentrações inibitórias mínimas

Cols: colaboradores

CTI: Centro de terapia intensiva

CVC: Cateter venoso central

CVCs: Cateteres venosos centrais

DDR: DIETAS DENUNCIAM RISCO

DHE: Distúrbio hidroeletrolítico

EHT: extremely high tension

E.coli: Escherichia coli

G1: grupo 1

G2: grupo 2

HCFMRP-USP: Hospital das Clínicas da Faculdade de Medicina de Ribeirão Preto da Universidade de São Paulo

IMC: Î́ndice de massa corpórea

K. pneumonae: Klebsiella pneumonae

Mag: Magnitude

MEV: Microscopia eletrônica de varredura

MH: Mueller-Hinton

MRSA: Staphylococcus aureus resistentes a meticilina

NTP: Nutroterapia Parenteral

PNT: Parenteral nutrition therapy

P. aeruginosa: Pseudomonas aeruginosa 
QD: Quinupristina+Dalfopristina

S. aureus: Staphylococcus aureus

S. coagulase negativo: Staphylococcus coagulase negativo

S. epidermidis: Staphyloccocus epidermidis

S. marcescens: Serratia marcescens

spp: espécies

SVR: sem valor de referência

TCLE: Termo de consentimento livre e esclarecido

UFC: Unidades formadoras de colônia

Vs.: Versus 


\section{LISTA DE SÍMBOLOS E UNIDADES}

\%: porcentagem

<: menor do que

>: maior do que

士: desvio padrão

<.tiff>: Tagged image file format

${ }^{\circ} \mathrm{C}$ : graus Celsius

Chí : teste do qui quadrado

G (-): gram negativo

g. $\mathrm{L}^{-1}$ : gramas por litro

kg: quilograma

kg. $\mathbf{m}^{-2}$ : quilogramas por metro quadrado

m: metro

mEq. $\mathrm{L}^{-1}$ : miliequivalentes por litro

$\mathbf{m g} \cdot \mathbf{d L}^{-1}$ : miligramas por decilitro

$\mathbf{m m}^{-3}$ : por milimetro cúbico

mmol.L ${ }^{-1}$ : milimol por litro

n: número

pH: potencial hidrogeniônico

$\mu \mathrm{g} \cdot \mathrm{ml}^{-1}$ : micrograma por mililitro

$\mu \mathrm{m}$ : micrometro 


\section{LISTA DE FIGURAS}

Figura 1 - Prováveis mecanismos associados à infecção de cateter venoso central utilizado na nutroterapia parenteral ............................ 2

Figura 2 - Estágios de formação e vida de um biofilme ............................. 4

Figura 3 - Microfotografias de cateteres venosos centrais utilizados para nutroterapia parenteral obtidas por microscopia eletrônica de varredura, mostrando micro-organismos aderidos aos lumens dos cateteres

Figura 4 - Irregularidades dos lumens internos dos cateteres venosos centrais observados à microscopia eletrônica de varredura .........

Figura 5 - Microfotografias de partículas químicas e residuais de soluções utilizadas para nutroterapia parenteral

Figura 6 - Delineamento experimental para avaliação de pacientes em nutroterapia parenteral no período de janeiro a junho de 2008 ...

Figura 7 - Delineamento experimental para avaliação de cateteres venosos centrais utilizados para nutroterapia parenteral no período de janeiro a junho de 2008

Figura 8 - Sítio de implante dos cateteres venosos centrais no período de janeiro a junho de 2008

Figura 9 - Tipos de cateteres utilizados para nutroterapia parenteral no período de janeiro a junho de 2008

Figura 10 - Frequência de Infecção e colonização do cateter quanto ao sítio de implante, janeiro a junho de 2008

Figura 11 - Frequência de Infecção e de colonização do dispositivo quanto ao tipo de cateter, janeiro a junho de 2008

Figura 12 - Comparação dos resultados das culturas semi quantitativa da ponta do cateter versus à análise obtida por microscopia eletrônica de varredura do mesmo cateter

Figura 13 - Características morfológicas dos micro-organismos observados no biofilme formados nos cateteres venosos centrais utilizados em janeiro a junho de 2008

Figura 14 - Microfotografias eletrônicas de varredura mostrando estruturas cocóides aderidas aos lumens dos cateteres venosos centrais 
utilizados para nutroterapia parenteral

Figura 15 - Microfotografias eletrônicas de varredura de bastonetes aderidos aos lumens dos cateteres venosos centrais utilizados para nutroterapia parenteral

Figura 16 - Microfotografias eletrônicas de varredura de cateteres venosos centrais utilizados para nutroterapia parenteral. $\mathrm{Na}$ cultura semiquantitativa observou o crescimento de Acinetobacter baumanni

Figura 17 - Microfotografia eletrônica de varredura de cateter venoso central utilizado para nutroterapia parenteral. $\mathrm{Na}$ cultura semiquantitativa observou o crescimento de Candida albicans ..

Figura 18 - Microfotografias eletrônicas de varredura de cateteres venosos centrais utilizados para nutroterapia parenteral mostrando materiais biológicos que favorecem à formação de biofilme

Figura 19 - Microfotografia eletrônica de varredura de hemácias aderidas ao lúmen do cateter venoso central utilizado para nutroterapia parenteral, HCFMRP-USP, janeiro a junho de 2008

Figura 20 - Microfotografia eletrônica de varredura de linfócitos aderidos ao lúmen do cateter venoso central utilizado para nutroterapia parenteral, HCFMRP-USP, janeiro a junho de 2008

Figura 21 - Microfotografias eletrônicas de varredura de estruturas arredondadas e de debris aderidos aos lumens dos cateteres venosos centrais utilizados para nutroterapia parenteral, HCFMRP-USP, janeiro a junho de 2008

Figura 22 - Resultados das culturas dos swabs de pele coletados no HCFMRP-USP, janeiro a junho de 2008

Figura 23 - Frequência de concordância entre resultados das culturas semiquantitativas do cateter e dos swabs de pele coletados no HCFMRP-USP, janeiro a junho de 2008 


\section{LISTA DE TABELAS}

Tabela 1- Patógenos mais comuns isolados em infecções associados ao cateter venoso central

Tabela 2- Fatores associados com risco de desnutrição: "DIETAS DENUNCIAM RISCO"

Tabela 3- Características demográficas e laboratoriais da população em nutroterapia parenteral no Hospital das Clínicas da Faculdade de Medicina de Ribeirão Preto, janeiro a junho de 2008

Tabela 4- Características demográficas e laboratoriais da população em nutroterapia parenteral no Hospital das Clínicas da Faculdade de Medicina de Ribeirão Preto em relação à presença de infecção associada ao cateter venoso central, janeiro a junho de 2008

Tabela 5- Características demográficas e laboratoriais da população em nutroterapia parenteral no Hospital das Clínicas da Faculdade de Medicina de Ribeirão Preto em relação à colonização microbiológica do cateter venoso central, janeiro a junho de 2008 ...

Tabela 6- Frequência de micro-organismos encontrados nas culturas semiquantitativas das pontas dos cateteres venosos centrais em relação à colonização e à infecção sanguínea

Tabela 7- Presença de biofilmes em relação aos resultados das culturas semiquantitativas dos cateteres venosos centrais, janeiro a junho de 2008

Tabela 8- Resultado das culturas dos swabs coletados, janeiro a junho de 2008

Tabela 9- Resultados das culturas semiquantitativas dos swabs coletados da mão e região auricular dos pacientes em uso de nutroterapia parenteral, janeiro a junho de 2008 


\section{SUMÁRIO}

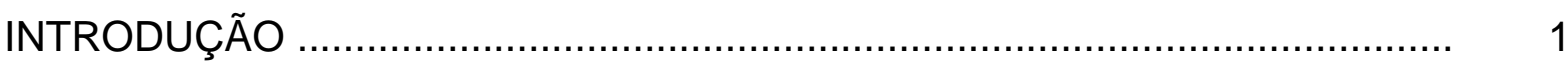

A.Biofilmes ........................................................................

B. Critérios diagnósticos de infecção associados ao cateter venoso central

C. Fatores de risco de infecção associado ao cateter venoso central utilizados em nutroterapia parenteral

HIPÓTESE

OBJETIVOS

DELINEAMENTO EXPERIMENTAL

MÉTODOS

A. Procedimento quando da retirada do cateter venoso central

B. Microscopia eletrônica de varredura

- Preparo da amostra

C. Processamento microbiológico dos cateteres venosos centrais

- Cultura semiquantitativa do cateter

- Hemocultura

D. Coleta dos swabs de pele

E. Termo de consentimento livre e esclarecido

F. Análise estatística

RESULTADOS

DISCUSSÃO

CONCLUSÕES

REFERÊNCIAS

ANEXOS

Anexo 1: Aprovação do Comitê de ética e Termo de consentimento livre e esclarecido

Anexo 2: Planilha com características clínicas e demográficas dos pacientes estudados

Anexo 3: Planilha com características dos cateteres venosos utilizados ......

Anexo 4: Artigo publicado no Journal of Parenteral and Enteral Nutrition ...... 
Anexo 6: Artigo publicado no British Medical Journal Case reports 
1

\section{Introdução}





\section{INTRODUÇÃO}

Após o final da década de 60 e início da década de 70 com a bem sucedida introdução da nutroterapia parenteral (NTP) foram criados métodos e técnicas que permitiram reduzir complicações clínicas e mecânicas associadas a esta modalidade terapêutica (O’Keefe et al.,2006; Heyland et al.,1998). O objetivo principal da NTP é tratar e prevenir carências nutricionais em pacientes com falência intestinal, ou naqueles que a dieta oral e/ou enteral é insuficiente para manter ou recuperar o equilíbrio do estado nutricional (Mullady et al., 2006; Kochevar et al., 2007; Marchini et al.1998). Entretanto, como todo procedimento médico a NTP não está isenta de complicações que podem ser agudas ou tardias. Dentre as agudas citamos distúrbios metabólicos, síndrome da realimentação, sepse associada ao cateter. As alterações hepáticas, alterações do metabolismo ósseo e infecção de cateteres de longa permanência são complicações tardias (Machado et al, 2009a).

A infecção de cateter venoso central (CVC) é a complicação mais frequente e quando diagnosticada atinge 5 a 26\% das cateterizações venosas (McGee, Gould, 2003). Vários são os fatores relacionados às infecções de CVC, destacando-se a formação de biofilmes (Schachter,2003), o local de inserção(McGee, Gould, 2003), o tipo de cateter utilizado (McGee, Gould, 2003), a migração de micro-organismos da pele para o lúmen do cateter (Veenstra et al., 1999), a administração de medicamentos (Sherertz, 2004), a manipulação do cateter, as condições clínicas dos pacientes (O'Grady et al, 2002) e a infusão de nutrientes (Begheto et al., 2005). Acredita-se que o risco relativo de infecção em paciente recebendo nutroterapia seja de 3,30, com intervalo de confiança (95\%) entre de 1,3 a 8,3 (Begheto et al., 2005). Em estudo realizado por Begheto et al. (2005) a desnutrição, o tempo de internação 
que antecedeu a inserção do CVC e a hiperglicemia sustentada não foram fatores de risco para aumento de infecção (Beghetto et al., 2005). A figura 01 representa de forma esquemática uma das hipóteses dos mecanismos etiopatogênicos envolvidos com a infecção sistêmica associada ao cateter (Gosbell, 2005).

Além das complicações acima citadas, tem-se a formação de biofilme, o qual é considerado o principal fator relacionado à infecção e a manutenção da mesma. Dados do The National Institute of Health (Bethesda, MD, EUA, 2002) estimam que $80 \%$ das infecções dos cateteres são causadas pelos biofilmes.

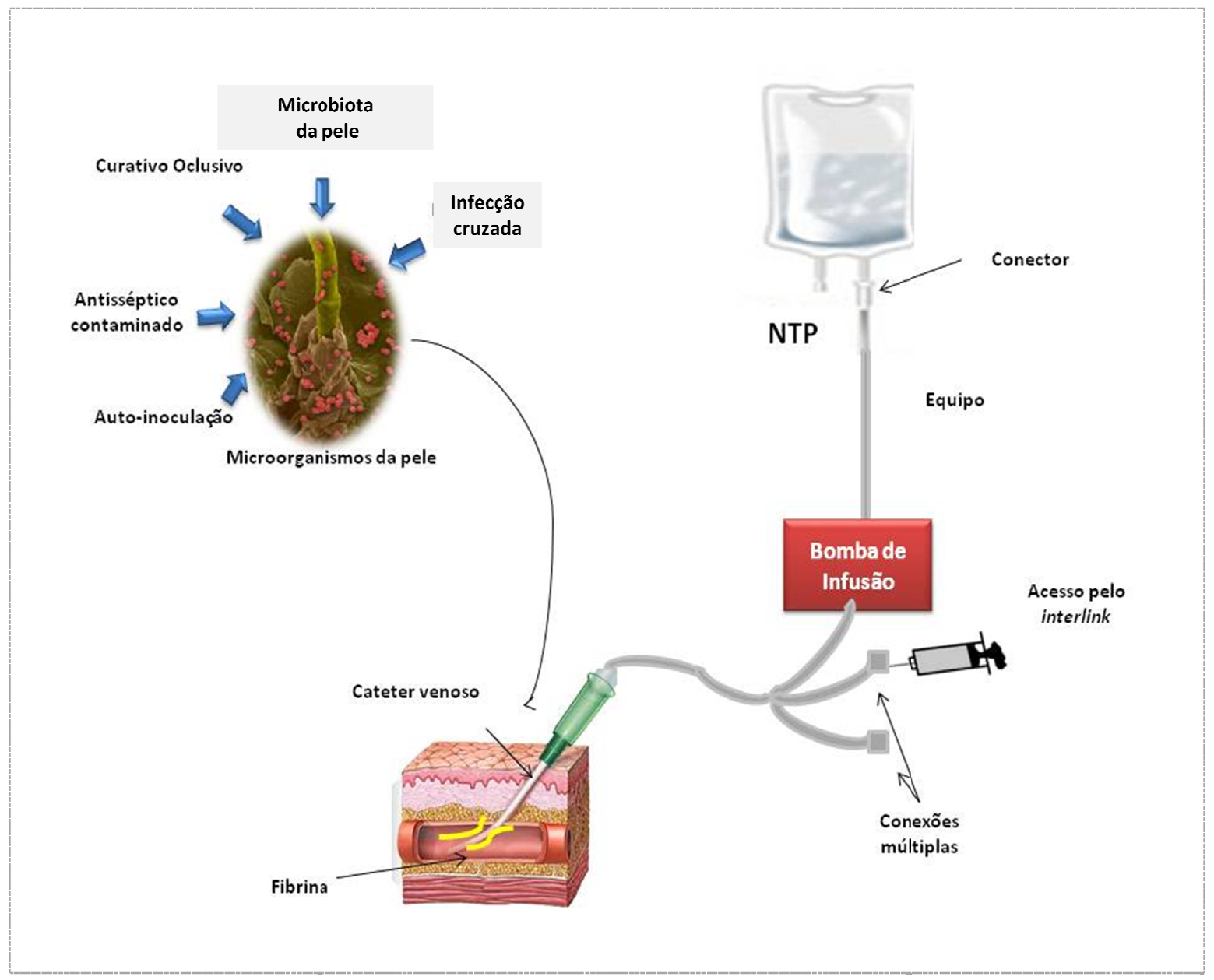

Figura 01: Prováveis mecanismos associados à infecção de cateter venoso central utilizado na nutroterapia parenteral (NTP). Adaptado de Gosbell, 2005. 


\section{A. Biofilmes}

Define-se biofilme como a agregação complexa de micro-organismos que produzem, por meio de excreção, uma matriz que predispõe a aderência de material orgânico, além de oferecer proteção ao micro-organismo aderido a ele (Coserton et al., 1995).

Os biofilmes são encontrados em superfícies que drenam água, comumente formando uma camada. As bactérias que ficam suspensas em água ou em meios aquosos são denominadas de planctônicas. Nestes meios líquidos, quando a bactéria adere à superfície e torna-se "séssil", produzindo uma espécie de cola que permite a sua ancoragem, forma-se o biofilme (Coserton et al., 1995). O biofilme pode ser formado por uma única espécie de bactéria, mas geralmente, no meio ambiente, os biofilmes são formados por várias espécies de bactérias, fungos, protozoários e debris ao longo de produtos com corrosão. A adesão à superfície torna o biofilme fator protetor para as bactérias contra agentes antimicrobianos, além de permitir trocas de nutrientes, metabólitos e material genético com outros micro-organismos próximos (Kumar, Prasad, 2006). Embora esta relação beneficie o crescimento bacteriano, destrói a superfície de contato, além de causar, no caso de cateteres venosos, sua obstrução. O processo de destruição da superfície ocasionado pelo biofilme (biofouling) é denominado de biocorrosão e biodeterioração, e está associado a danos e corrosões em vários produtos, dentre os quais destacamos os aparatos médicos. Os biofilmes podem variar na espessura desde camadas monocelulares até a $6-8 \mathrm{~cm}$ de espessura, mas na maioria das

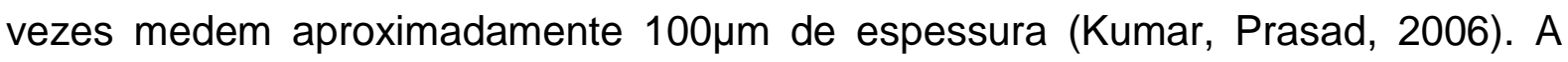


figura 02 mostra de forma esquemática a formação de biofilme (Jenkison,2001; Machado,2008).

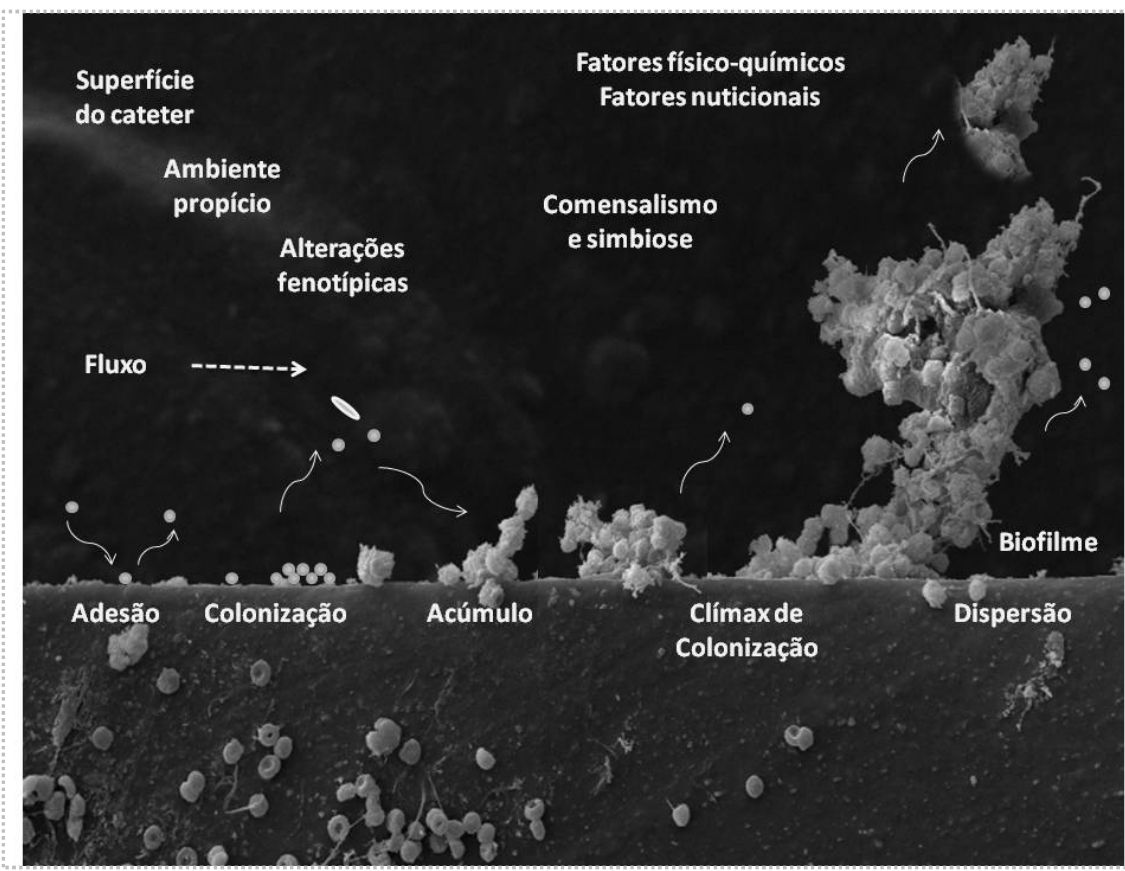

Figura 02: Estágios de formação e vida de um biofilme. Adaptado de Jenkinson, 2001 e Machado, $2008^{17}$.

Fatores que podem influenciar a adesão das bactérias à superfície são: disponibilidade de nutrientes na superfície, concentração de nutrientes, $\mathrm{pH}$, temperatura, concentração eletrolítica, o fluxo material e os tipos de superfície, ou seja( Jenkinson, 2001; Marshal, 1985,1986; Machado et al., 2009b):

- Materiais de alta energia: têm cargas negativas, formadas por material hidrofílico como vidro, metal e mineral,

- Materiais de baixa energia: podem ter cargas negativas ou positivas, formados por materiais de plásticos feitos a partir de polímeros orgânicos.

A figura 03 mostra a presença de biofilmes bacteriano e fúngico em cateter venoso utilizado em NTP. 


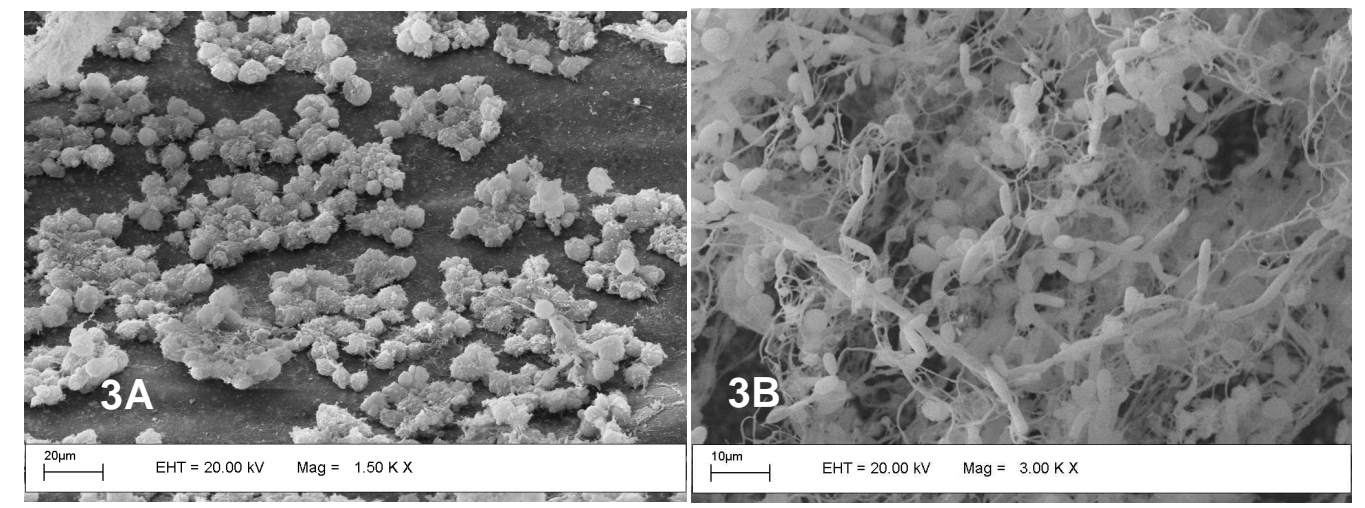

Figura 03: Microfotografias de cateteres venosos centrais utilizados para nutroterapia parenteral obtidas por microscopia eletrônica de varredura, mostrando micro-organismos aderidos aos lúmens dos cateteres. Em 3A, observam-se estruturas cocóides aderidos ao lúmen interno do cateter, cuja cultura semiquantitativa sugeriu colonização por Staphylococcus aureus (1.500X). Em 3B observamo-se hifas de Candida glabrata com magnitude de 3.000X. Adaptado de Machado et al., 2009b.

Experimentos in vitro surgerem que a bactéria envolvida por um biofilme pode se tornar cerca de 50 a 500 vezes mais resistentes à quimioterapia do que uma bactéria planctônica. A infecção nestes casos não se resolve e só é tratada a partir da retirada dos implantes infectados, levando uma maior morbidade e até mortalidade (El-Aziz et al., 2004). El-Aziz et al (2004) estudaram in vitro a formação de biofilmes de Staphylococcus aureus e Staphyloccocus epidermidis isolados de hemoculturas de pacientes com infecção e avaliaram a sensibilidade destes biofilmes íntegros e não íntegros à vancomicina, à linezolida e à quinupristina+dalfopristina (QD). Micro-organismos em suspensão foram utilizados como controle. Como resultados, obtiveram que os dois modelos estudados eram resistentes às concentrações inibitórias mínima $(\mathrm{CIM})$ dos antibióticos testados. Quando aumentaram a concentração dos antibióticos observaram que o biofilme 
íntegro era mais resistente à intervenção do que àqueles do não íntegro ( $p$ $<0,0001)$. Dos antibióticos testados, o QD mostrou melhor atividade contra os microorganismos do biofilme não íntegro nas concentrações superiores da CIM, sendo mais ativo do que a vancomicina na concentração de $50 \mu \mathrm{g} \cdot \mathrm{ml}^{-1}$. A vancomicina nas concentrações de 500 a $1000 \mu \mathrm{g} \cdot \mathrm{ml}^{-1}$ foi ativa contra o S. epidermidis e cepas de $S$. aureus resistentes a meticilina (MRSA). Das drogas testadas, o linezolida foi 0 menos eficaz no combate às bactérias analisadas (El-Aziz et al., 2004).

Como observado na figura 02 , os fragmentos de biofilmes podem se desprender da superfície e se dispersarem, permitindo que estes micro-organismos se espalhem para outros locais, que não o de implante, podendo levar a quadros clínicos de bacteremia e/ou fungemia. Há relatos de casos de endocardites, de infecções em pacientes com fibrose cística, de infecções de prótese ortopédicas e de valvas cardíacas secundárias à presença de biofilmes (Kumar, Prasad, 2006).

Alguns micro-organismos formadores do biofilme podem não só garantir a colonização, formando comunidades bacterianas, mas podem aguardar por hospedeiros susceptíveis. Exemplos são as micobactérias, Pseudomonas aeruginosa e leogionela que estão associadas com infecções oportunísticas em pacientes imunodeprimidos (Barbeau et al, 2004).

Outro agente formador de biofilme são as espécies de cândidas. O biofilme formado por estes micro-organismos está associado com um aumento drástico da resistência contra a maioria dos antifúngicos, o que pode permitir a persistência da infecção fúngica, apesar do tratamento medicamentoso. Alguns autores (Pankhurst et al.,1998; Chandra et al.,2005) sugerem que o biofilme da cândida exibe resistência à maioria dos antifúngicos, sendo considera-as exceções a esta regra as 
equinocandinas e as formulações lipídicas da anfotericina B (Pankhurst et al.,1998; Chandra et al.,2005).

\section{B. Critérios diagnósticos de infecção relacionada ao cateter venoso central}

Pelos critérios do Centers for Disease Control and Prevention (CDC, 2002), podemos classificar a infecção associadas aos cateteres em 3 tipos: 1) colonização do cateter confirmada pela cultura semiquantitativa da ponta do CVC; 2) infecção sistêmica relacionada com CVC, que ocorre quando há correlação da hemocultura do paciente com a cultura semiquantitativa e 3) infecção provavelmente relacionada com cateter quando há hemocultura positiva (periférica e cateter), sem outro foco infeccioso aparente, porém com cultura semiquantitativa do cateter negativa (O'Grady et al., 2002).

A história clássica de pacientes que têm um cateter e se suspeita de infecção é a evolução com hiperemia no local de inserção do cateter e a presença de sinais clínicos compatíveis com bacteremia como febre, instabilidade hemodinâmica, sem outros focos infecciosos conhecidos. Nestes casos a rotina médica a ser seguida é a retirada do cateter (Merrer et al., 2001). No entanto, mesmo em pacientes assintomáticos a colonização de cateteres é frequente. Em um estudo $50 \%$ dos pacientes assintomáticos tiveram culturas semiquantitativas positivas do CVC, versus (vs.) $81 \%$ dos pacientes sintomáticos (Machado et al. 2009c).

Quanto à espécie de micro-organismo, mais comum, relacionado com a infecção do cateter, Staphyloccoccus species (spp) é o agente mais comum contribuindo em cerca de 50 \% dos casos de infecção (O'Grady et al., 2002). 
Destes, as espécies coagulase-negativas contribuem para a maioria dos casos, porém S. aureus permanece um agente etiológico comum nestas infecções (O'Grady et al., 2002). Enterococcus, particularmente os resistentes a vancomicina, contribuem para $13 \%$ de todas as infecções por cateter (O'Grady et al., 2002). Fungos representam cerca de $8 \%$ das infecções nosocomiais relacionadas ao CVC, sendo Candida albicans a mais prevalente (O'Grady et al., 2002). Outros agentes comuns, principalmente em pacientes com manipulação do trato gastrintestinal e genitourinário, são representados por bactérias Gram negativas(G-) como: Klebsiella spp., Enterobacter spp., Serratia marcescens (Beck-Sagué, Jarvis, 1993). Entre pacientes neutropênicos. P. aeruginosa é patógeno comum (Beck-Sagué, Jarvis, 1993; Fridkin et al, 1997.). Dados epidemiológicos sobre infecções sanguíneas relacionadas ao CVC em pacientes em NTP mostram que Staphyloccoccus spp. foi o micro-organismo mais comum, seguido de Klebsiella pneumoniae e Candida parapsilosis (Marra et al.,2007).

No Hospital das Clínicas da Faculdade de Medicina de Ribeirão Preto da Universidade de São Paulo (HCFMRP-USP), por meio de estudo retrospectivo de aproximadamente nove anos de seguimento, avaliou-se as complicações infecciosas em cateteres totalmente implantados utilizados para nutroterapia parenteral (Unamuno et al., 2005). Nesse estudo, os principais micro-organismos colonizadores encontrados foram: S. epidermidis (52\%), fungos leveduriformes (22\%), S. aureus (9\%), E. coli (4\%) e S. marcescens (4\%), (Unamuno et al., 2005) . Dados semelhantes foram mostrados posteriormente pela Divisão de Nutrologia do HCFMRP-USP, onde os micro-organismos mais comuns relacionados à infecção do CVC utilizado para NTP também foram o Staphyloccoccus species (48\% das 
infecções), Candida spp. (19\%) e Enterococcus spp (14\%), durante o período de seguimento dos estudos (Machado et al, 2009b, 2009c).

A tabela 01 apresenta resultados de análise de culturas semiquantitativas de cateteres utilizados para NTP em diferentes situações e locais. Observa-se que em CVCa utilizados para NTP há uma frequência elevada de infecção por Candida spp (Machado et al, 2009b, Marra et al., 2007; Unamuno et al,2005). O motivo dessa maior prevalência de colonização por fungos pode ser justificado pela própria nutrição parenteral (Beghetto et al, 2005; Marra et al., 2007), cuja composição rica em glicose e lipídios permitiria que a cândida produzisse glicocálix semelhantes aos das bactérias, facilitando a formação de biofilmes (Chandra et al, 2005). Outros fatores que podem justificar este aumento na incidência, conforme dados da literatura, seria a imunossupressão destes pacientes, assim como patologias do trato gastrintestinal (Sherertz, 2000; Wey et al.,1989; Kojic,Darouiche, 2004).

A infecção por Candida spp. é um problema de saúde pública que merece atenção (Colombo et al., 2006; Chu et al., 2006; Pfaller, Diekema, 2007). Recentemente, Colombo et al. (2006) realizaram estudo epidemiológico de candidemia no Brasil e obtiveram taxas de 2,49 por 1000 admissões e 0,37 por 1000 pacientes dias. Esses resultados são cerca de 2 a 15 vezes maiores do que os reportados por países do hemisfério norte (Colombo et al., 2006; Chu et al., 2006; Pfaller, Diekema, 2007). Em outro estudo, Colombo et al. (2007) observaram que a candidemia está relacionada ao aumento da morbimortalidade dos pacientes, aumento do tempo de internação e consequentemente maiores gastos para a saúde pública (Colombo et al 2007). 
Tabela 1:Patógenos mais comuns isolados em infecções relacionadas a cateter venoso central

\begin{tabular}{|c|c|c|c|c|c|c|}
\hline $\begin{array}{l}\text { Período } \\
\text { Patógeno }\end{array}$ & $\begin{array}{c}\text { 1986-1989 } \\
(\%)^{a_{\star}}\end{array}$ & $\begin{array}{c}\text { 1992-1999 } \\
(\%)^{a_{*}}\end{array}$ & 2005 & $\begin{array}{l}2006 \\
(\%)^{a \neq}\end{array}$ & $\begin{array}{c}\text { 1981-2005 } \\
(\%)^{\text {b- }}\end{array}$ & $\begin{array}{l}2007 \\
(\%)^{\text {b§ }}\end{array}$ \\
\hline $\begin{array}{l}\text { Staphylococcus } \\
\text { coagulase-negativo }\end{array}$ & 27 & 37 & 52 & 33 & 33 & 24 \\
\hline $\begin{array}{l}\text { Staphylococcus } \\
\text { aureus }\end{array}$ & 16 & 13 & 9 & 19 & 11 & 24 \\
\hline Enterococcus & 8 & 13 & 3 & 3 & 7 & 14 \\
\hline Outros bacilos G (-) & 19 & 14 & 3 & 18 & 8 & 5 \\
\hline Escherichia coli & 6 & 2 & 3 & 1 & 3 & 5 \\
\hline Enterobacter & 5 & 5 & 4 & 4 & 2 & \\
\hline $\begin{array}{l}\text { Pseudomonas } \\
\text { aeruginosa }\end{array}$ & 4 & 4 & - & 9 & 1 & 9 \\
\hline $\begin{array}{l}\text { Klebsiella } \\
\text { pneumonae }\end{array}$ & 4 & 3 & 4 & 6 & 9 & - \\
\hline Candida spp. & 8 & 8 & 22 & 6 & 21 & 19 \\
\hline
\end{tabular}

$G(-)$ : gram negativo

a:Cateteres venosos centrais (CVCs) utilizados com múltiplas finalidades

${ }^{\mathrm{b}}$ : CVCs utilizados exclusivamente para nutroterapia parenteral (NTP)

* Dados do Centers for Disease Control and Prevention, (O'Grady et al.,2002)

† Dados de Unamuno et al. (2005), Divisão de Nutrologia do Hospital das Clínicas da Faculdade de Medicina de Ribeirão Preto da Universidade de São Paulo (HCFMRPUSP).

¥Dados do Laboratório de Microbiologia do HCFMRP-USP

${ }^{\dagger}$ Dados de Mara et al. (2007), Universidade de Virgínia

$\S$ Dados de Machado et al. (2009b).,HCFMRP-USP 


\section{Fatores de risco de infecção associados aos cateteres venosos centrais utilizados em nutroterapia parenteral}

Dentre os fatores que podem estar relacionados com risco aumentado de infecção do cateter venoso central, existem evidências de que o material utilizado na confecção do dispositivo clínico possa estar relacionado ou contribuir para sepse. Os cateteres venosos centrais de Teflon, silicone e poliuretano estão associados à menor risco de infecção do que os de polivinil ou polietileno. Atualmente os cateteres utilizados a curto ou a médio prazo são de poliuretano e os de médio a longo prazo são de silicone (Pittiruti et al, 2009). Outro fator seriam as deformidades ou irregularidades do lúmen do cateter que podem predispor a aderência de microorganismos (figura 4), (Machado, 2008; Machado et al.,2009b).

Além do cateter venoso, outro fator, independente, que contribui ou predispõe a infecção é a própria nutroterapia parenteral (Beghetto et al., 2005) ${ }^{12}$. Recentemente, esta questão foi ratificada e observada por Ishizuka et al.(2009), que ao acompanharem 109 pacientes que utilizaram 542 CVC, totalizando o total de 5.558 CVC-dias, não observaram diferenças clínicas naqueles pacientes que tiveram infecção relacionada com uso do cateter, com aqueles que não tiveram. Neste estudo a NTP foi o único fator de risco independente $(p=0,0001)$. Outros fatores como tipo de cateter, sexo, idade, dificuldades para punção, solução utilizada na assepsia, tempo de permanência do cateter, não contribuíram para o surgimento do processo infeccioso (Ishizuka et al.,2009) ${ }^{39}$.

Acredita-se que componentes da nutroterapia parenteral podem estar relacionados ao processo infeccioso. Swindell et al. (2009) observaram que a administração de emulsão lipídica é fator de risco para desenvolvimento de 
candidemia e formação de biofilme. Em estudo in vitro, esses autores observaram que a administração de lipídio aumentou a velocidade de crescimento das colônias de Candida albicans, como também predispôs tanto a mudanças morfológicas no biofilme formado pela levedura, quanto na sua virulência (Swindell et al., 2009) ${ }^{40}$.

O lipídio adicionado a solução parenteral, pode ainda promover a instabilidade da mesma e predispor à formação de precipitados, principalmente quando há adição de sais inorgânicos na bolsa de parenteral, fato observado por Sakamoto e cols (Figura 5A), (Sakamoto et al., 1999).

A contaminação da solução parenteral durante o preparo pode ser outro fator que pode estar relacionado ou contribuir com a infecção (Oie, Kamiya, 2005). A presença de substâncias contaminantes como partículas de vidro de ampolas de medicamentos, micro-organismo, seja bactéria ou fungo foram encontradas em soluções de parenterais desprezadas após uso clínico ${ }^{42}$. Estudo realizado no Japão onde foram avaliados 192 bolsas de nutrição parenteral residual, observou a presença de partículas de ampolas de vidro, plástico e vials nas bolsas de parentais utilizadas, com um número de partículas médio, variando de 3,4 (1-13), 0,79 (0-7) e 1,2 (0-8) respectivamente. Neste estudo os diâmetros das partículas encontradas, variaram de 1,3 a $50 \mu \mathrm{m}$ (figura 5B), (Oie, Kamiya, 2005) 


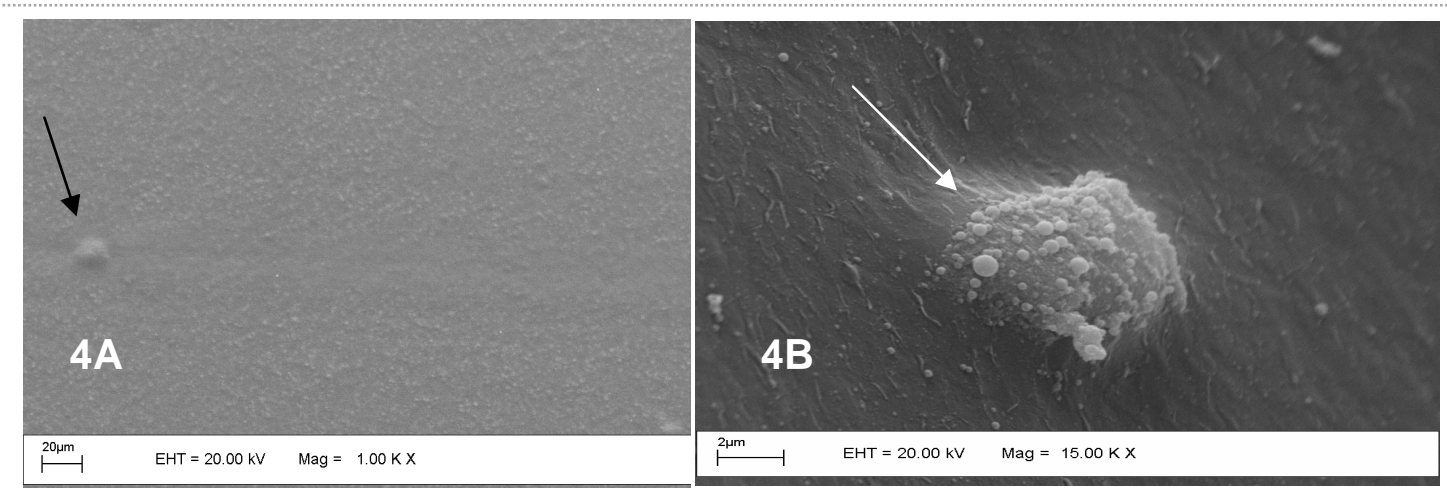

Figura 04: Irregularidades dos lumens internos dos cateteres venosos centrais observados à microscopia eletrônica de varredura. Em 4A mostra um cateter sem uso clínico prévio submetido à Microscopia eletrônica de varredura, onde percebe-se à ponta da seta irregularidades na parede do mesmo. Na 4B observamos estruturas esféricas aderidas ao abaulamento da parede interna do cateter (seta branca). A magnitude utilizada nas figuras foi $1.000 \mathrm{X} \mathrm{e}$ 15.000X. Adaptado de Machado, 2008 e de Machado et al.,2009b.
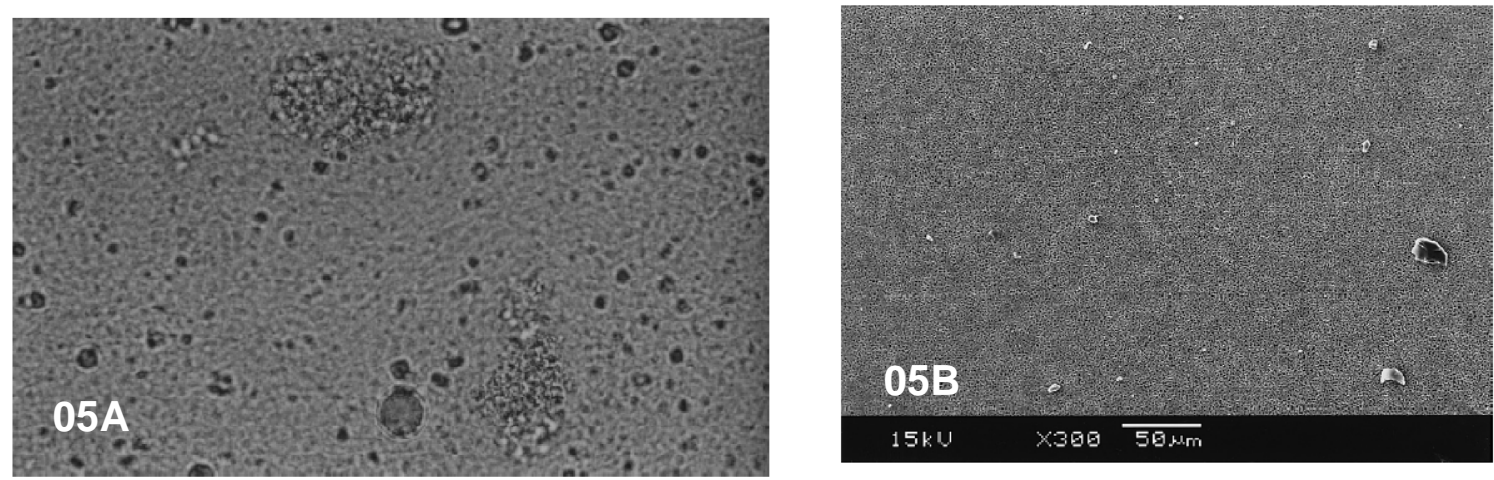

Figura 05: Microfotografias de partículas químicas e residuais de soluções utilizadas para nutroterapia parenteral. Em $5 \mathrm{~A}$ a microfotografia óptica mostra a presença de gotículas de gorduras aumentadas e agregadas e de fosfato de cálcio, no tempo de 30 minutos após preparo da solução parenteral. Em 5B observa-se a Microscopia Eletrônica de filtro de membrana de 0,22 $\mu \mathrm{m}$ utilizado para filtrar solução residual da Nutroterapia Parenteral. Adaptado de Sakamoto et al., 1999, 1999 e Oie, Kamiya, 2005. 
Baseados no que foi exposto e considerando os aspectos clínicos do paciente, com relação à nutrologia, principalmente naqueles submetidos ao implante do cateter venoso central e que somente podem ser mantidos vivos com terapia nutrológica parenteral, a infecção é complicação frequente. Assim, é importante que o biofilme e os fatores de risco relacionados à infecção sejam estudados, conhecidos e controlados, para que o procedimento nutroterápico seja mais efetivo e resulte em melhor custo benefício para o paciente. 
Hipótese \& Objetivos 



\section{HIPÓTESE}

Uso de cateteres venosos centrais (CVCs) utilizados para nutroterapia parenteral predispõe a formação e crescimento de biofilmes, secundário a colonização microbiológica dos mesmos e são responsáveis pela perpetuação do processo infeccioso. 


\section{OBJETIVOS}

Primário

- Em estudo clínico prospectivo avaliar a formação e as características do biofilme formado em CVCs utilizados para nutroterapia parenteral.

Secundários

- Levantamento epidemiológico das infecções relacionadas ao uso de CVCs utilizados para nutroterapia parenteral no HCFMRP-USP no período de janeiro a junho de 2008;

- Verificação fatores de riscos associados à infecção do cateter venoso central. 
Delineamento Experimental \& Método 



\section{DELINEAMENTO EXPERIMENTAL}

Estudo prospectivo realizado, entre os meses de janeiro a junho de 2008, no Hospital das Clínicas da Faculdade de Medicina de Ribeirão Preto da Universidade de São Paulo. Foram avaliados os pacientes internados no referido hospital que estavam em uso de NTP, assim como os cateteres venosos centrais por eles utilizados para tal finalidade terapêutica. Todos os pacientes acompanhados pelo presente estudos estavam cadastrados no setor da farmácia do HCFMRP-USP responsável pelo manuseio e preparo da solução de nutrição parenteral, assim como na Comissão de Terapia Nutricional Enteral e Parenteral, coordenada pela Divisão de Nutrologia da entidade.

O delineamento deste estudo encontra-se resumido nas figuras 06 e 07.

Em nenhum momento os pesquisadores interferiram na prescrição de nutroterapia parenteral, ou na sua suspensão, como na decisão da retirada do cateter venoso central. 


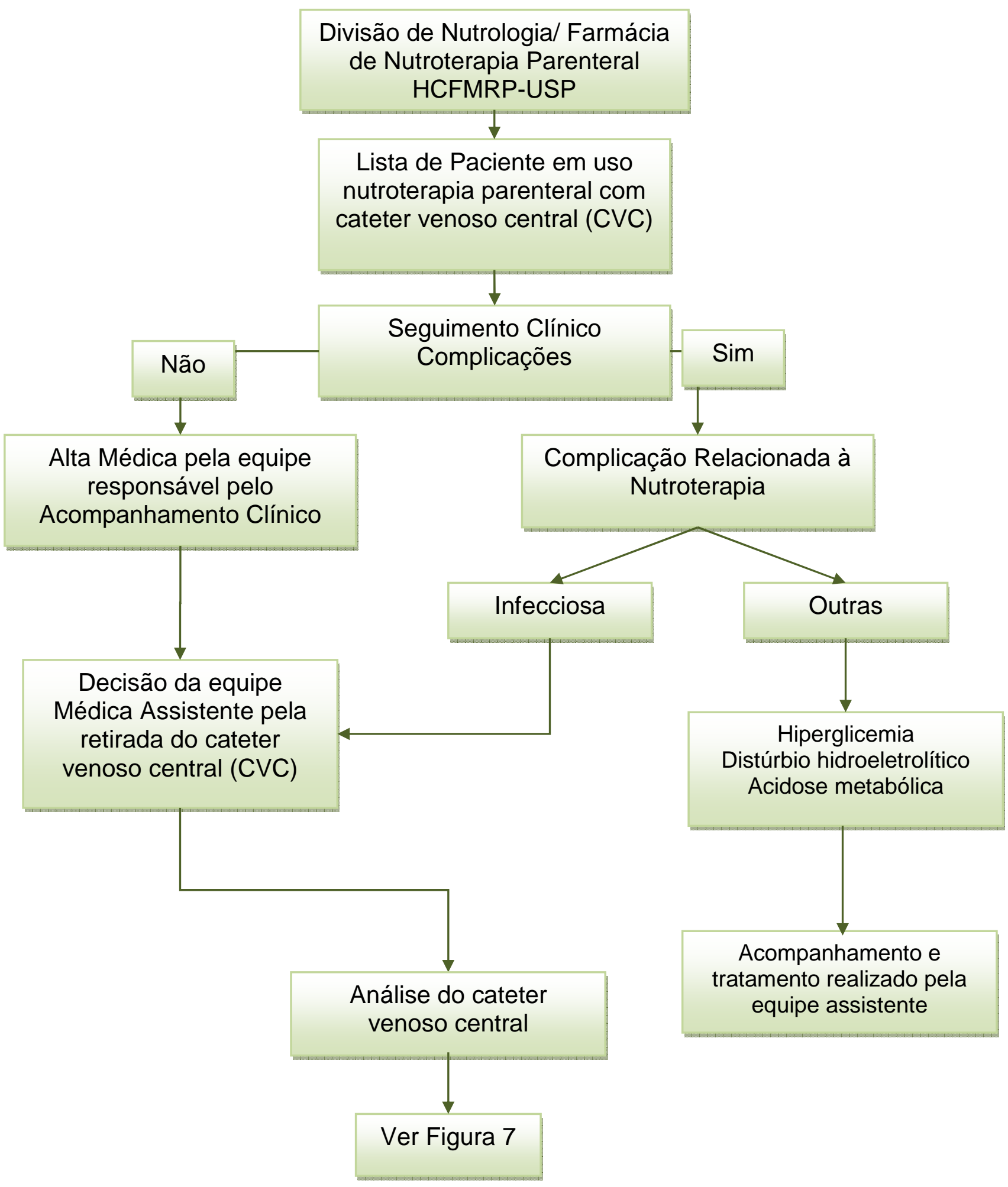

Figura 06: Delineamento experimental para avaliação de pacientes em nutroterapia parenteral no HCFMRP-USP, janeiro a junho 2008. Os autores não interferiram em nenhuma etapa da indicação ou suspensão da nutroterapia, coube à equipe que assiste ao paciente essa decisão. 


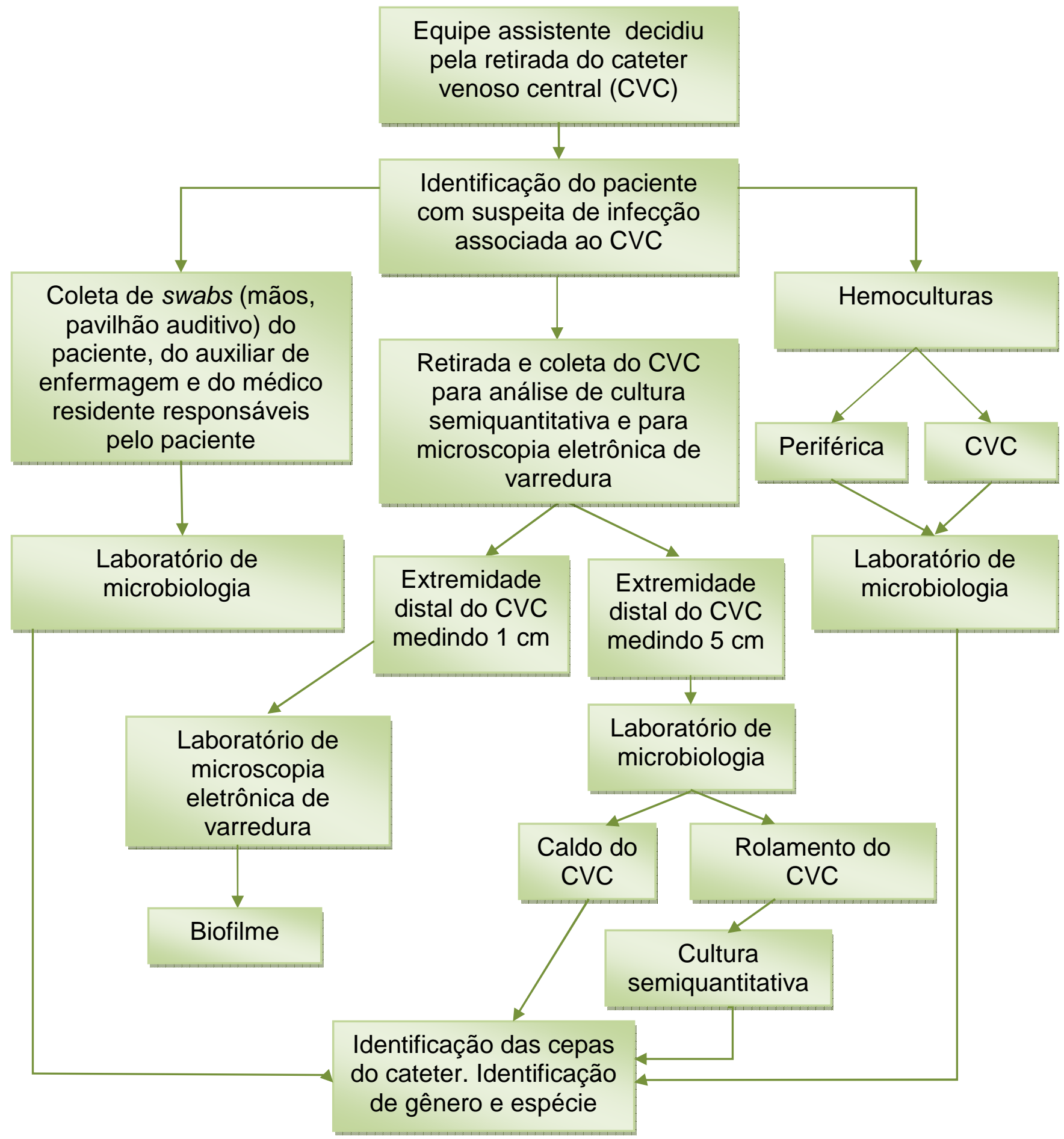

Figura 07 Delineamento experimental para avaliação de cateteres venosos centrais utilizados para nutroterapia parenteral.

CVC: cateter venoso central 


\section{MÉTODOS}

Foram incluídos neste estudo pacientes do sexo masculino ou feminino, com idade superior a 18 anos, que estivessem com acesso venoso central para administração nutroterapia parenteral (NTP) em seguimento do HCFMRP-USP no período de janeiro a junho de 2008, e que por indicação médica (infecção e/ou alta) retiraram o CVC. Os pacientes foram avaliados quanto ao sexo, idade (anos), peso $(\mathrm{kg})$, altura $(\mathrm{m})$, presença de comorbidades, motivo da indicação da NTP, presença de sinais ou sintomas que sugerissem infecção associada ao cateter (hiperemia do local de inserção do cateter, presença de secreção pericateter, bacteremia, febre temperatura axilar $>37,8^{\circ} \mathrm{C}$. De cada paciente também foram avaliados parâmetros laboratoriais: albumina $\left(\mathrm{g} \cdot \mathrm{L}^{-1}\right)$, glicemia $\left(\mathrm{mg} \cdot \mathrm{dl}^{-1}\right)$, linfócitos totais, gasometria, e eletrólitos; exames esses solicitados rotineiramente no seguimento clínico de pacientes em NTP.

A fim de se facilitar a análise posterior dos resultados dos dados obtidos foi optado em criar dois grupos de pacientes, àqueles que foram a óbito, denominado de grupo 1 (G1) e os que permaneceram vivos até o termina da NTP, grupo 2 (G2).

Todos os pacientes que participaram foram avaliados com intuito de quantificar o risco nutricional, por meio da ferramenta DIETAS DENUNCIAM RISCO (Machado,2008'; Leme et al. 2009), que resume as principais causas de desnutrição (Tabela 02). Para tal foi proposta uma modificação da mesma, atribuindo um escore que variava de zero a dois em cada critério de avaliação existente na ferramenta, onde zero (0) determinava ausência do fator de risco para

\footnotetext{
${ }^{1}$ Citado por Machado JDC em palestra sobre Avaliação Nutrológica no Curso Nacional de Nutrologia, São Paulo, 2008.
} 
desnutrição, um (1) presença leve ou controlada do fator e dois (2) presença do fator descompensado ou exacerbado.

A fim de se identificar a origem da infecção do cateter, no momento da retirada do mesmo foram colhidos swabs da região das mãos e pavilhão auditivo dos pacientes, sendo as amostras enviadas para o laboratório de microbiologia para que se pudesse realizar a cultura semiquantitativa dos mesmos.

Os cateteres venosos centrais retirados foram avaliados quanto ao tipo, ao material utilizado para sua confecção, ao número de vias, ao local de inserção e ao tempo de cateterização em dias. 


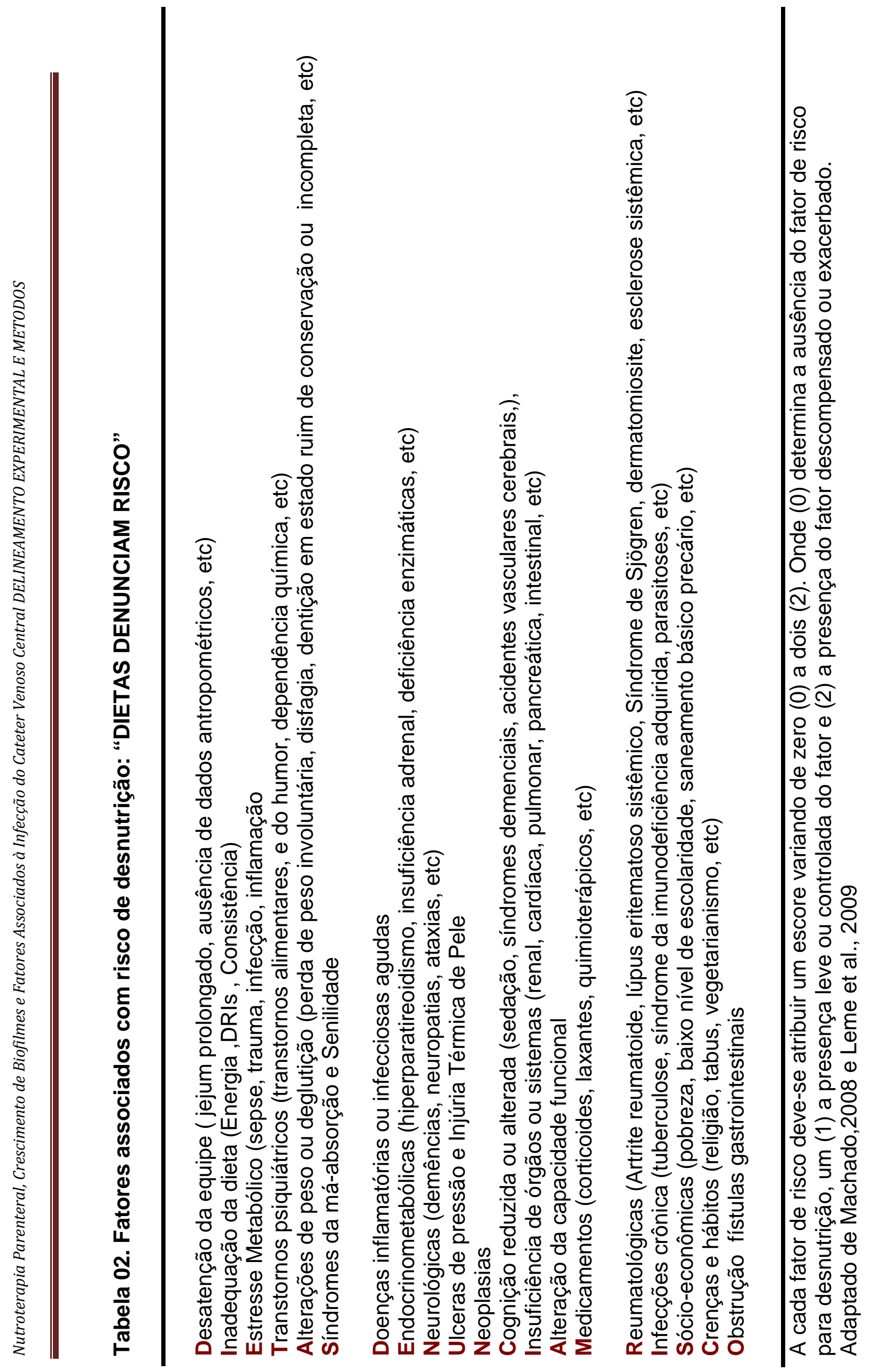




\section{A. Procedimentos quando da retirada do cateter venoso central}

Após a retirada do cateter, decidida pela equipe responsável pelo paciente, os seguintes procedimentos foram realizados na seguinte ordem:

1. Antissepsia da região pericateter,

2. Retirada do cateter respeitando-se técnicas de assepsia,

3. Divisão assepticamente da ponta do cateter em duas amostras:

A. A Primeira amostra foi enviada em tubo de ensaio estéril para o laboratório de microbiologia para cultura semiquantitativa (Maki et al., 1977).

B. A Segunda amostra foi submetida ao preparo para microscopia eletrônica de varredura, sendo enviado após ser fixado em solução de com glutaraldeído a $2 \%$.

Por tratar-se de procedimento de rotina e sob orientação da Comissão de Controle de Infecção Hospitalar do HCFMRP-USP, no momento da retirada do cateter foram coletadas uma amostra do sangue aspirado do cateter, quando possível e outra do sangue periférico. Caso este procedimento não fosse possível, eram coletadas duas amostras de sangue periférico, para realização de hemoculturas para aeróbios e fungos. Esse procedimento faz parte da rotina obrigatória dos pacientes nestas condições e foi realizado independente do protocolo de estudo. A importância em se analisar os resultados das hemoculturas é fazer a distinção entre infecção e/ou colonização do cateter, assim como identificar a infecção sanguínea associada ao CVC, respeitando-se os critérios recomendados pelo CDC (O'Grady et al., 2002), citados anteriormente. 
A extremidade distal de cada cateter retirada devia medir no mínimo cinco centímetros, a fim de permitir a realização da cultura semiquantitativa pela técnica de Maki et al. (1977). Em cerca de $29 \%$ das amostras, a extremidade distal do CVC foi dividido em dois seguimentos, medindo cinco e um centímetros. O menor seguimento foi enviado para avaliação por meio de microscopia eletrônica por varredura sem o conhecimento prévio do resultado da cultura semiquantitativa da ponta do cateter.

\section{B. Microscopia eletrônica por varredura (MEV).}

\section{Preparo da amostra}

A extremidade do CVC encaminhada para o Laboratório de Microscopia Eletrônica da Universidade Estadual de São Paulo de Botucatu (UNESP-Botucatu) para realização da MEV foi fixada em glutaraldeído a $2 \%$ por 120 a 180 minutos e conservada a uma temperatura entre $2^{\circ} \mathrm{C}$ a $8^{\circ} \mathrm{C}$. Depois de decorrido o tempo de

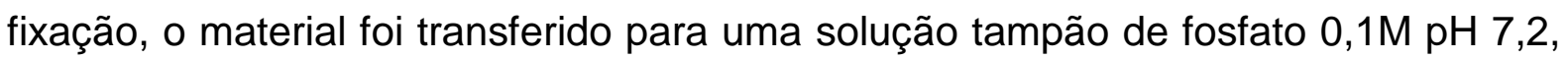
sendo novamente submetido à refrigeração entre $2^{\circ} \mathrm{C}$ a $8^{\circ} \mathrm{C}$. Em seguida os fragmentos foram submetidos a uma segunda fixação com ósmio durante duas horas. Após essa fixação, foram novamente lavados com tampão fosfato, sendo desidratados com etanol na seguinte incubação:

- Etanol a $50 \%$ por 10 minutos,

- Etanol a $70 \%$ por mais 10 minutos,

- Etanol a $90 \%$ por mais 10 minutos,

- Etanol a 95\% por mais 10 minutos, 
- Etanol a $100 \%$ por mais 15 minutos, sendo nesta etapa realizadas três incubações.

Após essas incubações, o material foi colocado no aparelho de ponto crítico da marca Bal-tec® CPD 030 (Boeckeler Instruments, Estados Unidos) a fim de se garantir a retirada do etanol. O gás utilizado para este processo foi o gás carbônico, cujo ponto crítico situa-se em torno de $31^{\circ} \mathrm{C}$. Durante este processo a amostra foi inicialmente resfriada a $4^{\circ} \mathrm{C}$ e posteriormente aquecida à temperatura máxima de $40^{\circ} \mathrm{C}$. A duração deste processo foi de 2 horas.

Após este processo, todos os cateteres foram segmentados para permitir a visualização do lúmen interno e também de sua parte externa. Foram, em seguida fixados com cola de prata ou de grafite em cilindros de alumínio denominados de "stubs" à temperatura ambiente.

Em seguida as amostras foram recobertas com ouro no aparelho Bal-tec® SCD 050 (Boeckeler Instruments, Estados Unidos) com a finalidade de permitir a condução elétrica e posterior visualização das amostras no MEV.

Os cateteres assim fixados foram adequadamente armazenados em caixas a temperatura ambiente e posterioemte foram submetidos à análise nos Microscópio Eletrônico de Varredura, da marca EVO 50® (Carl Zeiss, Alemanha). O resultado obtido foi devidamente fotografado durante a análise com definição de 1.024X768 pixels e arquivados em arquivos tipo Tagged image file format $<$. tiff>. 


\section{Processamento Microbiológico dos Cateteres Venosos Centrais}

\section{Cultura semiquantitativa do cateter.}

A retirada do cateter foi feita respeitando-se as técnicas de assepsia padronizadas (O'Grady et al., 2002), utilizando-se luvas estéreis, material de curativo contendo tesoura e pinça esterilizadas. A extremidade distal foi colocada em tubo seco, estéril, e imediatamente enviada ao laboratório de microbiologia do HCFMRP-USP. Sendo, a seguir, transferida para superfície de ágar sangueii, e "rolado" por no mínimo quatro vezes sobre esta. Depois disso, foi acrescentado caldo Mueller-Hinton (base $\mathrm{MH})^{\mathrm{iii}}$ no tubo do cateter e ambos, placa e caldo, foram incubados a $37^{\circ} \mathrm{C}$ em estufas bacteriológicas. As placas foram examinadas diariamente para se verificar a presença de crescimento de micro-organismos. A contagem de colônias foi feita em 24 e/ou em 48 horas de incubação, contando-se todas as colônias dos micro-organismos isolados. A partir daí, fez-se um subcultivo em placa ágar sangue, que foi processado da mesma forma que a placa primária semiquantitativa, para identificação do micro-organismo.

Foi considerado cultura positiva do rolamento da ponta do cateter, pelo método semiquantitativo de Maki quando fosse observada a formação superior da

\footnotetext{
${ }^{i}$ Neste ponto prestamos homenagem póstuma ao Professor Dr. José Fernando de Castro Figueiredo que orientou e viabilizou todo procedimento microbiológico utilizado neste projeto. O nosso muito obrigado.

ii É utilizado em laboratórios de análises clínicas como cultivo primário para o isolamento de Streptococcus spp e Staphylococcus spp. Composição: Peptona bacteriológica $10,0 \mathrm{~g} . \mathrm{L}^{-1}$; extrato nutritivo $10,0 \mathrm{~g} \cdot \mathrm{L}^{-1}$; cloreto de sódio $5,0 \mathrm{~g} \cdot \mathrm{L}^{-1}$; agar $15,0 \mathrm{~g} \cdot \mathrm{L}^{-1}$; sangue de carneiro desfibrinado a $7 \%$; água para $1 \mathrm{~L}$. (BioMéieux®,França).

iii Caldo para ser utilizado em procedimentos quantitativos para teste de susceptibilidade de bactérias aeróbias e anaeróbias facultativas de crescimento rápido isoladas de espécimes clínicos. Composição: Infusão de bife $300,00 \mathrm{~g} \cdot \mathrm{L}^{-1}$; caseína acida hidrolisada: $17,50 \mathrm{~g} \cdot \mathrm{L}^{-1}$; amido: 1,50 g.. $\mathrm{L}^{-1}$. (BioMéieux®,França).
} 
15 UFC (unidades formadoras de colônia). A identificação do micro-organismo, em gênero e espécie, foi feita por técnicas padronizadas (Koneman et al., Organon Tekinika, 1999). Feitas a partir da observação das características das colônias isoladas (a olho nu, com lupa ou microscópio, usando a objetiva de menor aumento). Os seguintes critérios são utilizados para a caracterização colonial: forma, tamanho, elevação, bordos, superfície, estrutura, caracteres ópticos e cromogenia. Já os testes de sensibilidade antimicrobianos seguiram as técnicas de Bauer et al. (1966) e Kiehlbauch et al. (2000).

\section{Hemocultura}

Após a retirada do cateter, todos os pacientes tiveram duas amostras sanguíneas colhidas, do sangue periférico ou do aspirado do cateter, quando possível, a fim de se identificar o possível agente patogênico. A realização da cultura de sangue periférico ou do sangue aspirado do cateter foi feita por meio de sistema automatizado de monitoração contínua BACT/ALERT (Organon Teknika), onde cada frasco do tipo "Standardiv" para adulto e cultura de aeróbio tem a capacidade de armazenar $10 \mathrm{ml}$ de sangue coletados para hemocultura. Os microorganismos cresceram em uma mistura de caldo Brain Hearth Infusion ${ }^{v}$ (BHI) e sangue, com monitoração a cada 10 minutos. A positividade dos frascos foi aferida

\footnotetext{
iv Contém $40 \mathrm{ml}$ de meio de cultura e um sensor interno que detecta o dióxido de carbono. Não exigem aeração. Composição: digestão pancreática de caseína: $1,7 \%$ p/v; digestão da soja pela papína: $0,3 \% \mathrm{p} / \mathrm{v}$; polianetosulfonato de sódio: $0,035 \% \mathrm{p} / \mathrm{v}$; hidrocloreto de piridoxina: $0,001 \% \mathrm{p} / \mathrm{v}$ e de outros complexos de aminoácidos e substratos de carboidratos em água purificada (BioMéieux®,França).

`É um meio sólido recomendado para o cultivo de bactérias patogênicas fastídicas, bactérias aeróbicas e anaeróbicas, leveduras e bolores. Pode posteriormente ser enriquecido pela adição de sangue ou torna-lo seletivo pela adição de antibióticos. É um meio de cultura de propósito geral usado para 0 isolamento primário de bactérias aeróbicas de espécimes clínicos. Composição: infusão de cérebro de bezerro: 200,00 g. $\mathrm{L}^{-1}$; infusão de bife e coração: $250,00 \mathrm{~g} \cdot \mathrm{L}^{-1}$; peptona proteose: $10,00 \mathrm{~g} . \mathrm{L}^{-1}$; dextrose: $2,00 \mathrm{~g} . \mathrm{L}^{-1}$; cloreto de sódio: $5,00 \mathrm{~g} \cdot \mathrm{L}^{-1}$; fosfato dissódico: $2,50 \mathrm{~g} \cdot \mathrm{L}^{-1}$; agar: 15,00 g. $\mathrm{L}^{-1} ; \mathrm{pH}$ final: 7,4. (BioMéieux®,França).
} 
pela concentração de $\mathrm{CO}_{2}$ produzido pelos micro-organismos (Koneman et al., Organon Tekinika, 1999). O sistema de detecção microbiana BACT/ALERT (Organon Teknika, 1999) utiliza um sensor colorimétrico, com luz refletida para monitorar a presença de dióxido de carbono $\left(\mathrm{CO}_{2}\right)$ dissolvido no meio de cultura. Se o crescimento dos micro-organismos produz $\mathrm{CO}_{2}$, a cor do sensor do gás permeável que se encontra no fundo de cada frasco é alterada de verde para amarelo (Koneman et al., Organon Tekinika, 1999).

As culturas de sangue periférico com resultado positivo foram semeadas em placas de ágar chocolate (base $\mathrm{MH}+5 \%$ de sangue de carneiro desfibrinado + aquecimento a $80^{\circ} \mathrm{C}$ ) e incubadas a $37^{\circ} \mathrm{C}$ por 24 horas em jarra de microaerofilia (Organon Tekinika, 1999). Após o crescimento na placa de ágar chocolate, foi realizado a identificação bacteriana, em gênero e espécie, por meio de técnicas padronizadas citadas anteriormente (Koneman et al., Organon Tekinika, 1999).

\section{Coletas dos Swabs de Pele}

Após a decisão da retirada do cateter venoso central pela equipe assistente, os pesquisadores, aleatoriamente, entravam em contato com os mesmos para que fosse colhido o swab da pele da região auricular do médico residente e do auxiliar de enfermagem responsáveis pelo paciente durante o período de internação, desde que os mesmos concordassem em participar do estudo.

Foi optado por escolher esses membros da equipe assistente por terem maior contato com paciente durante o período da internação. 
Após o consentimento, eram colhidas amostras de swabs da região auricular do médico residente e do auxiliar de enfermagem, sendo estas amostras coletadas com hastes de algodão estéreis e após coletas os mesmos foram acondicionados em tubo estéril com meio de transporte Amies $^{\mathrm{vi}}$, que viabilizava o transporte do material por até 48 horas.

Foram coletadas ainda, amostras de swabs da região auricular e da mão dominante do paciente que estava em uso de nutroterapia parenteral, sendo os procedimentos de coleta semelhantes as utilizadas na coleta do material da equipe assistente.

Os swabs de pele da região auricular ou das mãos dos participantes foram colhidos respeitando-se técnica de assepsia recomendadas pela Comissão de Infecção Hospitalar do HCFMRP-USP.

Após a coleta, o material foi encaminhado para o laboratório particular de microbiologia para que fosse realizada a cultura dos mesmos. O material foi inoculado em placa de ágar sangue, MacConkey vii e manitol salgado, que foram incubados a $35^{\circ} \mathrm{C}$ por 24 horas e ágar sabouraud ${ }^{\text {viii a }} 25^{\circ} \mathrm{C}$ por 5 dias. Posteriormente foi realizada a identificação e o antibiograma das amostras positivas.

\footnotetext{
${ }^{v i}$ É usado para transporte e preservação de espécime microbiológica. Composição: cloreto de sódio: $3,0 \mathrm{~g} \cdot \mathrm{L}^{-1}$; cloreto de potássio $0,2 \mathrm{~g} \cdot \mathrm{L}^{-1}$; cloreto de cálcio $0,1 \mathrm{~g} \cdot \mathrm{L}^{-1}$; cloreto de magnésio $0,1 \mathrm{~g} \cdot \mathrm{L}^{-1}$; fosfato de monopotássico $0,2 \mathrm{~g} \cdot \mathrm{L}^{-1}$; fosfato dissódico $1,15 \mathrm{~g} \cdot \mathrm{L}^{-1}$; tioglicolato de sódio: $1,0 \mathrm{~g} \cdot \mathrm{L}^{-1}$; ágar bacteiológico $7,5 \mathrm{~g} \cdot \mathrm{L}^{-1}$ e carvão $10,0 \mathrm{~g} \cdot \mathrm{L}^{-1} ; \mathrm{pH}$ final 7,2. (BioMéieux®,França).

vii É meio seletivo de escolha para o isolamento de Gram negativos. Meio diferencial pois propicia a visualização de colônias fermentadoras ou não da lactose. As colônias rosadas são consideradas lactose positivas e as transparentes lactose negativa. Composição: digestão péptica de tecido animal: $20,00 \mathrm{~g} . \mathrm{L}^{-1}$; sais biliares: $5,00 \mathrm{~g} . \mathrm{L}^{-1}$; cloreto de sódio: $5,00 \mathrm{~g} . \mathrm{L}^{-1}$; lactose: $10,00 \mathrm{~g} . \mathrm{L}^{-1}$; vermelho neutro: $\quad 0,07 \quad \mathrm{~g} \cdot \mathrm{L}^{-1} ; \quad$ agar: $\quad 15,30 \mathrm{~g} \cdot \mathrm{L}^{-1} ; \quad \mathrm{pH}$ final: $7,4 . \quad$ (BioMéieux@,França).

viii É recomendado para o cultivo, isolamento e identificação de fungos patogênicos e leveduras. $O$ ótimo crescimento dos fungos se deve às altas concentrações de carboidratos. Composição: peptona

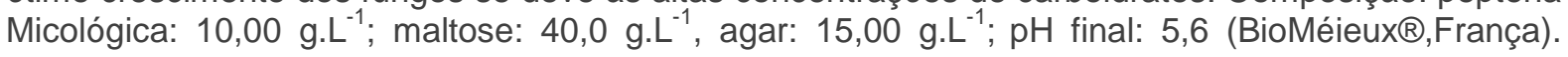




\section{E. Termo de Consentimento Livre e Esclarecido (TCLE)}

Foi criado um TCLE esclarecendo o motivo e objetivo da pesquisa, garantidose a não identificação dos funcionários que participaram da pesquisa. Este termo foi aprovado pelo Comitê de Ética do Hospital das Clínicas de Ribeirão Preto (ANEXO I).

\section{F. ANÁLISE ESTATÍTICA E TABULAÇÃO DE DADOS}

Os dados obtidos foram tabulados em planilhas de cálculos apropriadas, que continham as variáveis a serem analisadas. Quando necessário foram criados códigos a fim de facilitar a posterior análise de dados.

Foi realizada análise descritiva dos resultados obtidos com relação à frequência, média e desvio padrão. Todos os dados foram verificados quanto a normalidade (Lapponi, 2005). Em caso positivo foi utilizado o Teste T-Student para duas amostras, teste do $\mathrm{Ch}^{2}$ ou análise de variância para amostras múltiplas. Os equivalentes não paramétricos a estes testes foram utilizados quando a amostra teve uma distribuição não normal. Foi considerado o resultado com diferença significativa, quando o $p$ obtido fosse menor o igual a 0,05 $(p<0,05)$. 
1

Resultados 



\section{RESULTADOS}

\section{A. Características clínicas dos pacientes}

O presente estudo foi realizado com 145 pacientes internados no HCFMRPUSP entre janeiro e junho de 2008, que necessitaram de NTP em alguma fase de sua de internação. Desses, 81 (56\%) eram do sexo masculino e 64 (44\%) do feminino, a idade média foi de $53 \pm 16$ anos, com peso médio de $64 \pm 18 \mathrm{~kg}$ e com índice de massa corpórea médio de $23 \pm 6 \mathrm{~kg} \cdot \mathrm{m}^{-2}$.

Todos os pacientes avaliados tinham indicação clínica de uso de nutroterapia parenteral, fôsse pelo trato digestivo não funcionante (íleo paralítico, ressecção intestinal, obstrução intestinal, fistula de alto débito), ou então como terapia mista, para atingir a meta nutrológica previamente indicada pela equipe responsável pelos pacientes (queimados, quimioterapia, mucosite e ou lesão cáustica do esôfago), ou ainda como terapia complementar dos pacientes submetidos a transplante de medula óssea. Dezenove pacientes (13\%) tinham falência intestinal orgânica, como síndrome do intestino curto e doença inflamatória intestinal, que necessitavam de nutroterapia parenteral prolongada.

A avaliação laboratorial clínica realizada desses pacientes, evidenciou albunemia média de $30 \pm 6 \mathrm{~g} \cdot \mathrm{L}^{-1}$, linfócitos totais de $1471 \pm 844 \mathrm{~mm}^{-3}$. Os 145 pacientes utilizaram 179 cateteres venosos centrais. A média de permanência do cateter foi de $46 \pm 160$ dias, o que representou um total de 8256 CVC-dia, com frequência de infecção de 34\%, correspondendo a uma taxa de infecção de 7,5 por 1000 CVC-dia. Durante a nutroterapia parenteral 30 pacientes (21\%) não apresentaram distúrbio hidroeletrolítico. A hiper/hiponatremia foram os distúrbios 
mais frequentes encontrados com uma natremia média dos pacientes de $137 \pm 6$ mmol.L ${ }^{-1}$, seguido da hipocalemia, com calemia média de $3,9 \pm 0,5$ mmol.L-1. A fosfatemia média foi de $3,7 \pm 0,9 \mathrm{mg}^{-1}{ }^{-1}$. Os níveis magnésio sérico foram de

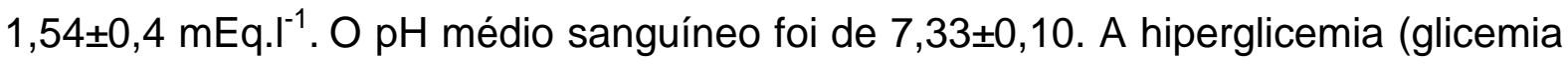
capilar ou sanguínea superior a $140 \mathrm{mg} . \mathrm{dl}^{-1}$ ) ocorreu em $63 \%$ dos casos, com picos hiperglicêmicos médios de $193 \pm 85 \mathrm{mg} \mathrm{dl}^{-1}$. O óbito, durante a internação, aconteceu em 62 dos 145 (43\%) pacientes acompanhados (tabela 3).

Ao avaliarmos os pacientes com a ferramenta modificada para quantificação e qualificação do risco nutrológico ("DIETAS DENUCIAM RISCO - DDR)", obtivemos um escore médio de $7,5 \pm 2,5$ pontos. A análise destes indicadores mostrou que itens imprescindíveis para prescrição nutrológica não foram avaliados, como por exemplo: não obtenção do peso (24\%) e jejum por mais de 48 horas (18\%).

O grupo 1 (G1), pacientes que evoluíram com óbito, apresentou mais complicações clínicas durante o seguimento como infecção associada ao acesso venoso $(p=0,007)$, distúrbios hidroeletrolíticos $(p=0,036)$ e hiperglicemia $(p=$ 0,0001). Do ponto de vista nutrológico, os pacientes que evoluíram com óbito, apesar de apresentarem IMC mais elevado do que o grupo 2 (25 \pm 6 vs. $22 \pm 5 \mathrm{~kg} \cdot \mathrm{m}^{-2}$, $(p=0,002)$, eram mais desnutridos, com albumina média de $28 \pm 6 \mathrm{~g} \cdot \mathrm{L}^{-1} \mathrm{vs} .30 \pm 7 \mathrm{~g} \cdot \mathrm{L}^{-1}$ $(p=0,03)$. Apesar dos pacientes do grupo 1 apresentarem mais complicações infecciosas do que o do grupo 2, não observamos diferença significante no número de linfócitos totais entre os dois grupos $(p=0,38)$. Ao utilizarmos o escore do DDR observamos que os pacientes que foram a óbito possuíam maior pontuação ( $p$ = 0,007).

Quando comparamos o grupo de pacientes que evoluíram com infecção associada ao CVC, independente do óbito, com o grupo sem infecção não 
observamos diferenças laboratoriais e clínicas significativas quanto à glicemia, a distúrbios hidroeletrolíticos e/ou ácido-básico, ao estado nutricional dos pacientes avaliados e ao escore DDR. As características desses pacientes foram resumidas na tabela 04 , tendo-se que no grupo com infecção houve predomínio do sexo masculino (62\%), a idade média foi $51 \pm 15$ anos, o peso médio de $66 \pm 21 \mathrm{~kg}$, IMC médio de $24 \pm 6 \mathrm{~kg} \cdot \mathrm{m}^{-2}$, a albunemia média de $30 \pm 5 \mathrm{~g} \cdot \mathrm{L}^{-1}$, a glicemia média de $194 \pm 79 \mathrm{mg} \cdot \mathrm{dl}^{-1}$, a natremia média de $138 \pm 6 \mathrm{mmo}^{-1}$, a calemia média $3,9 \pm 0,5$ mmol...-1 , fosfatemia média $3,73 \pm 1,1 \mathrm{mg} . \mathrm{dl}^{-1}$, magnesemia média de $1,7 \pm 0,5 \mathrm{mEq} . \mathrm{L}^{-}$

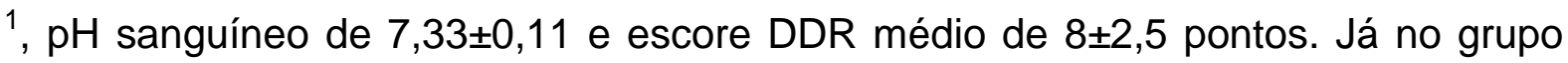
sem infecção associada ao CVC também observamos predomínio do sexo masculino (54\%), a idade média foi $52 \pm 16$ anos, o peso médio de $63 \pm 17 \mathrm{~kg}$, IMC médio de $23 \pm 5 \mathrm{~kg} \cdot \mathrm{m}^{-2}$, a albunemia média de $29 \pm 6 \mathrm{~g} \cdot \mathrm{L}^{-1}$, a glicemia média de $197 \pm 88 \mathrm{mg} \cdot \mathrm{dl}^{-1}$, a natremia média de $137 \pm 6 \mathrm{mmo}^{-1}$, a calemia média $3,9 \pm 0,5$ mmol.L ${ }^{-1}$, fosfatemia média 3,65 $\pm 0,7 \mathrm{mg} . \mathrm{dl}^{-1}$, magnesemia média de $1,7 \pm 0,5 \mathrm{mEq} \cdot \mathrm{L}^{-}$

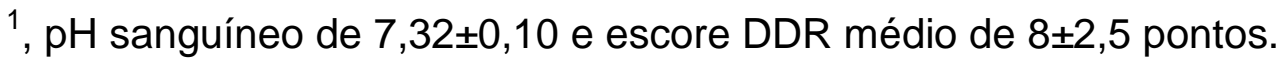

Com relação à presença de colonização do cateter venoso, podendo ou não estar relacionada à infecção sistêmica, observamos também que não houve diferenças clínicas e laboratoriais significativas no grupo dos que tiveram colonização do cateter, com o grupo que não cursou com a mesma. As características encontram-se resumidas na tabela 05 . Notando-se predomínio do sexo masculino em ambos grupos avaliados, sendo no grupo com colonização do CVC essa frequência de $61 \%$ e a do grupo sem colonização, 53\%; a diferença média de idade entre os dois grupos de 4 anos (64 \pm 20 vs.54 \pm 17 anos); maior frequência de hiperglicemia no grupo sem colonização (62 vs. 59\%) e menor 
frequencia de DHE nesse grupo, quando comparado ao da colonização do cateter (72 vs. $76 \%)$. 
Tabela 3: Características demográficas e laboratoriais da população em nutroterapia parenteral no Hospital das Clínicas da Faculdade de Medicina de Ribeirão Preto, janeiro a junho de 2008

\begin{tabular}{|c|c|c|c|c|}
\hline Características & $\begin{array}{l}\text { Grupo } 1 \\
(n=62)\end{array}$ & $\begin{array}{c}\text { Grupo } 2 \\
(n=83)\end{array}$ & $\begin{array}{c}P \\
(<0,05)\end{array}$ & $\begin{array}{l}\text { Valores de } \\
\text { Referência }\end{array}$ \\
\hline \multicolumn{5}{|l|}{ Sexo } \\
\hline - Masculino (n) & 32 & 49 & & SVR \\
\hline - Feminino $(\mathrm{n})$ & 30 & 34 & & \\
\hline Idade (anos) & $54 \pm 15^{7}$ & $50 \pm 16^{7}$ & $0,12^{\mathrm{a}}$ & SVR \\
\hline Peso (kg) & $69 \pm 19^{*}$ & $61 \pm 17^{¥}$ & $0,02^{a}$ & SVR \\
\hline IMC $\left(\mathrm{kg} \cdot \mathrm{m}^{-2}\right)$ & $25 \pm 6^{7}$ & $22 \pm 5^{¥}$ & $0,002^{a}$ & $18,5-24,9$ \\
\hline Albuminemia $\left(\mathrm{g} \cdot \mathrm{L}^{-1}\right)$ & $28 \pm 6^{7}$ & $30 \pm 7^{¥}$ & $0,03^{a}$ & $35-48$ \\
\hline Hiperglicemia (\%) & 77 & 52 & $0,001^{b}$ & $\operatorname{SVR}^{\infty}$ \\
\hline Glicemia (mg.dl $\left.{ }^{-1}\right)$ & $228 \pm 103^{\#}$ & $168 \pm 53^{¥}$ & $0,0001^{a}$ & $70-140$ \\
\hline Linfócitos $\left(\mathrm{mm}^{-3}\right)$ & $1406 \pm 847^{¥}$ & $1440 \pm 932^{*}$ & $0,38^{a}$ & $1000-3630$ \\
\hline DHE (\%) & 82 & 62 & $0,036^{b}$ & $\mathrm{SR}^{\infty}$ \\
\hline Natremia (mmol.L-1) & $140 \pm 7^{¥}$ & $136 \pm 5^{¥}$ & $0,0005^{a}$ & $135-140$ \\
\hline Calemia $\left(\mathrm{mmol} . \mathrm{L}^{-1}\right)$ & $3,9 \pm 0,5^{*}$ & $3,8 \pm 0,5^{*}$ & $0,069^{a}$ & $3,5-5,0$ \\
\hline Fosfatemia $\left(\mathrm{mg} \cdot \mathrm{dl}^{-1}\right)$ & $3,65 \pm 1^{*}$ & $3,7 \pm 0,8^{*}$ & $0,44^{\mathrm{a}}$ & $2,5-5,6$ \\
\hline Magnesemia $\left(\mathrm{mEq} \cdot \mathrm{L}^{-1}\right)$ & $1,7 \pm 0,6^{*}$ & $1,5 \pm 0,26^{¥}$ & $0,17^{\mathrm{a}}$ & $1,5-2,3$ \\
\hline pH sanguíneo & $7,29 \pm 0,11^{¥}$ & $7,37 \pm 0,08^{¥}$ & $0,018^{c}$ & $7,35-7,45$ \\
\hline Escore DDR & $9 \pm 2^{*}$ & $7 \pm 2^{*}$ & $0,007^{b}$ & $0-40$ \\
\hline $\begin{array}{l}\text { Infecção sistêmica } \\
\text { relacionada ao CVC }\end{array}$ & $59 \%$ & $36 \%$ & $0,007^{b}$ & $\mathrm{SVR}^{\infty}$ \\
\hline
\end{tabular}

Grupo 1: pacientes que evoluíram com óbito; Grupo 2: pacientes que permaneceram vivos ao término da nutroterapia parenteral.

IMC: Índice de Massa Corpórea; DHE: distúrbio hidroeletrolítico; DDR: DIETAS DENUCIAM RISCO CVC: cateter venoso central.

n: número; \%: porcentagem; kg: quilogramas; $\mathrm{kg}^{-2}$ : quilogramas por metro quadrado; g. $\mathrm{L}^{-1}:$ gramas por litro; miligramas por decilitro; $\mathrm{mm}^{-3}$ : por milímetro cúbico; mol..-1: milimol por litro; $\mathrm{mEq} . \mathrm{L}^{-1}$ : miliequivalente por litro

${ }^{\infty}$ SVR: sem valor de referência

*:média \pm desvio padrão

${ }^{a} t$-Student

${ }^{b} \mathrm{Chi}^{2}$

${ }^{\mathrm{c}}$ Teste $\mathrm{F}$ 
Tabela 4: Características demográficas e laboratoriais da população em nutroterapia parenteral no Hospital das Clínicas da Faculdade de Medicina de Ribeirão Preto em relação à presença de infecção associada ao cateter venoso central, janeiro a junho de 2008

\begin{tabular}{|c|c|c|c|c|}
\hline Características & $\begin{array}{l}\text { Com Infecção } \\
\text { Relacionada } \\
\begin{array}{l}\text { ao CVC } \\
(n=60)\end{array}\end{array}$ & $\begin{array}{l}\text { Sem Infecção } \\
\text { Relacionada ao } \\
\text { CVC } \\
(119)^{\pi}\end{array}$ & $\begin{array}{c}\mathrm{P} \\
(<0.05)\end{array}$ & $\begin{array}{l}\text { Valores de } \\
\text { Referência }\end{array}$ \\
\hline \multicolumn{5}{|l|}{ Sexo } \\
\hline - Masculino (n) & 37 & 64 & & SR \\
\hline - Feminino (n) & 23 & 55 & & \\
\hline Idade (anos) & $51 \pm 15^{*}$ & $52 \pm 16^{7}$ & $0,34^{\mathrm{a}}$ & SR \\
\hline Peso (kg) & $66 \pm 21^{*}$ & $63 \pm 17^{*}$ & $0,25^{\mathrm{a}}$ & SR \\
\hline IMC $\left(\mathrm{kg} \cdot \mathrm{m}^{-2}\right)$ & $24 \pm 6^{*}$ & $23 \pm 5^{*}$ & $0,24^{a}$ & $18,5-24,9$ \\
\hline Albuminemia $\left(\mathrm{g} \cdot \mathrm{L}^{-1}\right)$ & $30 \pm 5^{*}$ & $29 \pm 6^{*}$ & $0,24^{a}$ & $35-48$ \\
\hline Hiperglicemia (\%) & 35 & 33 & $0,88^{b}$ & SR \\
\hline Glicemia (mg.d ${ }^{-1}$ ) & $194 \pm 79^{*}$ & $197 \pm 88^{*}$ & $0,43^{a}$ & $70-140$ \\
\hline Linfócitos $\left(\mathrm{mm}^{-3}\right)$ & $1333 \pm 808^{¥}$ & $1528 \pm 865^{*}$ & $0,11^{a}$ & $1000-3630$ \\
\hline DHE (\%) & 80 & 72 & $0,29^{b}$ & SR \\
\hline Natremia (mmol.L-1) & $138 \pm 6^{*}$ & $137 \pm 6^{*}$ & $0,3^{a}$ & $135-140$ \\
\hline Calemia $\left(\mathrm{mmol} . \mathrm{L}^{-1}\right)$ & $3,9 \pm 0,5^{*}$ & $3,9 \pm 0,5^{*}$ & $0,3^{a}$ & $3,5-5,0$ \\
\hline Fosfatemia $\left(\mathrm{mg} \cdot \mathrm{dl}^{-1}\right)$ & $3,7 \pm 1,1^{¥}$ & $3,7 \pm 0,7^{7}$ & $0,38^{a}$ & $2,5-5,6$ \\
\hline Magnesemia (mEq. $\mathrm{L}^{-1}$ ) & $1,7 \pm 0,5^{¥}$ & $1,5 \pm 0,5^{¥}$ & $0,12^{a}$ & $1,5-2,3$ \\
\hline pH sanguíneo & $7,33 \pm 0,1^{*}$ & $7,32 \pm 0,1^{¥}$ & $0,28^{a}$ & $7,35-7,45$ \\
\hline Escore DDR & $8 \pm 3^{*}$ & $8 \pm 2^{*}$ & $0,08^{\mathrm{a}}$ & $0-40$ \\
\hline \multicolumn{5}{|c|}{ 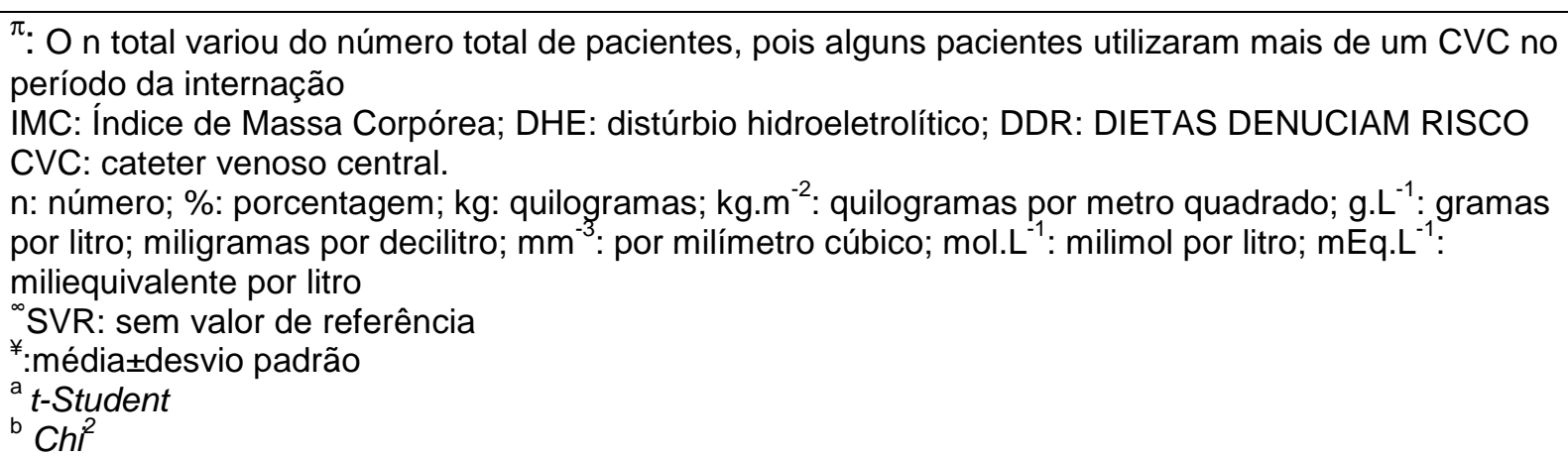 } \\
\hline
\end{tabular}


Tabela 5: Características demográficas e laboratoriais da população em nutroterapia parenteral no Hospital das Clínicas da Faculdade de Medicina de Ribeirão Preto em relação à colonização microbiológica do cateter venoso central, janeiro a junho de 2008

\begin{tabular}{|c|c|c|c|c|}
\hline Características & $\begin{array}{c}\text { Com } \\
\text { Colonização } \\
\text { do CVC } \\
(\mathrm{n}=87)^{\pi}\end{array}$ & $\begin{array}{c}\text { Sem } \\
\text { Colonização do } \\
\text { CVC } \\
(n=92)^{\pi}\end{array}$ & $\begin{array}{c}P \\
(<0.05)\end{array}$ & $\begin{array}{l}\text { Valores de } \\
\text { Referência }\end{array}$ \\
\hline \multicolumn{5}{|l|}{ Sexo } \\
\hline - Masculino (n) & 53 & 49 & & $\mathrm{SVR}^{\infty}$ \\
\hline - Feminino (n) & 34 & 43 & & \\
\hline Idade (anos) & $50 \pm 14^{*}$ & $54 \pm 17^{*}$ & $0,08^{\mathrm{a}}$ & $\mathrm{SVR}^{\infty}$ \\
\hline Peso (kg) & $64 \pm 20^{*}$ & $63 \pm 16^{*}$ & $0,37^{\mathrm{a}}$ & $\mathrm{SVR}^{\infty}$ \\
\hline IMC $\left(\mathrm{kg} \cdot \mathrm{m}^{-2}\right)$ & $23,3 \pm 6^{*}$ & $22,9 \pm 5^{*}$ & $0,24^{a}$ & $18,5-24,9$ \\
\hline Albuminemia $\left(\mathrm{g} \cdot \mathrm{L}^{-1}\right)$ & $29 \pm 5^{*}$ & $29 \pm 6^{*}$ & $0,38^{a}$ & $35-48$ \\
\hline Hiperglicemia (\%) & $59 \%$ & $62 \%$ & $0,57^{b}$ & $S R^{\infty}$ \\
\hline Glicemia (mg.dl $\left.{ }^{-1}\right)$ & $196 \pm 83^{*}$ & $195 \pm 82^{*}$ & $0,46^{\mathrm{a}}$ & $70-140$ \\
\hline Linfócitos $\left(\mathrm{mm}^{-3}\right)$ & $1354 \pm 841^{*}$ & $1548 \pm 849^{¥}$ & $0,10^{a}$ & $1000-3630$ \\
\hline DHE (\%) & $76 \%$ & $72 \%$ & $0,57^{\mathrm{b}}$ & $\mathrm{SVR}^{\infty}$ \\
\hline Natremia (mmol.L-1) & $138 \pm 6^{*}$ & $137 \pm 7^{*}$ & $0,3^{a}$ & $135-140$ \\
\hline Calemia $\left(\mathrm{mmol} . \mathrm{L}^{-1}\right)$ & $3,9 \pm 0,5^{*}$ & $3,9 \pm 0,5^{¥}$ & $0,48^{a}$ & $3,5-5,0$ \\
\hline Fosfatemia (mg.dl $\left.{ }^{-1}\right)$ & $3,6 \pm 1^{*}$ & $3,7 \pm 0,7^{¥}$ & $0,3^{\mathrm{a}}$ & $2,5-5,6$ \\
\hline Magnesemia (mEq. $\mathrm{L}^{-1}$ ) & $1,65 \pm 0,5^{¥}$ & $1,5 \pm 0,3^{¥}$ & $0,14^{a}$ & $1,5-2,3$ \\
\hline pH sanguíneo & $7,34 \pm 0,1^{*}$ & $7,32 \pm 0,1^{*}$ & $0,23^{\mathrm{a}}$ & $7,35-7,45$ \\
\hline Escore DDR & $8 \pm 3^{*}$ & $8 \pm 2^{*}$ & $0,16^{\mathrm{a}}$ & $0-40$ \\
\hline \multicolumn{5}{|c|}{ 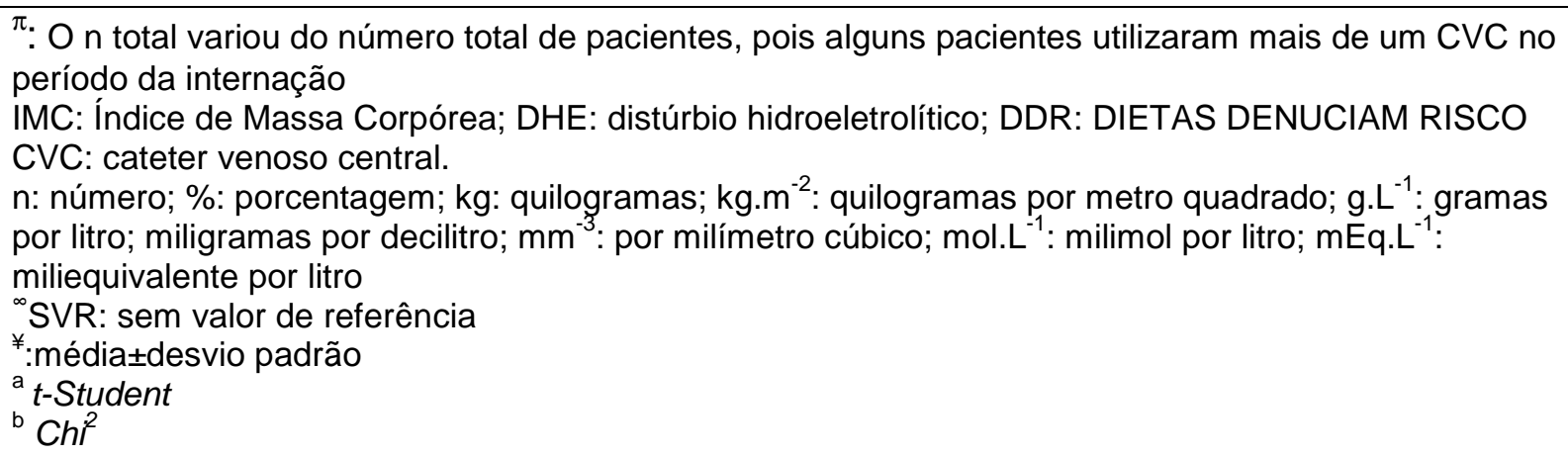 } \\
\hline
\end{tabular}




\section{B. Características dos cateteres venosos centrais utilizados}

Durante o acompanhamento dos pacientes em nutroterapia parenteral no HCFMRP-USP foram utilizados 179 cateteres venosos, sendo que todos os cateteres eram de poliuretano ou silicone.

A maioria dos pacientes teve puncionada a jugular interna (70\%), seguido da subclávia (27\%), e por último a femoral (3\%), (Figura 08). Dos cateteres implantados, $6 \%$ possuíam três lumens, $7 \%$ eram totalmente implantáveis, $16 \%$ tinham lúmen único e 71\% eram de duplo-lúmen. (Figura 09).

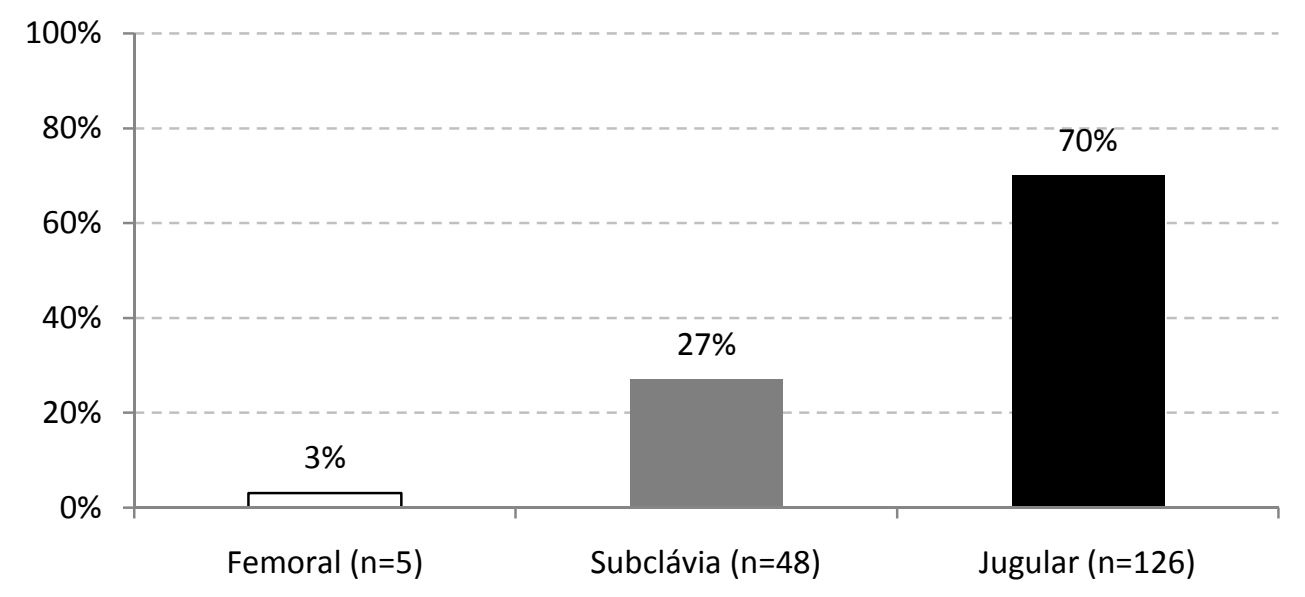

Figura 8: Sítio de implante dos cateteres venosos centrais no período de janeiro a junho de 2008 


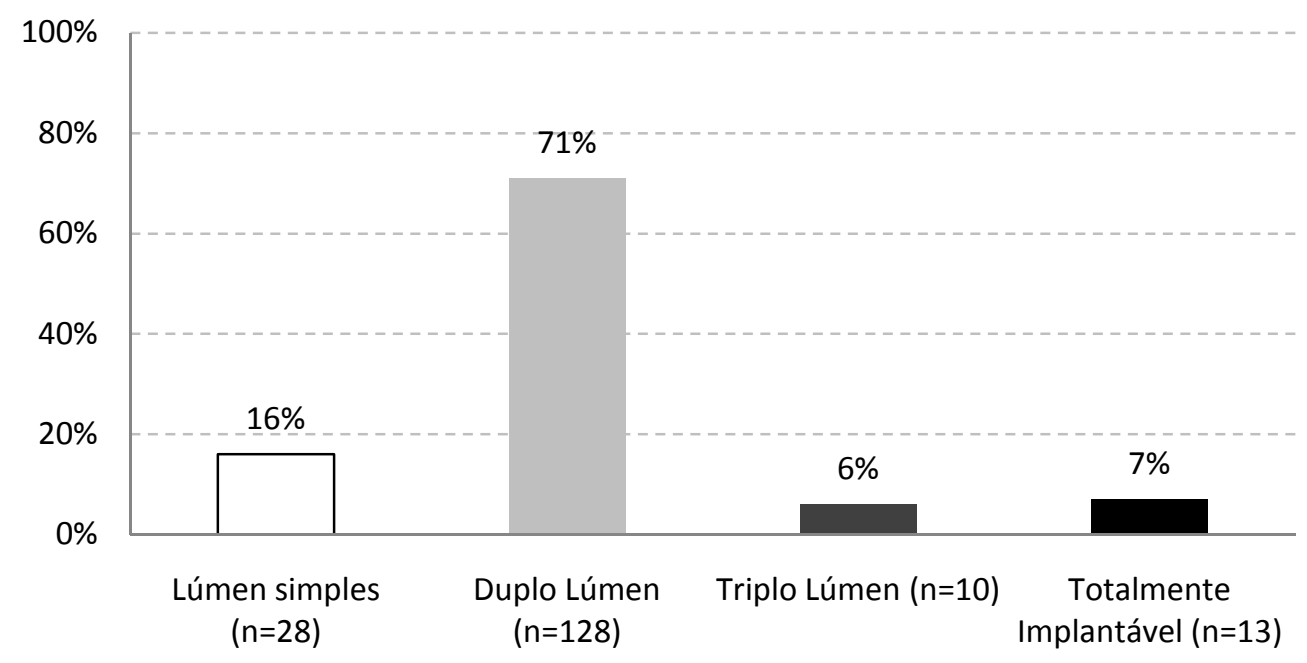

Figura 9: Tipos de cateteres utilizados para nutroterapia parenteral, período de janeiro a junho de 2008

Com relação à colonização da ponta do CVC e infecção sistêmica associada ao cateter, observamos que a colonização foi mais frequente que a infecção sistêmica ocorrendo respectivamente em 88 (49\%) e 62 (35\%) dos 179 cateteres avaliados utilizados pelos 145 pacientes avaliados. A figura 10 ilustra a frequência de infecção e colonização dos cateteres quanto ao sítio de implante do mesmo. Embora observamos que a jugular foi o local com mais infecção, não houve diferença estatística quanto ao sítio da punção ( $p=0,78$ e $p=0,39$, respectivamente). 


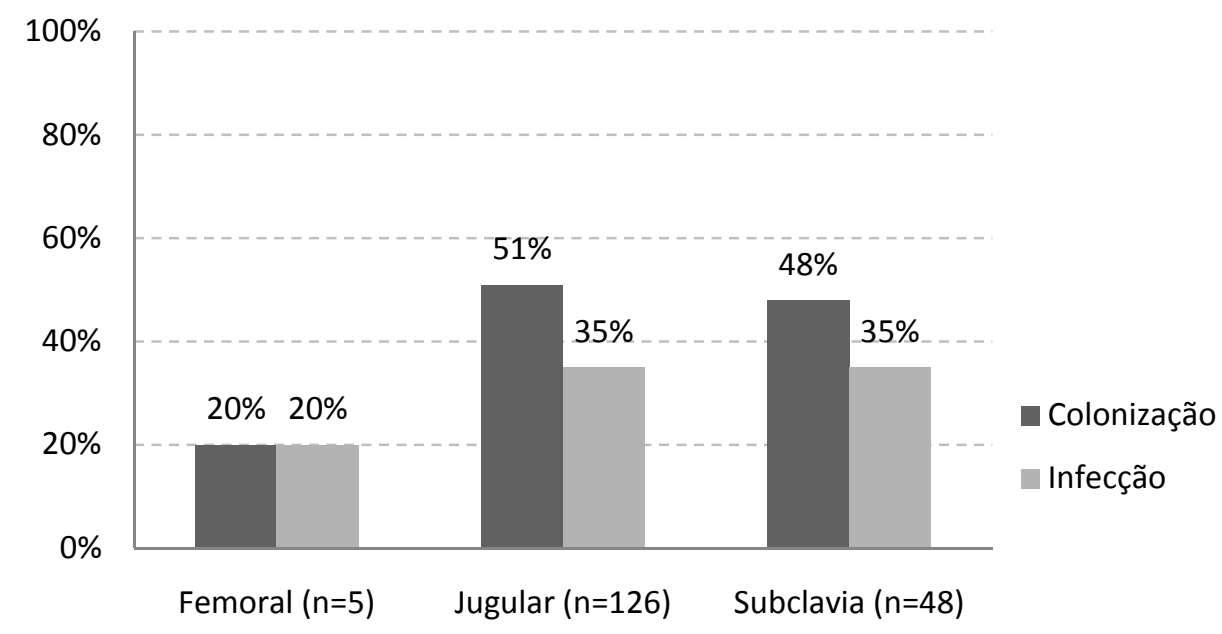

Figura 10: Frequência de Infecção e colonização do cateter quanto ao sítio de implante, janeiro a junho de 2008

Quanto ao tipo de cateter utilizado a maior frequência de infecção e colonização ocorreu principalmente no cateter de longa permanência, ou seja, o totalmente implantável. Com relação aos CVC de curta duração, observamos a frequência de colonização de $54 \%$ no cateter de lúmen simples, seguido pelo de triplo lúmen (50\%) e por duplo lúmen (46\%). Novamente sem diferença estatística $(p=0,28$ e $p=0,42)$ para o tipo de cateter utilizado ( figura 11 ). 


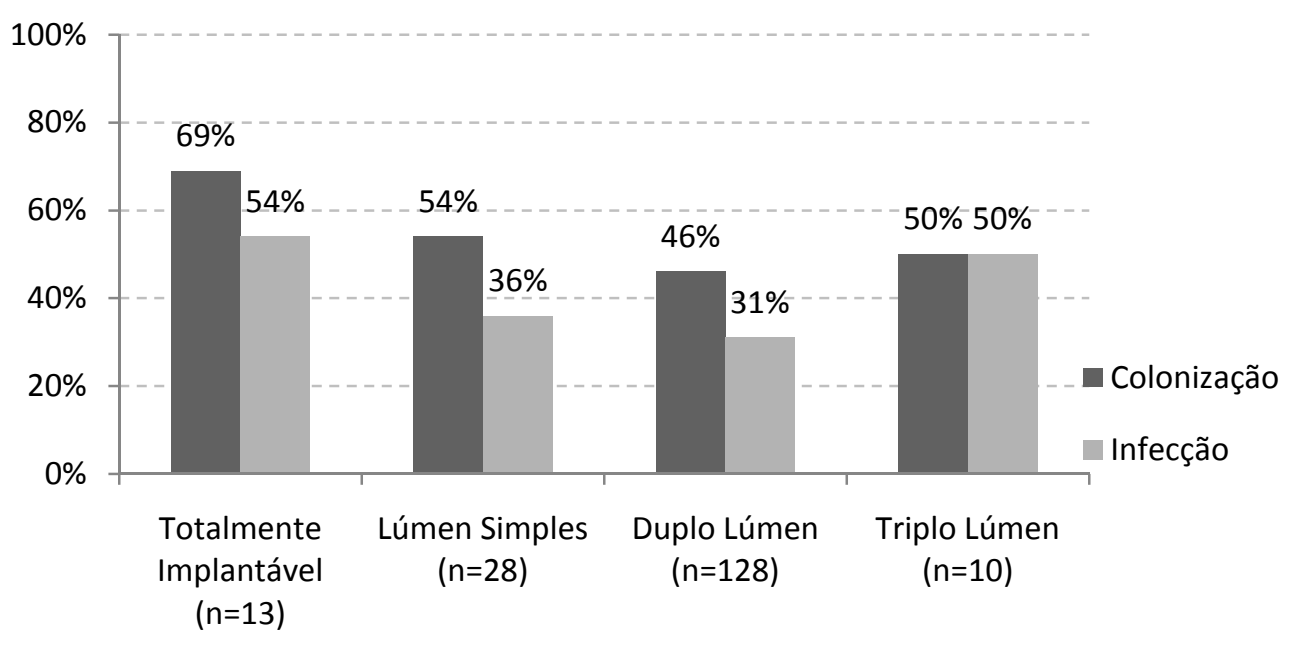

Figura 11: Frequência de Infecção e de colonização do dispositivo quanto ao tipo de cateter, janeiro a junho de 2008

De acordo com as culturas semiquantitativas das pontas dos cateteres venosos centrais utilizados, associados a hemoculturas periféricas e as do aspirado do lúmen do cateter, classificamos os resultados em colonização exclusiva da ponta do cateter e infecção sanguínea relacionada ao cateter. Tanto na colonização quanto na infecção o S. aureus, S. coagulase negativo e Candida spp.foram os micro-organismos mais frequentes (Tabela 06). 
Tabela 6: Frequência de micro-organismos encontrados nas culturas semiquantitativas das pontas dos cateteres venosos centrais em relação à colonização e à infecção sanguínea

\begin{tabular}{|c|c|c|}
\hline Microrganismo & $\begin{array}{l}\text { Colonização do } \\
\qquad \begin{array}{c}\text { CVC } \\
(n=100)\end{array}\end{array}$ & $\begin{array}{l}\text { Infecção Sanguínea } \\
\text { relacionada ao CVC } \\
\qquad(n=50)\end{array}$ \\
\hline Staphylococcus aureus ${ }^{\mathrm{a}}$ & $18(18 \%)$ & $9(18 \%)$ \\
\hline Staphylococcus coagulase negativo ${ }^{a}$ & $21(21 \%)$ & $5(10 \%)$ \\
\hline Enterococcus $^{\mathrm{a}}$ & $4(4 \%)$ & $1(2 \%)$ \\
\hline Pseudomonas aeruginosa ${ }^{\mathrm{b}}$ & $14(14 \%)$ & $5(10 \%)$ \\
\hline Acinetobacter baumann ${ }^{b}$ & $9(9 \%)$ & $4(8 \%)$ \\
\hline Enterobacter $\mathrm{spp}^{\mathrm{b}}$ & $4(4 \%)$ & $3(6 \%)$ \\
\hline Klebsiela pneumoniae ${ }^{b}$ & $3(3 \%)$ & $3(6 \%)$ \\
\hline Proteus spp $p^{b}$ & $2(2 \%)$ & $1(2 \%)$ \\
\hline Escherichia colp ${ }^{b}$ & $2(2 \%)$ & $1(2 \%)$ \\
\hline Serratia spp ${ }^{\mathrm{b}}$ & $1(1 \%)$ & $1(2 \%)$ \\
\hline Stenotrophomas maltophilia ${ }^{\mathrm{b}}$ & $1(1 \%)$ & $1(2 \%)$ \\
\hline Burkholderia cepacia $^{\mathrm{b}}$ & $1(1 \%)$ & $0(0 \%)$ \\
\hline Candida spp..$^{\mathrm{C}}$ & $19(19 \%)$ & $15(30 \%)$ \\
\hline - Candida albicans & $11(11 \%)$ & $8(16 \%)$ \\
\hline - Candida tropicalis & $4(4 \%)$ & $3(6 \%)$ \\
\hline - Candida glabrata & $2(2 \%)$ & $2(4 \%)$ \\
\hline - Candida parapsilosis & $2(2 \%)$ & $2(4 \%)$ \\
\hline Trichosporon inkin ${ }^{\mathrm{C}}$ & $1(1 \%)$ & $1(1 \%)$ \\
\hline
\end{tabular}

CVC: cateter venoso central

n: número

spp: espécie

$\%$ : porcentagem

a: cocos gram positivos

b: bacilos gram negativos

c: fungos e/ou hifas 


\section{C.Biofilme}

Foi aleatoriamente analisado um total de 52(29\%) amostras pela microscopia eletrônica de varredura. Das amostras analisadas, observamos a presença de micro-organismos aderidos ao lúmen do dispositivo em 32 (62\%) amostras. Mesmo em amostras com cultura semiquantitativa da ponta do cateter venoso negativo, observamos a presença de micro-organismos aderidos ao lúmen na visualização da microscopia eletrônica de varredura $(p<0,01)$, (tabela 7 ). A comparação dos resultados das culturas com o resultado da microscopia eletrônica de varredura está representada na figura 12.

Tabela 7: Presença de biofilmes em relação aos resultados das culturas semiquantitativas dos cateteres venosos centrais, janeiro a junho de 2008

$$
\text { CS Negativa Positiva }
$$

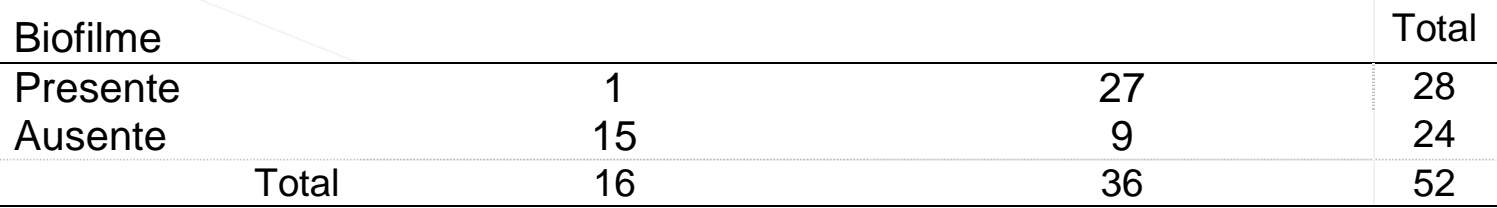

CS: Cultura semiquantitativa

$\mathrm{Chi}^{2}=18.391, \mathrm{p}<0.001$ 


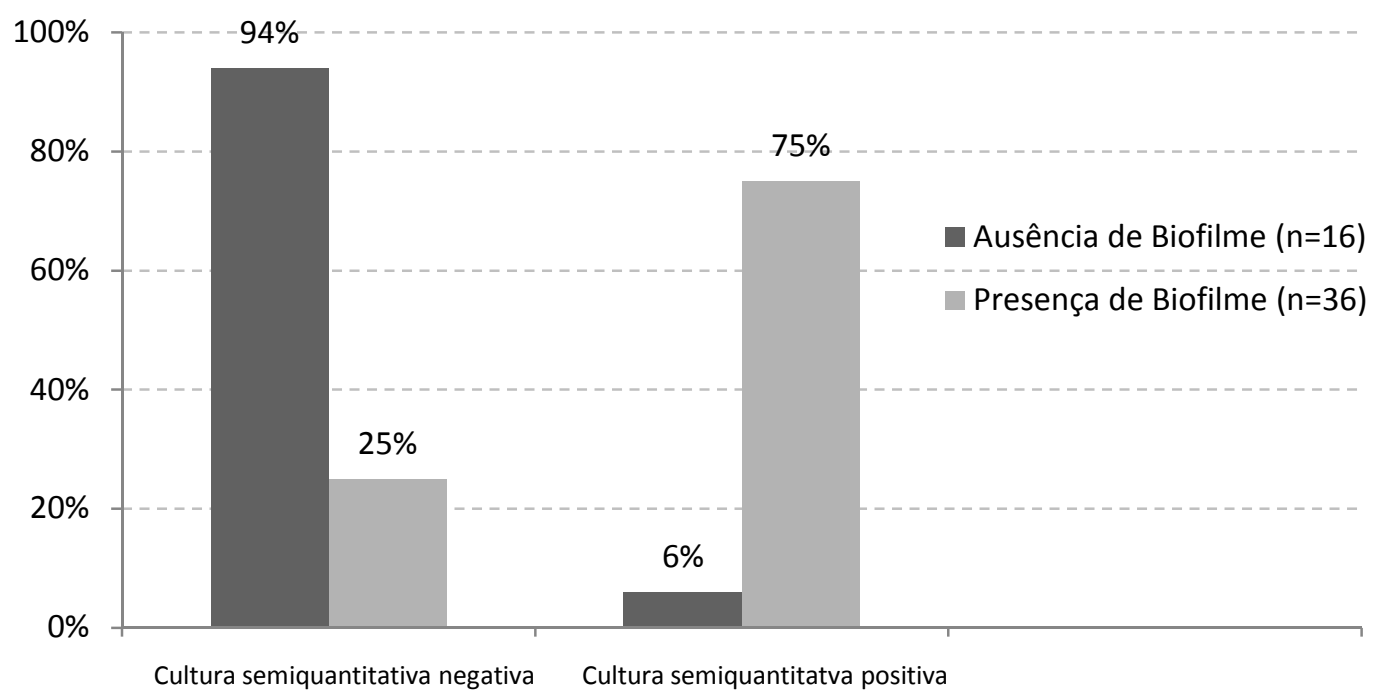

Figura 12: Comparação dos Resultados da cultura semiquantitativa da ponta do cateter versus microscopia eletrônica de varredura

Quanto às características morfológicas dos micro-organismos encontrados, durante a análise microscópica, observou-se predomínio de estruturas cocóides, seguida de bastonetes ou bacilos e, menos frequente, a presença de fungos leveduriformes (Figura 13).

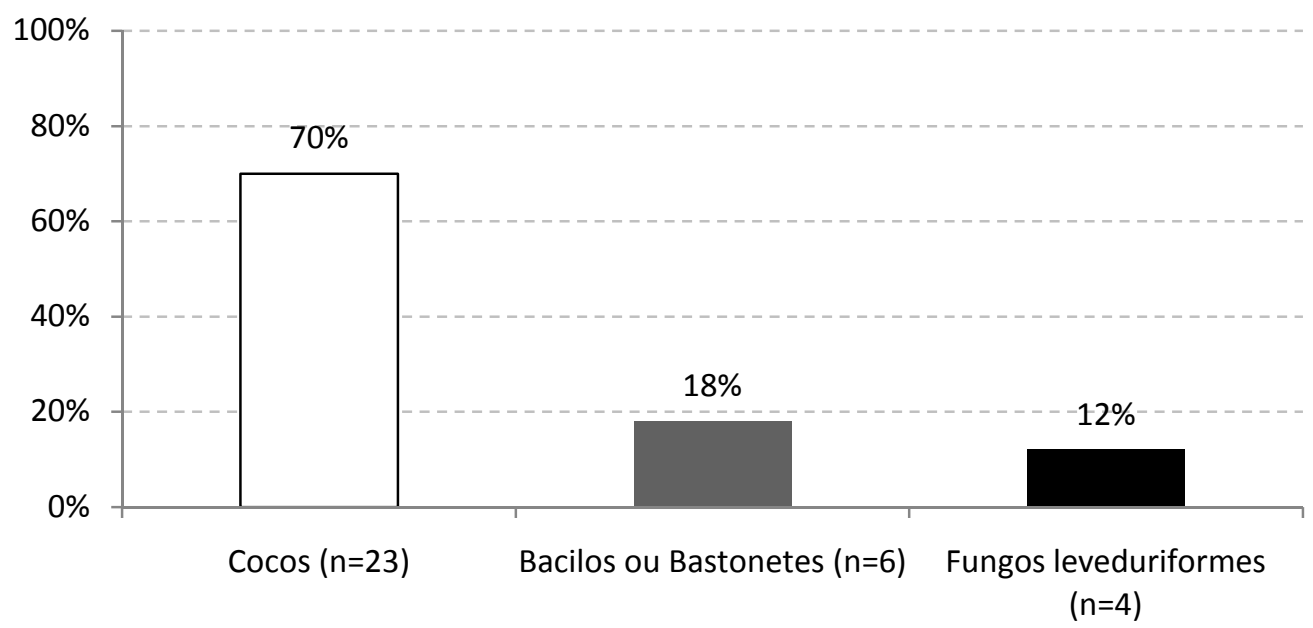

Figura 13: Características morfológicas dos micro-organismos observados no biofilme formados nos cateteres venosos centrais utilizados em janeiro a junho de 2008 
As estruturas cocóides mais frequentes, de acordo com a cultura semiquantitativa foram a de cocos gram positivos: $S$. aureus e $S$. coagulase negativo (87\%) do Enterococcus (13\%). Quanto aos bacilos e/ou bastonetes observamos a seguinte frequência: P.aeruginosa (49\%), E. coli (17\%), Proteus spp (17\%) e A. baumanni (17\%). Já em relação aos fungos observamos C. albicans (50\%), Candida glabrata (25\%) e C. parapsilosis (25\%). As Figuras 14, 15, 16 e 17 mostram a características morfológicas das estruturas observadas à microscopia eletrônica.

Além da presença do micro-organismo percebemos a presença de material denso, que contribui para a formação do glicocálix da matriz do biofilme em formação (Figura 18)

Além da presença de material biológico como hemácias, linfócitos (Figuras 19 e 20) e macrófagos observamos a presença de partículas de componentes da nutroterapia parenteral, como partículas de gordura e cristais provavelmente de sais inorgânicos utilizados na mistura da solução parenteral (figura 21)
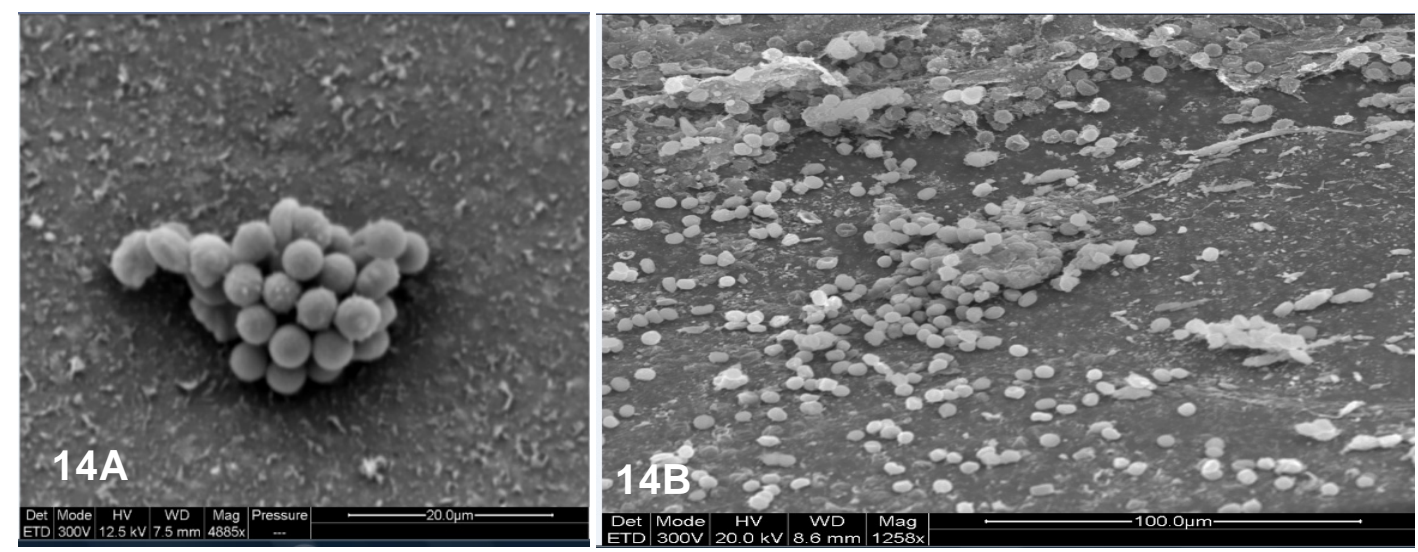

Figura 14: Microfotografias eletrônicas de varredura mostrando estruturas cocóides aderidos aos lumens dos cateteres venosos centrais utilizados para nutroterapia parenteral (14A e 14B). 

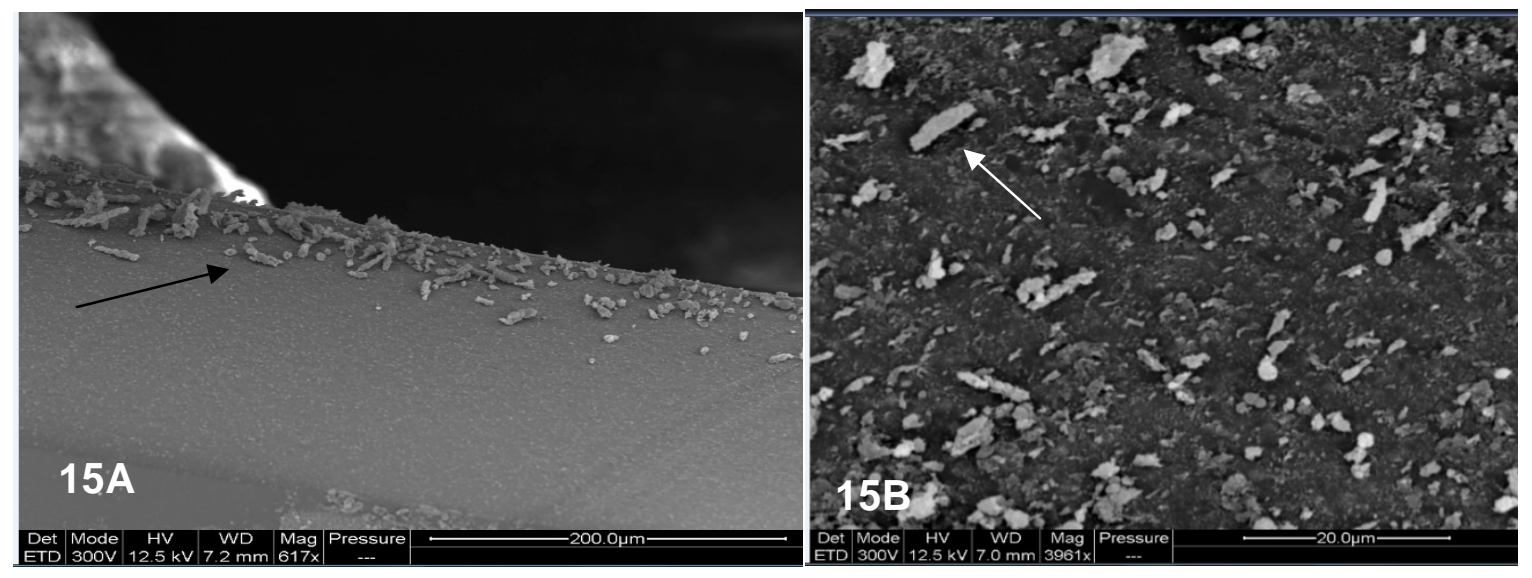

Figura 15: Microfotografias eletrônicas de varredura de bastonetes aderidos aos lumens dos cateteres venosos centrais utilizados para nutroterapia parenteral. Em 15A ponta da seta preta e em 15B ponta da seta branca. 

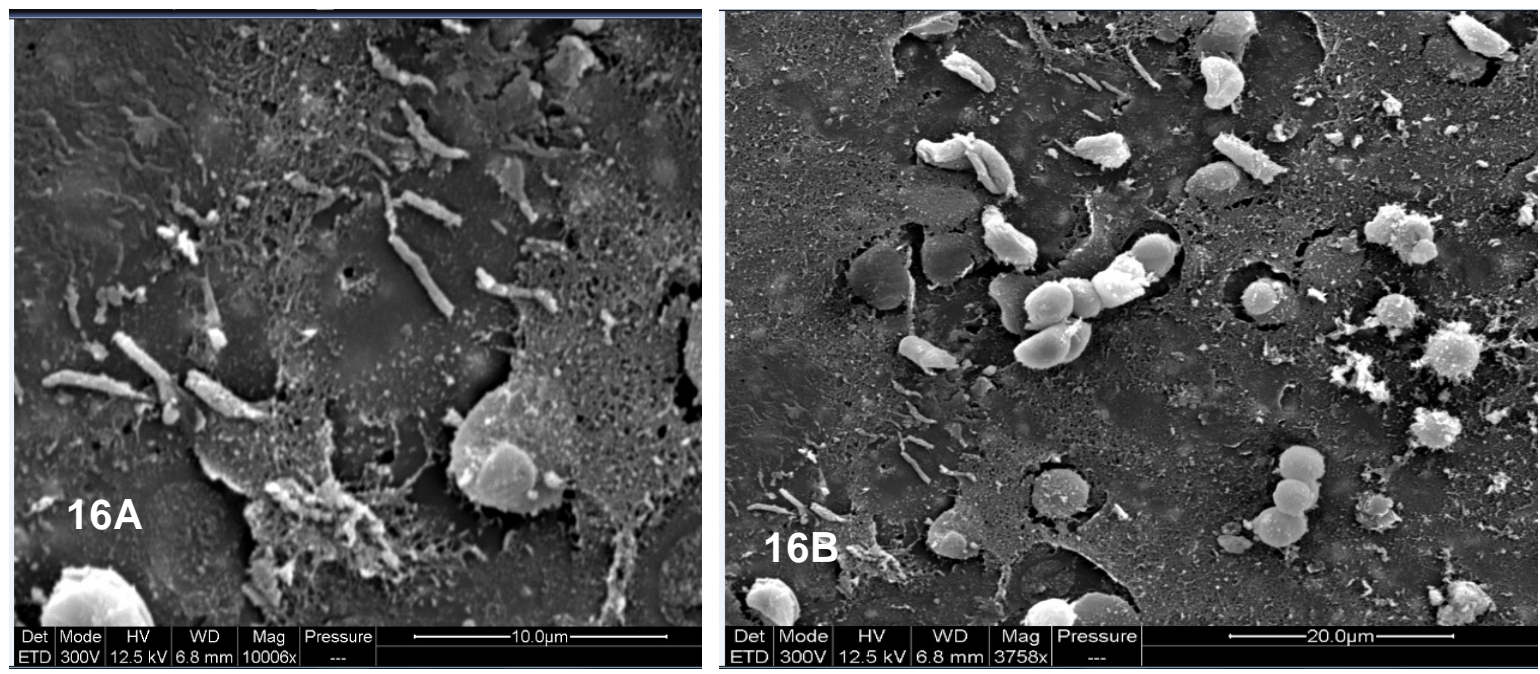

Figura 16: Microfotografias eletrônicas de varredura de cateteres venosos centrais utilizados para nutroterapia parenteral. $\mathrm{Na}$ cultura semiquantitativa observou o crescimento de Acinetobacter baumanni. Em 16A utilizou-se magnitude de 1000x e em 16B, 3750x.

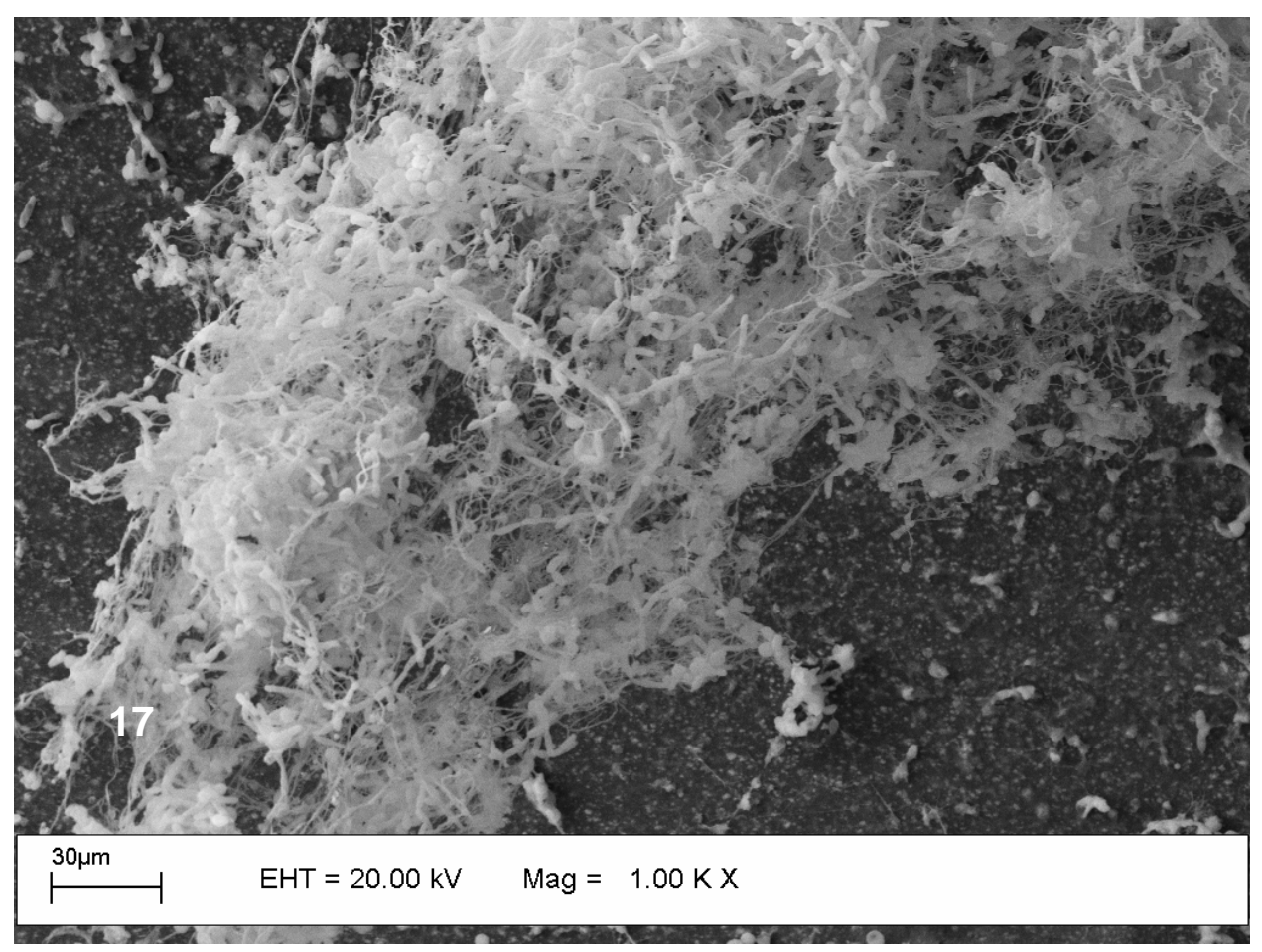

Figura 17: Microfotografia eletrônica de varredura de cateter venoso central utilizado para nutroterapia parenteral. $\mathrm{Na}$ cultura semiquantitativa observou $\mathrm{O}$ crescimento de Candida albicans. 

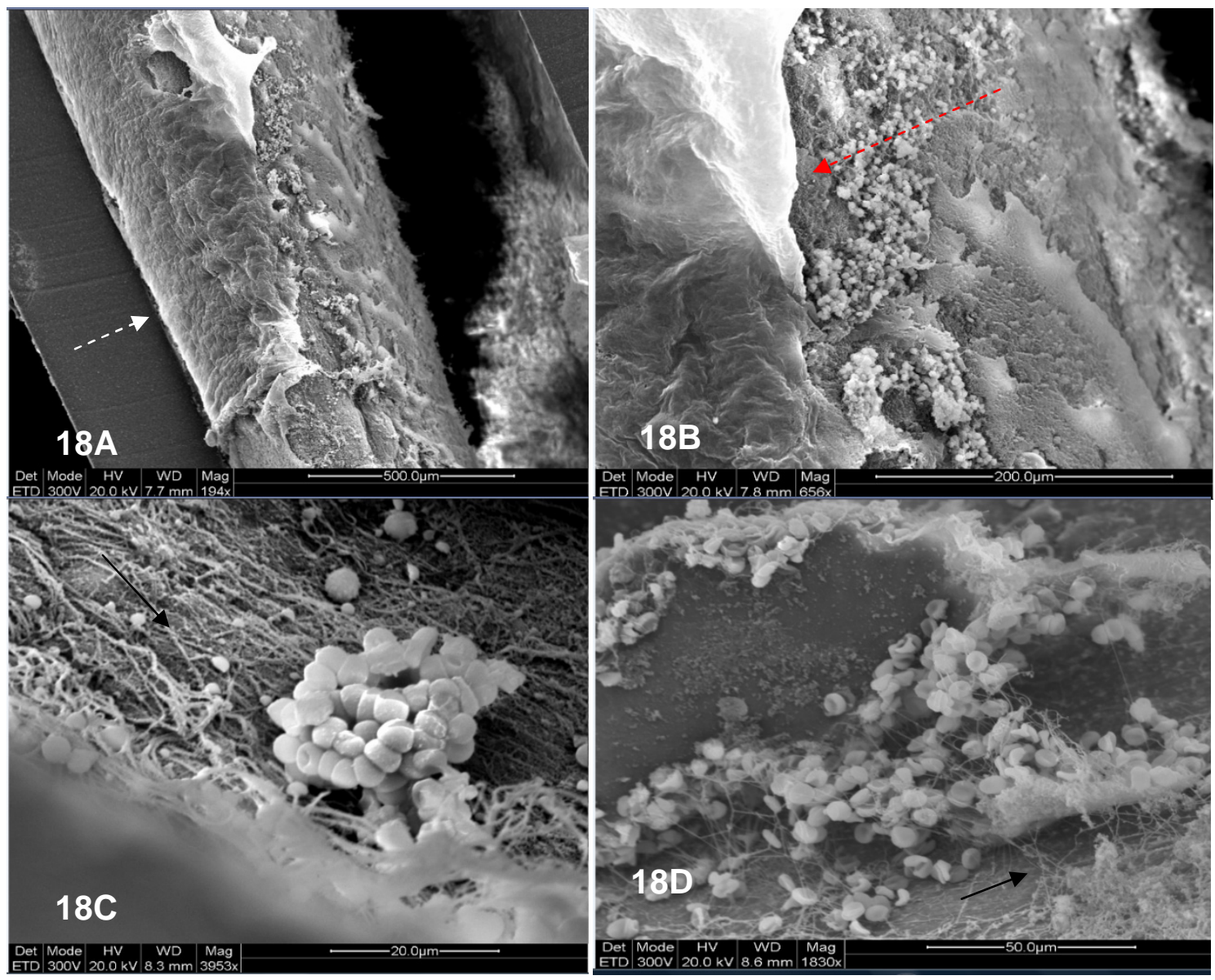

Figura 18: Microfotografias eletrônicas de varredura de cateteres venosos centrais utilizados para nutroterapia parenteral mostrando materiais biológicos que favorecem à formação de biofilme. Observa-se a presença da matriz do biofilme- seta pontilhada (18A e 18B), como fibrina (seta) aderido ao lúmen que pode propiciar e/ou facilitar a aderência de microorganismo ao lúmen do cateter assim como propiciar a colonização de mesmo, além de dificultar a penetração de agentes antimicrobianos (18C e 18D). 


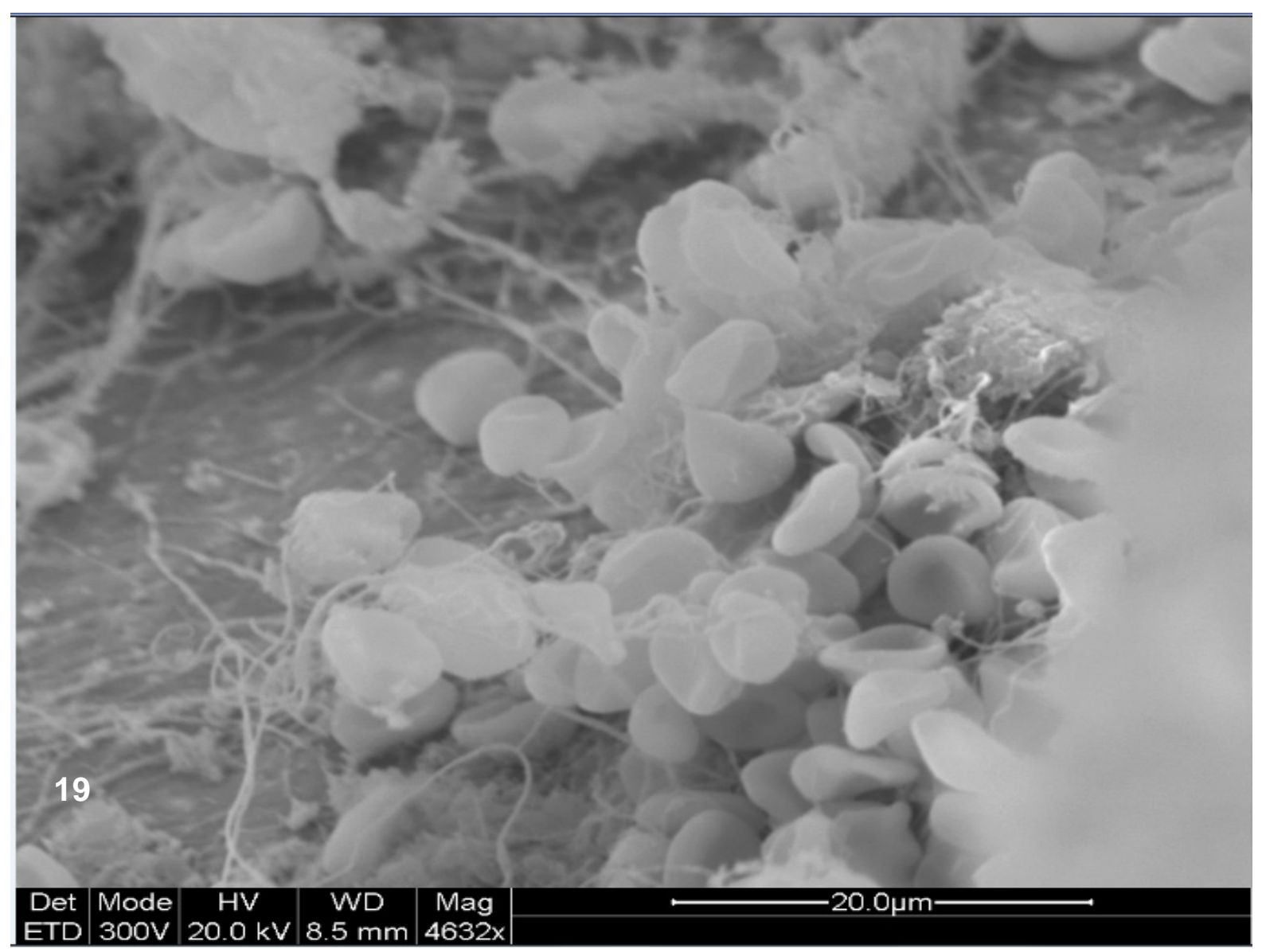

Figura 19: Microfotografia eletrônica de varredura de hemácias aderidas ao lúmen do cateter venoso central utilizado para nutroterapia parenteral, HCFMRP-USP, janeiro a junho de 2008 


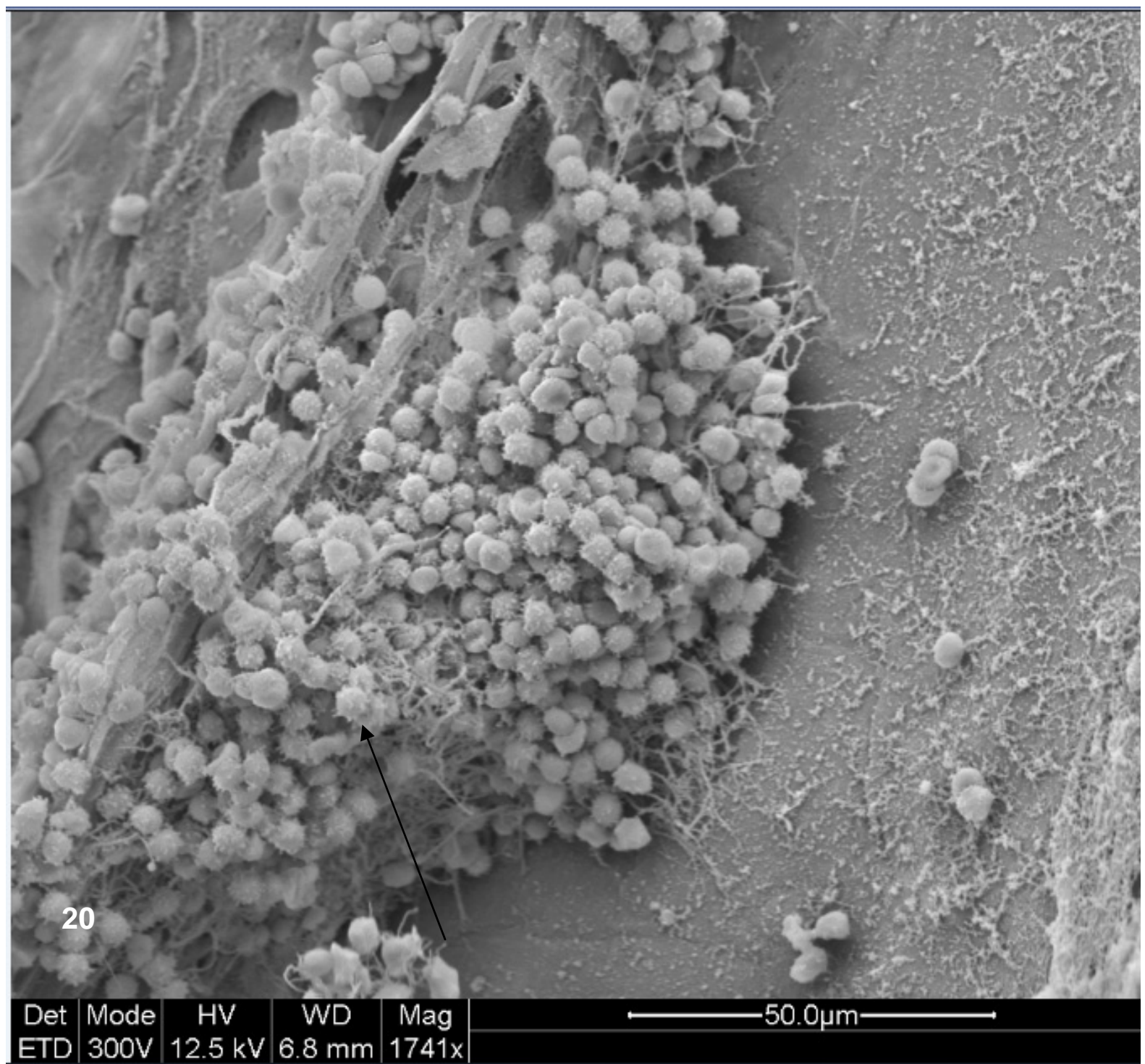

Figura 20: Microfotografia eletrônica de varredura de linfócitos aderidos ao lúmen do cateter venoso central utilizado para nutroterapia parenteral, HCFMRP-USP, janeiro a junho de 2008 (seta). 

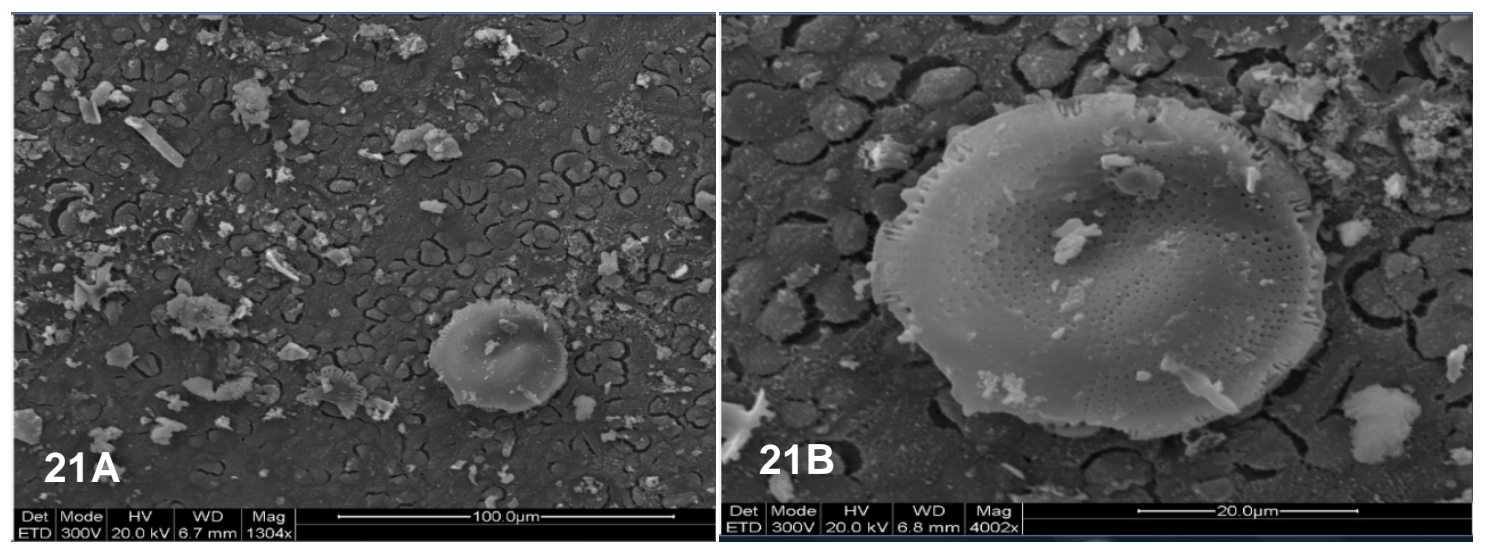

Figura 21: Microfotografias eletrônica de varredura de estruturas arredondadas e de debris aderidos ao lúmen do cateter venoso central utilizado para nutroterapia parenteral, HCFMRP-USP, janeiro a junho de 2008. Em 21 A utilizou-se magnitude de 1300x e em 21B de 4000x. 
D.Swabs de pele dos pacientes, médicos residentes e auxiliares de enfermagem

A fim de se determinar o risco de infecção cruzada ou risco de migração do micro-organismo da pele do paciente para o lúmen do cateter venoso central foram coletados de pacientes aleatórios 28 swabs da região auricular do paciente, 28 do auxiliar de enfermagem e 28 do médico residente, além de mais 28 swabs da mão dominante do paciente avaliado. Não observamos diferença significativa entre os resultados da cultura dos swabs realizados (Tabela 08). A figura 22 ilustra os resultados negativos e positivos de cada amostra coletada.

Tabela 8: Resultado das culturas dos swabs coletados, janeiro a junho de 2008

\begin{tabular}{lcc}
\hline Região dos Swabs & $\begin{array}{c}\text { Cutura positiva } \\
\mathrm{n}(\%)\end{array}$ & $\begin{array}{c}\text { Cultura negativa } \\
\mathrm{n}(\%)\end{array}$ \\
\hline Mão do paciente & $13(46 \%)$ & $15(54 \%)$ \\
Auricular do paciente & $12(43 \%)$ & $16(57 \%)$ \\
Auricular do médico & $8(29 \%)$ & $20(71 \%)$ \\
Auricular da enfermagem & $4(14 \%)$ & $24(86 \%)$ \\
\hline Chi ${ }^{2}=0,000 ; \mathrm{p}=1,0$ & & \\
$\mathrm{n}:$ número & & \\
$\%:$ porcentagem & &
\end{tabular}




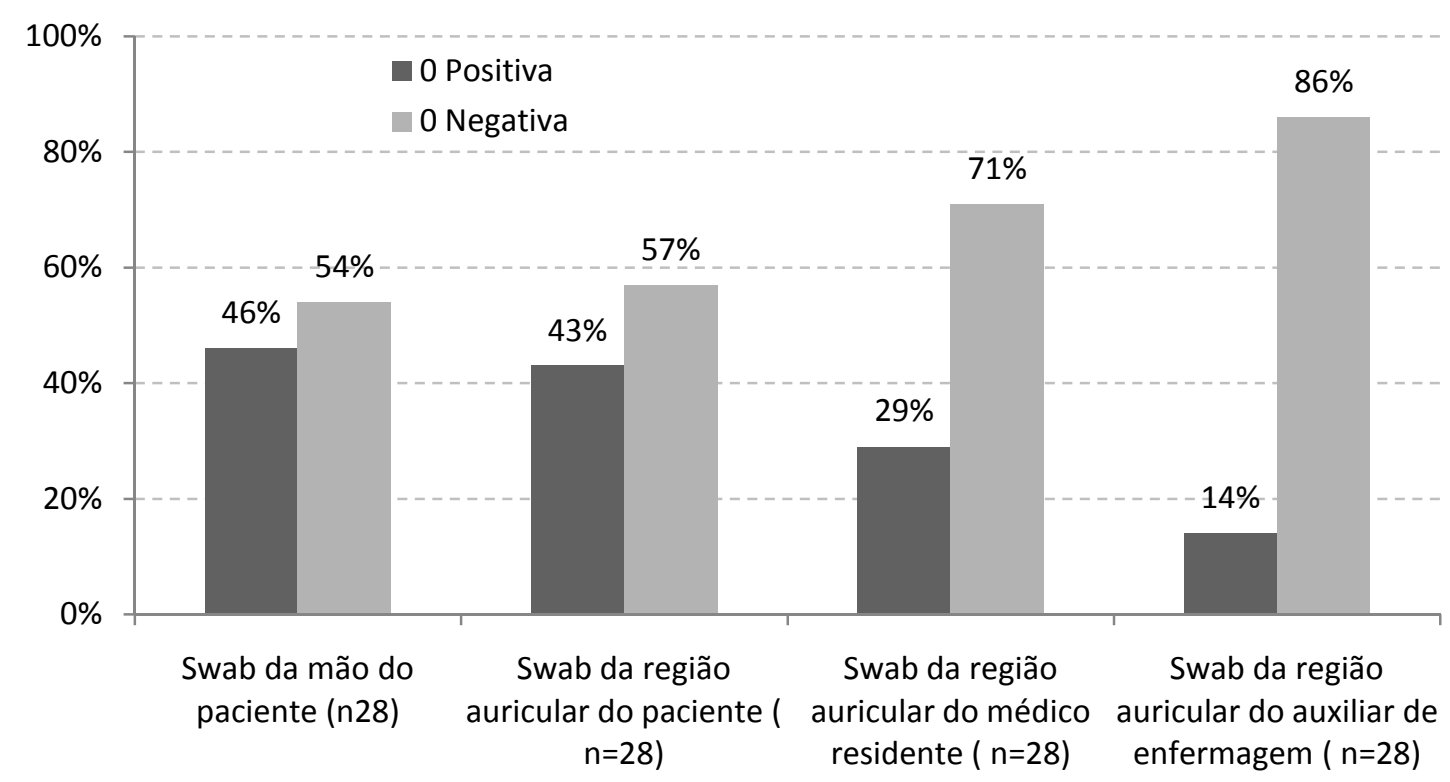

Figura 22: Resultados das culturas dos swabs de pele coletados no HCFMRPUSP, janeiro a junho de 2008

Ao avaliarmos o risco de infecção cruzada ou de migração de microorganismo da própria pele do paciente, observamos que houve concordância no crescimento de micro-organismo coletado pelo swab de pele com a cultura semiquantitativa da ponta do cateter. A figura 23 mostra a frequência desta concordância. 


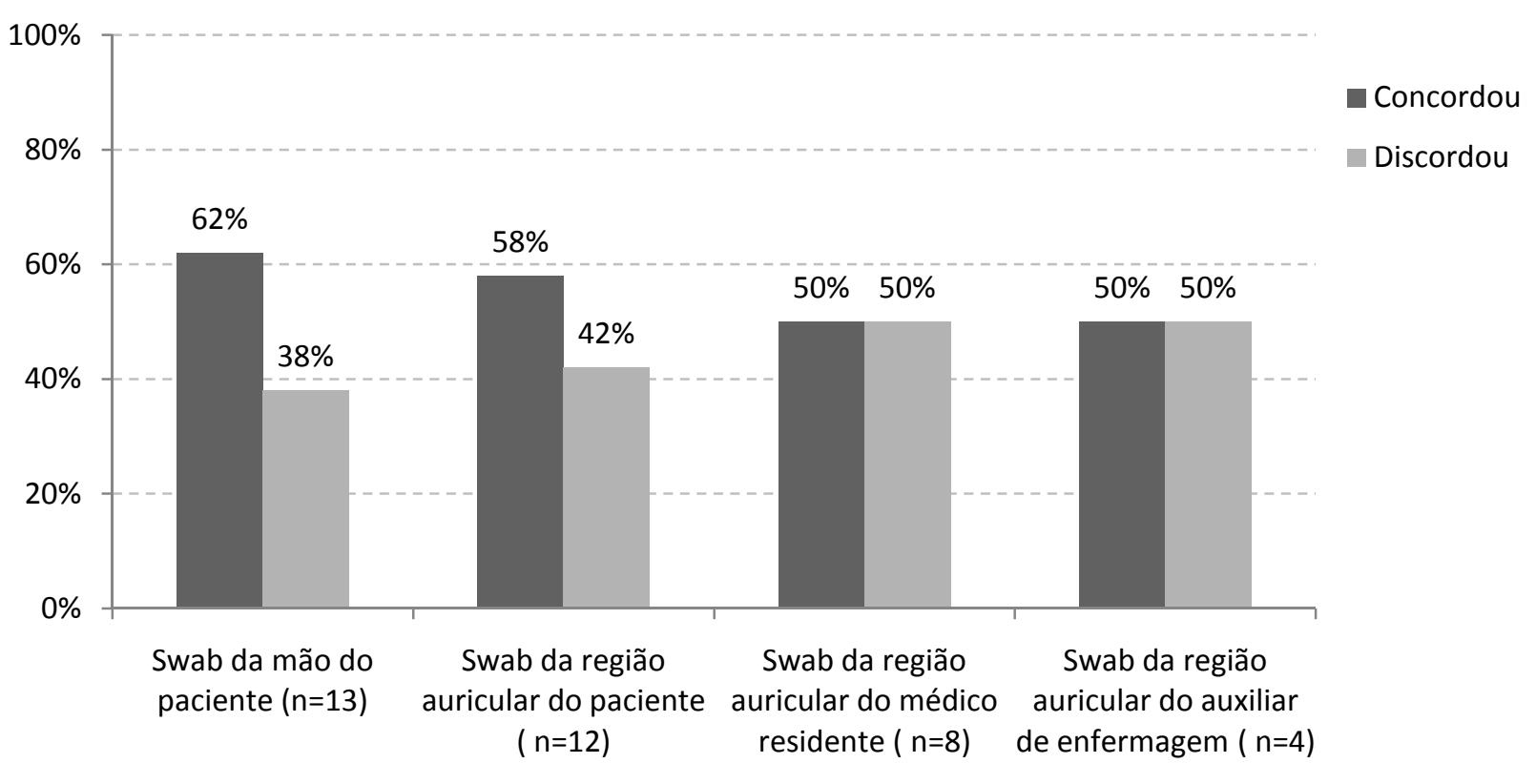

Figura 23: Frequência de concordância entre resultados das culturas semiquantitativas do cateter e dos swabs de pele coletados no HCFMRPUSP, janeiro a junho de 2008

Quanto ao tipo de micro-organismo encontrado nos pacientes tanto no swab auricular, quanto nas mãos $S$. aureus foi o mais frequente, seguido por $S$. coagulase negativo. Já a cultura dos swabs dos médicos residentes e do auxiliar de enfermagem observamos o crescimento isolado de cepas de $S$. aureus, sendo 4 casos no grupo dos auxiliares e 8 casos no grupo dos residentes médicos. A tabela 09 resume os resultados das culturas dos swabs obtidos. 
Tabela 9: Resultados das culturas semiquantitativas dos swabs coletados da mão e região auricular dos pacientes em uso de nutroterapia parenteral, janeiro a junho de 2008

\begin{tabular}{lcc}
\hline Microrganismo & $\begin{array}{c}\text { Swab da mão } \\
\text { do paciente } \\
(\mathrm{n}=16)\end{array}$ & $\begin{array}{c}\text { Swab da região auricular } \\
\text { do paciente } \\
(\mathrm{n}=16)\end{array}$ \\
\hline Staphylococcus aureus & $6(40 \%)$ & $8(50 \%)$ \\
Staphylococcus coagulase negativo & $5(33 \%)$ & $5(32 \%)$ \\
Acinetobacter baumanni & $2(13 \%)$ & $1(6 \%)$ \\
Proteus spp & $1(7 \%)$ & $1(6 \%)$ \\
Escherichia coli & $1(7 \%)$ & $1(6 \%)$ \\
\hline
\end{tabular}

CVC: cateter venoso central spp: espécie

n: número

$\%$ : porcentagem 

1

Discussão 



\section{DISCUSSÃO}

Os resultados encontrados no presente trabalho, relacionando fatores de risco com terapia nutrológica parenteral, colocação de cateter venoso central e existência de biofilme, validam a hipótese sugerida do trabalho. Assim, por hipótese tinha-se que o uso de cateteres venosos centrais, utilizados para nutroterapia, predispõe à formação de biofilmes e contribuem para manutenção e surgimento de processo infeccioso.

$\mathrm{Na}$ ocasião do início do presente estudo, os pacientes em seguimento, que estavam internados no HCFMRP-USP, apresentavam indicação de prescrição da nutroterapia parenteral. Dados da literatura demonstram que a não utilização da terapia adequada nutrológica pode chegar a $10 \%$ dos pacientes hospitalizados (Waitzberg et al.,2001). A adequação da nutroterapia está associada a melhor desfecho clínico de pacientes internados, principalmente se introduzida precocemente (McClave et al.,2009; Bristian, Driscoll, 2008).

Os pacientes que foram objeto do presente trabalho, em sua maioria eram portadores de doença aguda, muitos necessitavam de cuidados intensivos, com falência de órgãos e sistemas. A doença crítica per si esta relacionada a distúrbios hidroeletrolíticos, fato que pode justificar a alta frequência destes distúrbios em nossos pacientes. Outro fator a ser considerado é que apenas $13 \%$ dos pacientes avaliados faziam uso prolongado de parenteral. Está bem descrito na literatura, que a introdução de nutroterapia parenteral pode estar relacionada com distúrbios hidroeletrolíticos e metabólicos principalmente se essa for administrada inadequadamente. Se não identificadas podem contribuir para maior morbimortalidade dos pacientes (Machado et al., 2009d; Ziegler, 2009). 
Paralelamente, como descrito na literatura, a nutroterapia está relacionada a complicações desde a escolha da via, como a distúrbios metabólicos e hidroeletrolíticos, dentre os quais se destacam a síndrome da realimentação que quando não diagnosticada pode contribuir de maneira desfavorável ao prognóstico clínico dos pacientes (Machado et al., 2009d; Ziegler, 2009, Stanga et al., 2008).

A monitorização irregular ou a "desatenção" da equipe que assiste ao paciente quanto à inadequação da dieta, fato observado em $24 \%$ e $18 \%$ dos casos seguidos, podem contribuir para que haja sub ou superestimação das necessidades calóricas do paciente, aumentando o risco das complicações relacionadas com nutroterapia, sendo mais um fator de risco que pode contribuir para aumento da morbimortalidade dos pacientes (Gillanders et al., 2008; Staun et al.,2009). A desatenção pode ser atribuída a não pesagem ou estimativa do peso do paciente. Já a inadequação é atribuída ao jejum prolongado e/ou a hipo ou hiperalimentação ofertada aos pacientes. Nos pacientes avaliados a frequência de distúrbio hidroeletrolítico foi de $79 \%$ e a hiperglicemia $63 \%$.

A hiperglicemia na maioria destes pacientes pode ser justificada pela resposta a fase aguda da doença, quando há aumento da resistência a ação da insulina, ou então pelo excesso de calorias oferecidas aos pacientes (Ziegler, 2009). Em nosso estudo a presença de hiperglicemia contribuiu para maior mortalidade, porém não se associou ao maior risco de infecção relacionada com o uso de cateter. Estudos prévios em pacientes críticos também observaram que alterações dos níveis plasmáticos da glicose, relacionam-se com 0 aumento da morbimortalidade de pacientes críticos, principalmente quando esses permanecem por mais de 72 horas (3 dias) no centro de terapia intensiva (CTI) (NICE-SUGAR Study, 2009, Van den Berghe et al. 2001,2006). 
Embora a hiperglicemia esteja associada ao aumento da morbimortalidade de pacientes com tempo de internação em CTI superior a 3 dias (Van den Berghe et al. $2001,2006)$, estudo recente mostrou que o controle muito rigoroso da glicemia pode estar relacionado ao aumento da mortalidade (NICE-SUGAR Study, 2009). Segundo os autores, a justificativa para esses resultados foi o risco de hipoglicemia ser mais frequente no grupo com tratamento intensivo com insulina para controle glicêmico mais rigoroso (NICE-SUGAR Study, 2009).

Outro fator que esteve relacionado à maior mortalidade em nosso estudo foi o peso e o índice de massa corpórea (IMC). Os pacientes que evoluíram para o óbito tinham peso e IMC superior, comparado ao grupo que sobreviveu. Apesar do IMC, os pacientes que evoluíram para óbito eram mais desnutridos. A hipoalbuminemia pode justificar a diferença do peso entre os grupos, já que está relacionada à presença de edema e a Kwashiokor (Mehta, Duggan, 2009).

A desnutrição clínica intra-hospitalar é frequente e está relacionada ao aumento da morbimortalidade dos pacientes internados (Correia, Waitzberg, 2003). Estudos mostram que a desnutrição pode estar associada tanto ao maior risco de complicações infecciosas, quanto às não infecciosas, além de ser mais onerosa para o serviço de saúde (Correia, Waitzberg, 2003). Em nosso estudo, essa hipótese pôde ser evidenciada, uma vez que no grupo que foi a óbito as complicações clínicas e infecciosas foram mais frequentes do que no grupo que sobreviveu.

A nutroterapia parenteral per si parece contribuir para infecção sanguínea associada ao uso do cateter venoso central. A frequência dessa complicação na literatura varia entre 1,5 a 6,5 por 1000 CVC-dia (Machado et al., 2009b; Marra et.al, 
2007; Unamuno et al., 2005). Em nosso estudo essa taxa foi superior à maioria dos estudos.

Outro fator que pode ser considerado como de risco para infecção, foi a presença de infecção cruzada percebida por meio da realização de swabs da região auricular do médico residente e do auxiliar de enfermagem. Naqueles com amostras positivas, metade dos casos apresentou concordância com o resultado da cultura semiquantitativa da ponta do cateter. A existência de infecção cruzada já foi descrita anteriormente por de Cicco et al. (1989), em estudo prospectivo. Nesse estudo observou-se que os fatores contribuidores para a colonização e/ou infecção do cateter incluíam os dispositivos do equipo conectados ao cateter, a migração de micro-organismos da pele do próprio paciente, o tipo de curativo utilizado (de Cicco et al., 1989). A presença do mesmo micro-organismo presente tanto no cateter, quanto na pele da equipe da enfermagem responsável pela troca das bolsas de nutroterapia parenteral foi percebida em $27 \%$ dos casos (6/22) (de Cicco et al., 1989).

Autoinoculação e a migração de micro-organismo da flora da pele do próprio paciente também é fator contribuinte para infecção do cateter. Dos swabs coletados da mão e da região auricular dos pacientes, observamos que houve uma concordância com a cultura semiquantitativa da ponta em aproximadamente $60 \%$ casos com culturas da pele positiva, sendo cocos gram positivo o micro-organismo mais prevalente. Anteriormente, outro estudo tinha evidenciado que a colonização da pele de pacientes contribuiu para aparecimento de infecção em pacientes submetidos a transplantes de medula (Naoum et al., 2002). Nesse estudo os locais mais associados à colonização foram: região anal, orofaringe, axila e região nasal(Naoum et al., 2002). Estudo com neonatos em uso de CVC obteve uma 
frequência de infecção de aproximadamente $18 \%$, sendo a pele do próprio paciente a fonte de infecção mais comum, representando $22 \%$ dos casos (Oliveira et al., 2008).

A infecção mais frequente em nosso grupo de pacientes também pode ser justificada pela doença de base dos pacientes. Sugere-se que a presença de doenças infecciosas, neoplasia, quimioterapia, falência sistêmica de órgãos, cirurgias do trato digestivo e o doente crítico, predispõem ao aumento da morbimortalidade dos pacientes, aumentando inclusive o risco de infecção (Polderman, Girbes, 2002). Em nosso estudo a maioria dos pacientes eram críticos, de alta gravidade, ou tinham manipulação do trato digestivo, como na síndrome do intestino curto, ou estavam em tratamento de algum tipo de neoplasias. Vale ressaltar ainda que devido à imunossupressão destes pacientes, os mesmos podem ainda evoluir assintomáticos, mesmo na presença de infecção sanguínea associada ao cateter, como observado anteriormente por Machado e cols. em pacientes em uso de nutroterapia parenteral (Machado et al, 2009c).

Outro fator de risco que está associado ao maior risco de infecção, é o local de implante do cateter venoso central, a literatura mostra que a veia femoral e a jugular, têm maior risco de infecção quando comparadas a escolha do acesso na veia subclávia (Polderman, Girbes, 2002; Almuneeff et al., 2006). Porém em nosso estudo não observamos diferença quanto à escolha do local para implante do CVC. Fato também observado por Yilmaz, et al. (2007), em estudo de fatores de risco associados à infecção em cateteres utilizados em nutroterapia (Yilmaz et al., 2007). Nesse estudo os fatores de risco associados foram: o escore APACHE II, o tempo de cateterização, a punção do acesso em caráter de emergência e a higiene precária dos pacientes (Yilmaz et al., 2007). 
Em nosso estudo o número de vias não contribuiu para o risco de infecção diferentemente de dados da literatura (McGee, Gould, 2003; Pittiruti et al., 2009; Chen et al.,2006). E apesar das recomendações das diretrizes sugerirem que pacientes em uso de nutroterapia parenteral tenham preferencialmente um acesso central de via única (Kochevar et al.,2007; Gillanders et al. 2008; Staun et al., 2009), em nosso estudo observamos maior frequência de cateteres de duplo lúmen, quando comparado a lúmen simples, ou a triplo lúmen. A diferença quanto ao número de cateteres utilizados pode ter contribuído para ausência de relação de infecção vs. número de lúmen de cateteres.

Quanto ao agente microbiológico mais comumente associado à infecção de CVC em pacientes em nutroterapia, o nosso estudo está de acordo com estudos de cateteres utilizados com essa finalidade. Estudos epidemiológicos prévios mostram que a infecção e/ou colonização desses cateteres ocorrem geralmente por gram positivo, gram negativos e fungos (Mara et al., 2007; Yilmaz et al.,2007).

Dentre as bactérias gram positivas destacam-se $S$. aureus, $S$. coagulase negativo, Enterococcus spp. Nota-se que Staphylococcus spp.é mais frequente e, estudo recente de análise univariada sugere que o uso de nutroterapia parenteral pode ser fator de risco para a infecção por $S$. aureus meticilina-resistente em pacientes críticos (Oztoprak et al.,2006).

Dentre os gram negativos em nosso estudo observamos uma maior frequência de $P$. aeruginosa, $A$. baumanni e Enterobacter spp., dados semelhantes ao encontrado por Marra et al. (2007). Em estudo realizado por Yilmaz et al.(2007), as bactérias gram negativas foram a infecção mais comum no grupo de pacientes avaliados, sendo essa infecção justificada por meio de infecção cruzada e da 
contaminação das soluções administradas parenteral (Yilmaz et al., 2007). Em nosso estudo a presença de $P$. aeruginosa e $A$. baumanni nos swabs da mão e da região auricular dos pacientes foi frequente. Além de estarem associadas à colonização da ponta do CVC.

Em nosso estudo a infecção sanguínea por Candida spp. foi superior ao encontrado na literatura. Em estudos anteriores a frequência desta infecção variou entre 16-22\% (Machado et al.2009b; Marra et al., 2007; Yilmaz et al., 2007). Estudos prévios (Colombo et al.,2006; Chu et al., 2006; Pfaller, Diekema, 2007) mostram que a nutroterapia parenteral é fator de risco isolado para o surgimento de candidemia em pacientes internados, sendo o risco relativo desta infecção de 5,9 (Oliveira et al., 2008). Alguns autores sugerem que a candidemia esta se tornando mais frequente devido ao uso indiscriminado de agentes antimicrobianos (Yilmaz et al., 2007). O aumento da frequência da fungemia em nosso estudo é fator preocupante, uma vez que estudos mostram que a fungemia nosocomial está relacionada a maior morbimortalidade dos pacientes admitidos em hospitais gerais (Gómez et al.,2001; Yapar et al., 2005). A infecção por cândida pode eventualmente estar associada à alta mortalidade da nossa população, assim como relato por outros (Gómez et al.,2001).

A formação de biofilmes em dispositivos médicos é um agravante e contribui para maior morbimortalidade dos pacientes que necessitam da utilização destes materiais (Bryers, 2008). Apesar de toda tecnicobioengenharia existente para a fabricação dos cateteres venosos centrais, estes são suscetíveis à formação de biofilmes. Seja pela resposta inflamatória do paciente ao implante do cateter, uma vez que o mesmo atua como corpo estranho no organismo do hospedeiro, seja pela 
presença de deformidades existentes no lúmen do cateter que predispõem a aderência de micro-organismo ao lúmen do cateter, fato evidenciado pelos autores em estudo prévio realizado em cateteres sem utilização clínica (Machado et al, 2009b). Em nosso estudo, observamos a formação do biofilme em $62 \%$ das amostras avaliadas.

Alguns autores (Costerton et al., 1995; Kumar, Prasad, 2006; El-Aziz et al., 2004) sugerem que a presença de biofilme dificulta a penetração de agentes antimicrobianos, fato que contribuiria para manutenção do quadro infeccioso em pacientes em uso de CVCs, principalmente naqueles que se utiliza de cateteres de longa permanência e em alguns casos poderia contraindicar o tratamento local para infecção deste dispositivo médico (Machado et al.,2009b, 2009c; Rosenthal et al., 2006; Pronovost et al., 2006). Em estudo prévio realizado por Machado e cols, observou-se que a colonização desses cateteres e a presença de biofilmes foram responsáveis por episódios de bacteremia, mesmo em pacientes assintomáticos, todas as vezes que o cateter venoso era utilizado (Machado et al., 2009c).

Em nosso estudo, observamos que em alguns cateteres a matriz do biofilme era bastante densa, e às vezes funcionava como barreira protetora para os microrganismos nele aderidos. Estudo in vitro, realizado por El-Aziz et al. (2005) confirmaram essa hipótese, quando observaram dificuldade de penetração e resistência a antimicrobianos em biofilmes formados por Staphylococcus spp (ElAziz et al., 2005).

Baseados no que foi exposto e nos riscos associados à infecção relacionada com o CVC, algumas estratégias podem ser utilizadas para diminuir o risco de infecção associada ao cateter venoso central como: uso de cateteres impregnados 
com antibiótico, utilização de cateteres com via única, adequação de sítio de implante do dispositivo, punção do acesso guiado por ultrassom, uso de barreira durante inserção do cateter, treinamento da equipe e do paciente quanto a manipulação do cateter, lavagem de mãos, uso de clorexidina a $2 \%$ para desinfecção de pele, curativo adequado e troca de equipo utilizado para nutroterapia parenteral regularmente (Pittiruti et al.,2009; Gillanders et al., 2008; Staun et al.,2009).

Estudo realizado em centro hospitalar que adotou essas medidas preventivas foi eficaz em reduzir a taxa de infecção relacionada ao cateter de 7,7 por 1000 CVCdia para 1,4 por 1000 CVC-dia em 18 meses de seguimento (Pronovost et al., 2006). Em nosso estudo estas técnicas não foram seguidas. Além disso, ainda não é padronizada a realização de assepsia para manipulação do cateter e seus dispositivos com clorexidina. Em algumas unidades a assepsia é realizada com outros agentes desinfectantes.

Já medidas como troca regular do acesso, profilaxia com antibiótico e uso de heparina parecem não ser eficientes para prevenir a infecção do sítio de implante do CVC (Swindell et al., 2009). 

1

Conclusões 



\section{CONCLUSÕES}

- Os CVCs utilizados para nutroterapia parenteral estão associados à formação do biofilme;

- A formação de biofilmes bacterianos, fúngicos ou misto é comum nestes cateteres;

- A ocorrência de infecção relacionada com CVC utilizado em nutroterapia é frequente;

- Os micro-organismos mais frequentes encontrados foram $S$. aureus, $S$. coagulase negativo e Candida spp.;

- A infecção cruzada é fator de risco para infecção sanguínea relacionada com cateter venoso central e/ou colonização do mesmo;

- A autoinoculação de micro-organismo é fator contribuinte para infecção do paciente que necessita utilizar CVC para nutroterapia;

- As complicações metabólicas, a hiperglicemia e o estado nutrológico dos pacientes parecem estar associados à maior mortalidade, além de predisporem esses pacientes a maior risco de infecção;

- Etapas como avaliação nutrológica inicial do paciente candidato a nutroterapia ainda é negligenciada e/ou esquecida por equipes de saúde;

- É necessária a criação de protocolos que visem à redução do risco de infecção;

- A aplicação rotineira e a verificação de uma lista de problemas, como o sugerido ("DIETAS DENUNCIAM RISCO"), podem ser úteis na identificação de pacientes em risco nutrológico. 

1

Referências 



\section{REFERÊNCIAS ${ }^{1}$}

Almuneef MA, Memish ZA, Balkhy HH, Hijazi O, Cunningham G, Francis C. Rate, risk factors and outcomes of catheter-related bloodstream infection in a paediatric intensive care unit in Saudi Arabia. J Hosp Infect. 2006;62:207-13.

Bauer AW, Kirby WM, Sherris JC, Turck M. Antibiotic susceptibility testing by a standardized single disk method.Am J Clin Pathol. 1966;45:493-6

Barbeau J, Gauthier C, Payment P. Biofilms, infectious agents and dental unit waterlines: a review. Can J Microbiol. 1998; 44:1019-28.

Beck-Sagué, CM, Jarvis WR. Secular trends in the epidemiology of nosocomial fungal infections in the United States, 1980-1990. J Infect Dis. 1993;167:1247-51.

Beghetto MG, Victorino J, Teixeira L, Azevedo MJ. Parenteral Nutrition as a Risk Factor for Central Venous Catheter-Related Infection. JPEN. J. Parenter Enteral Nutr 2005; 29:367-73.

Bistrian BR, Driscoll DF. Enteral and Parenteral Nutrition. In: Fauci AS, Braunwald E, Kasper DL, Hauser SL, Longo DL, Jameson JL, Loscalzo J. Harrison's Internal Medicine. Mc Graw Hill, 17ª ed New York. 2008.Pg. 455-61.

Bryers JD. Medical biofilms. Biotechnol. Bioeng. 2008;100: 1-18.

Chen H, Wang FD, Lin M, Huang LJ, Liu CY. Risk factors for central cenous catheter-related infections. J Microbiol Immunol Infect 2006; 39:231-6.

Chu JH, Feudtner C, Heydon K, Walsh TJ, Zaoutis TE. Hospitalizations for endemic mycoses: a population-based national study. Clin Infect Dis. 2006. 42:822-5.

Colombo AL, Nucci M, Park BJ, Nouér SA, Arthington-Skaggs B, Matta DA, et al. For the Brazilian Network Candidemia Study. Epidemiology of Candidemia in Brazil: a Nationwide Sentinel Surveillance of Candidemia in Eleven Medical Centers. J Clin Microbiol. 2006;44:2816-23.

Colombo AL, Guimarães T, Silva LRBF, Monfardini LPA, Cunha AKB, Rady P, et al. Prospective Observational Study of Candidemia in São Paulo,Brazil: Incidence Rate, Epidemiology, and Predictors of Mortality. Infect Control Hosp Epidemiol. 2007; 28:570-6.

\footnotetext{
${ }^{1}$ De acordo com o Estilo Vancouver Autor-data.
} 
Correia MI, Waitzberg DL. The impact of malnutrition on morbidity, mortality,length of hospital stay and costs evaluated through a multivariate model analysis. Clin Nutr 2003;22:235-9.

Costerton JW, Lewandowski Z, Caldwell DE, Korber DR, Lappin-Scott HM. Microbial biofilms. Ann Rev Microbiol. 1995; 49:711-45.

Chandra J, Zhou G, Ghannoum MA. Fungal biofilms and antimycotics. Curr Drug Targets. 2005; 6: 887-94.

de Cicco M, Panarello G, Chiaradia V, Fracasso A, Veronesi A, Testa V, et al. Source and route of microbial colonisation of parenteral nutrition catheters. Lancet. 1989; 2:1258-61.

El-Aziz M, Rao S, Kanchanapoom T, Khardori N. In vitro activity of vancomycin, quinupristin/dalfopristin, and linezolid against intact and disrupted biofilms of staphylococci. Ann Clin Microbiol Antimicrob. 2005, 4:1-9.

Fridkin SK, Welbel SF, Weinstein RA. Magnitude and prevention of nosocomial infections in the intensive care unit. Inf Dis Clin North Am. 1997; 11:479-96.

Heyland DK, MacDonald S, Keefe L, Drover JW. Total parenteral nutrition in the critically ill patient: a metaanalysis. JAMA. 1998, 280:2013-19.

Gillanders L, Angstmann K, Ball P, Chapman-Kiddell C, Hardy G, Hope J, et al.; Australasian Society of Parenteral and Enteral Nutrition. AuSPEN clinical practice guideline for home parenteral nutrition patients in Australia and New Zealand. Nutrition. 2008; 24:998-1012.

Gómez J, Baños V, Simarro E, Ruiz J, Requena L, Pérez J, et al. Nosocomial fungemias in a general hospital. Epidemiology and prognostic factors. Prospective study 1993-1998. Enferm Infecc Microbiol Clin 2001; 19: 304-7.

Gosbell IB. Diagnosis and management of catheter-related bloodstream infections due to Staphylococcus aureus. Int Med J. 2005; 35: S45-S62.

Ishizuka M, Nagata $\mathrm{H}$, Takagi $\mathrm{K}$, Kubota $\mathrm{K}$. Femoral venous catheterization is a major risk factor for central venous catheter-related bloodstream infection. $J$ Invest Surg. 2009; 22:16-21.

Jenkinson HF, Lappin-Scott HM. Biofilms adhere to stay. Trends Microbiol. 2001; 9:9-10. 
Kochevar M, Guenter P, Holcombe B, Malone A, Mirtallo J; ASPEN Board of Directors and Task Force on Parenteral Nutrition Standardization ASPEN statement on parenteral nutrition standardization. JPEN J. Parenter Enteral Nutr. 2007;31:441-8.

Kiehlbauch JA, Hannett GE, Salfinger M, Archinal W, Monserrat C, Carlyn C. Use of the NCCLS guidelines for disk diffusion susceptibility testing in New York state laboratories. J. Clin. Microbiol 2000; 38:3341-8.

Kojic EM, Darouiche RO. Candida infections of medical devices. Clin Microbiol Rev. 2004;17:255-67.

Koneman EW, Winn WC, Allen S, Janda W, Procop G, Woods G et al. Koneman's Color Atlas and Textbook of Diagnostic Microbiology. 6ed Philadelphia. Lippincott Williams \& Wilkins; 2005 pg1-1736.

Kumar A, Prasad R. Biofilms. J K Science. 2006; 8:14-17.

Lapponi JC. Estatistica usando excel.4ed. Rio de Janeiro. Elsevier.2005. pg1476.

Leme IA, Machado JDC, Rabito EI, Marchini JS. Avaliação Nutrológica: clínica e ambulatorial. In: Machado JDC, Silvestre SCM, Marchini JS. Manual de Procedimentos em nutrologia. Guanabara-Koogan, $1^{\text {a }}$ Ed.Rio de Janeiro,2009. Pg.21-49.

Machado JDC. Nutrição Parenteral e avaliação microbiológica de cateteres venosos centrais, por meio de microscopia eletrônica de varredura Dissertação de Mestrado - Programa de Pós Graduação em Clínica Médica - Área de Investigação Clínica - Faculdade de Medicina de Ribeirão Preto, 2008, 150p.

Machado JDC, Chueire FB,Marchini JS. Terapia Nutricional Parenteral. In: Machado JDC, Silvestre SCM, Marchini JS. Manual de Procedimentos em nutrologia. Guanabara-Koogan, 1르 Ed.Rio de Janeiro,2009a. Pg.182-94.

Machado JDC, Suen VMM, Figueiredo JFC, Marchini JC. Biofilms, infection and Parenteral Nutrition. JPEN J Parenter Enteral Nutr. 2009b; 33:397-403.

Machado JDC, Suen VMM, Figueiredo JFC, Marchini JC. Pacientes assintomáticos apresentam infecção relacionada ao cateter venoso utilizado para terapia nutricional parenteral. Rev Nutr. 2009c; 22:787-93. 
Machado JDC, Suen VMM, Chueire FB, Marchini JFM, Marchini JS. Refeeding syndrome, an undiagnosed and forgotten potentially fatal condition. BMJ Case Reports 2009d; doi:10.1136/bcr.07.2008.0521.

Maki DG, Weise CE, Sarafin HW. A semiquantitative culture method for identifying intravenous-catheter-related infection. N Engl J Med. 1977; 296:13059.

Manual de utilização BACT/ALERT e MB/BACT. Organon Teknika. julho, 1999.

Marchini JS; Okano N; Cupo P; Passos NMRRS; Sakamoto LM; Basile-Filho A. Nutrição Parenteral - Princípios gerais, formulários de prescrição e monitorização. Medicina 1998;31:62-72.

Marra AR, Opilla M, Edmond MB, Kirby F. Epidemiology of bloodstream infections in patients receiving long-term total parenteral nutrition. J Clin Gastroenterol. 2007;41:19-28.

Marshall KC. Mechanisms of bacterial adhesion at solid-water interfaces. In "Bacterial Adhesion, Mechanisms and Physiological Significance." Savage DC and Fletcher M eds .Plenum Press, New York, London 1985. pp. 131-61.

Marshall KC. Adsorption and adhesion process in microbial growth at interfaces. Adv Colloid Interface Sci. 1986; 1: 59-86.

McClave SA, Martindale RG, Vanek VW, McCarthy M, Roberts P, Taylor B et al.; A.S.P.E.N. Board of Directors; American College of Critical Care Medicine; Society of Critical Care Medicine. Guidelines for the Provision and Assessment of Nutrition Support Therapy in the Adult Critically III Patient: Society of Critical Care Medicine (SCCM) and American Society for Parenteral and Enteral Nutrition (A.S.P.E.N.). JPEN J Parenter Enteral Nutr. 2009; 33:277-316.

McGee DC, Gould MK. Preventing complications of central venous catheterization. N Engl J Med. 2003; 348:1123-1133.

Mehta NM, Duggan CP.Nutritional deficiencies during critical illness. Pediatr Clin NAm 2009: 1143-60.

Merrer J, De Jonghe B, Golliot F, Lefrant JY, Raffy B, Barre E, et al.; French Catheter Study Group in Intensive Care. Complications of femoral and subclavian venous catherization in critically ill patients: a randomized controlled trial. JAMA. $2001 ; 286: 700-7$. 
Mullady DK; O'Keefe SJ. Treatment of intestinal failure: home parenteral nutrition. Nat Clin Pract Gastroenterol Hepatol. 2006; 3:492-504.

$\mathrm{NIH}$, National Heart, Lung, and Blood Institute. Research on microbial biofilms (PA-03-047)". 2002. Disponível em: http://grants.nih.gov/grants/guide/pafiles/PA-03-047.html

Naoum FA, Martins LTV, Castro NS, Barros JC, Chiattone CS Perfil microbiológico dos pacientes nos primeiros trinta dias pós transplante de medula óssea Rev. Bras. Hematol. Hemoter.2002;.24:91-6.

O'Grady NP, Alexander M, Dellinger EP, Gerberding JL, Heard SO, Maki DG, et al. Guidelines for the prevention of intravascular catheter-related infections. Centers for Disease Control and Prevention. MMWR Recomm Rep. 2002; 51(No. RR-10):1-29.

O'Keefe SJ, Buchman AL, Fishbein TM, Jeejeebhoy KN, Jeppesen PB, Shaffer J. Short bowel syndrome and intestinal failure: consensus definitions and overview. Clin gastroenterol Hepatol. 2006, 4: 6-10.

Oie S, Kamiya A. Particulate and Microbial Contamination in In-Use Admixed Parenteral Nutrition Solutions. Biol Pharm Bull. 2005,28:2268-70.

Oliveira NA, Brito DD, Brito CS, Silva MSS, Abdallah VOS, Gontijo-Filho PP. Incidence and etiology of bloodstream infection associated of central vascular catheter in critical neonates. Rev Panam Infectol. 2008;10:18-23.

Oztoprak N, Cevik MA, Akinci E, Korkmaz K, Erbay A, Eren SS, et al. Risk factors for ICU-acquired methicillin-resistant Staphylococcus aureus infections. Am J Infect Control 2006;34:1-5.

Pankhurst CL, Johnson NW, Woods RG. Microbial contamination of dental unit waterlines: the scientific argument. Int Dent J. 1998; 48:359-68.

Pfaller MA, Diekema DJ. Epidemiology of Invasive Candidiasis: a Persistent Public Health Problem. Clin Microbiol Rev. 2007; 20:133-63.

Pittiruti M, Hamilton H, Biffi R, MacFie J, Pertkiewicz M; ESPEN. ESPEN Guidelines on Parenteral Nutrition: central venous catheters (access, care, diagnosis and therapy of complications). Clin Nutr. 2009; 28:365-77.

Polderman KH, Girbes ARJ. Central venous catheter use. Part 2: infectious complications. Intensive Care Med 2002; 28:18-28. 
Pronovost P, Needham D, Berenholtz S, Sinopoli D, Chu H, Cosgrove S, et al. An Intervention to Decrease Catheter-Related Bloodstream Infections in the ICU. N Engl J Med. 2006; 355:2725-32.

Rosenthal VD; Maki DG, Salomao R, Ivarez-Moreno CA, Mehta Y, Higuera F,et al., for the International Nosocomial Infection Control Consortium* DeviceAssociated Nosocomial Infections in 55 Intensive Care Units of 8 Developing Countries. Ann Intern Med. 2006;145:582-91.

Sakamoto LM, Alcântara ST, Passos NMRRS, Hotta JKS, Marchini JS. The importance of the use of filters during the infusion of parenteral nutrition containing lipid emulsion. Medicina, Ribeirão Preto. 1999; 32:478-85.

Schachter B. Slimy business - the biotechnology of biofilms. Nat. Biotech. 2003; 21:361-65.

Sherertz RJ. Pathogenesis of vascular catheter infections. In: Waldvogel FA, Bisno AL, eds. Infections Associated with Indwelling Medical Devices. Washington: ASM Press. 2000: 111-25.

Sherertz RJ. Update on vascular catheter infections. Curr Opin Infect Dis. 2004;17:303-7.

Stanga Z, Brunner A, Leuenberger M, Grimble RF, Shenkin A, Allison SP, et al. Nutrition in clinical practice -- the refeeding syndrome: illustrative cases and guidelines for prevention and treatment. Eur J Clin Nutr 2008;62:687-694.

Staun M, Pironi L, Bozzetti F, Baxter J, Forbes A, Joly F, et al. ESPEN. ESPEN Guidelines on Parenteral Nutrition: home parenteral nutrition (HPN) in adult patients. Clin Nutr. 2009; 28:467-79.

Swindell K, Lattif AA.,Chandra J.,Mukherjee PK, Ghannoum MA. Parenteral lipid emulsion induces germination of Candida albicans and increases biofilme formation on medical catheter surfaces.J.Infect.Dis.2009; 200: 473-80.

The NICE-SUGAR Study Investigators, Finfer S, Chittock DR, Su SY, Blair D, Foster D, Dhingra $\mathrm{V}$, et al. Intensive versus conventional glucose control in critically ill patients. N Engl J Med 2009;360:1283-97.

Unamuno MRDL; Carneiro JJ; Chueire FB; Marchini JS; Suen VMM. Uso de cateteres venosos totalmente implantados para nutrição parenteral: cuidados, 
tempo de permanência e ocorrência de complicações infecciosas. Rev Nutr. 2005, 18:261-9.

Van den Berghe G, Wouters P, Weekers F, Verwaest C, Bruyninckx F, Schetz M, et al. Intensive insulin therapy in critically ill patients. $N$ Engl $J$ Med 2001;345:1359-67.

Van den Berghe G, Wilmer A, Hermans G, Meersseman W, Wouters PJ, Milants I, et al. Intensive insulin therapy in the medical ICU. N Engl J Med. 2006;354:44961.

Veenstra DL; Saint S; Saha S; Lumley T; Sullivan SD. Efficacy of antisepticimpregnated central venous catheter in preventing catheter-related bloodstream infection: a meta-analysis. JAMA. 1999; 281:261-7.

Waitzberg DL, Caiaffa WT, Correia MITD. Hospital malnutrition: the Brazilian national survey (IBRANUTRI): a study of 4000 patients. Nutrition 2001; 17:57380 .

Wey SB, Mori M, Pfaller MA, Woolson RF, Wenzel RP. Risk factors for hospitalacquired candidemia. A matched case-control study. Arch Intern Med. 1989;149:2349-53.

Yapar N, Uysal U, Yucesoy M, Cakir N, Yuce A. Nosocomial bloodstream infections associated with Candida species in a Turkish University Hospital. Mycoses 2005; 49:134-8.

Yilmaz G; Koksal I; Aydin K; Caylan R; Sucu N; Aksoy F. Risk Factors of Catheter-Related Bloodstream Infections in Parenteral Nutrition Catheterization. JPEN J Parenter Enteral Nutr 2007; 31: 284-7.

Ziegler TR. Parenteral nutrition in the critically ill patient. $N$ Engl $J$ Med 2009;361:1088-97. 

1

Anexos 

HOSPITAL DAS CLÍNICAS DA FACULDADE DE MEDICINA DE RIBEIRÃO PRETO DA UNIVERSIDADE DE SÃO PAULO

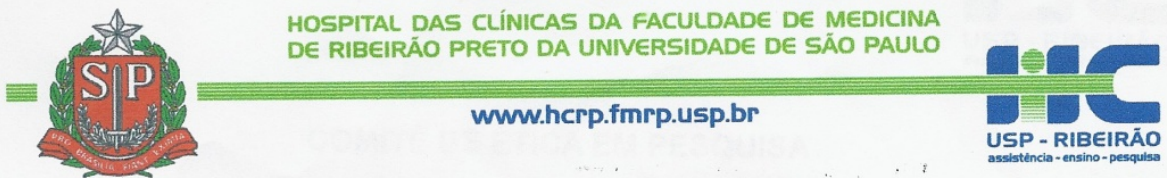

Ribeirão Preto, 12 de março de 2008

Ofício $\mathrm{n}^{\circ} 883 / 2008$

$\mathrm{CEP} / \mathrm{SPC}$

Prezada Senhora,

O trabalho intitulado "TERAPIA NUTRICIONAL PARENTERAL E CRESCIMENTO DE MICROORGANISMOS EM BIOFILME", foi analisado pelo Comitê de Ética em Pesquisa, em sua $262^{a}$ Reunião Ordinária realizada em 10/03/2008, e enquadrado na categoria: APROVADO, bem como o Termo de Consentimento Livre e Esclarecido, de acordo com o Processo HCRP n ${ }^{\circ} 11477 / 2007$.

Este Comitê segue integralmente a Conferência Internacional de Harmonização de Boas Práticas Clínicas (IGH-GCP), bem como a Resolução $n^{\circ}$ 196/96 CNS/MS.

Lembramos que devem ser apresentados a este CEP, o Relatório Parcial e o Relatório Final da pesquisa.

Atenciosamente.

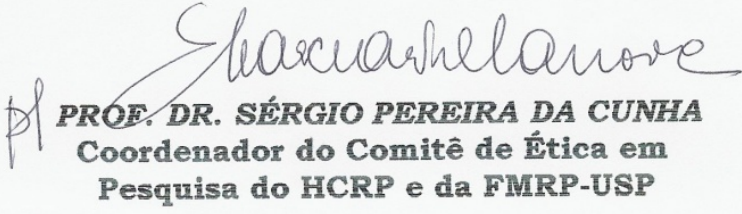

Ilustrissima Senhora

JULIANA DE CARVALHO MACHADO

Depto. de Clínica Médica - Divisão de Nutrologia

Comitê de Ética em Pesquisa HCRP e FMRP-USP - Campus Universitário

FWA - 0000 2733; IRB - 00002186 e Registro SISNEP/CONEP n ${ }^{\circ} 4$

Fone (16) 3602-2228 - E-mail : cep@hcrp.fmrp.usp.br

Monte Alegre 14048-900 Ribeirão Preto SP 


\section{Pesquisa: Nutroterapia Parenteral, Crescimento de microorganismos em Biofilme e Fatores Relacionados à Infecção do Cateter Venoso Central}

A infecção de cateter venoso central é uma complicação freqüente em pacientes que necessitam deste dispositivo médico para terapia nutricional, ou para administração de medicamentos ou qualquer outro tipo de tratamento. Há muito tempo tem sido estudado mecanismo relacionado à etiologia, como também mecanismos que visam prevenir e diminuir a sua incidência no ambiente hospitalar. Até hoje, as intervenções realizadas na maioria dos estudos relacionados à infecção de cateter venoso central não são suficientes para esclarecer todas as dúvidas de como se evitar e controlar a infecção deste dispositivo médico amplamente utilizado do mundo. Por isso são realizadas pesquisas em busca de novas informações.

Sendo assim, esta pesquisa tem como objetivo avaliar os mecanismos relacionados à infecção do cateter venoso central, destacando a formação de biofilmes que estão relacionados com a manutenção do processo infeccioso, como também pode agravar a mesma em pacientes que necessitam deste dispositivo para terapia nutricional parenteral. Será avaliado por meio de microscopia eletrônica de varredura, associado à cultura semiquantitativa a ponta distal do cateter venoso central, além de coleta de hemocultura, sendo este dois últimos procedimento rotina, durante à retirada de todo cateter venoso central no Hospital das Clínicas de Ribeirão Preto. Caberá a equipe que assiste ao paciente a decisão pela retirada do mesmo, sem interferência dos pesquisadores responsáveis pelo projeto. Como a microflora da pele do paciente pode contribuir para migração de microorganismos para o interior do cateter, os pacientes que participarem do projeto serão convidados a coletar swabs da região pericateter, auricular e das mãos.

Como a infecção cruzada é um dos mecanismos que contribuem para contaminação e infecção do cateter venoso central, um dos objetivos da pesquisa é comparar se há relação do microorganismo colonizador do cateter com a flora bacteriana que possa existir na região auricular e nas mãos dos profissionais de saúde que estejam acompanhado o paciente durante a terapia nutricional. A equipe de saúde a ser avaliada será aquele que tenha manipulado o cateter em alguma ocasião (médico residente, enfermeira e auxiliar de enfermagem). Para que esta avaliação seja possível serão coletados swabs da região auricular e das mãos dos profissionais. As amostras serão avaliadas através de culturas semiquantitativas e quando necessário através de microscopia eletrônica de varredura..

Estes procedimentos não oferecerão riscos à saúde ou à moral dos pacientes e aos profissionais de saúde, que poderão concordar ou não em participar da pesquisa, sem sofrer qualquer prejuízo. Como também é direito do participante desistir de participar da pesquisa em qualquer etapa da pesquisa, sem que seja prejudicado.

Os resultados obtidos na pesquisa poderão ser publicados em periódicos especializados, sendo mantidos em sigilo identidade dos participantes e os procedimentos durante a pesquisa.

Dúvidas poderão ser esclarecidas com a responsável pela pesquisa, Juliana de Carvalho Machado, que se coloca à disposição pelo telefone (16) 3964-5644 ou (16) 8121-4620 ou por e-mail: juliana@infonet.com.br. 
Juliana de carvalho Machado

Tendo sido devidamente informado(a) sobre o objetivo da pesquisa "Terapia nutricional parenteral e crescimento de microorganismos em biofilme", eu, procedimentos a serem realizados.

estou de acordo com os

Assinatura do paciente ou responsável

Ribeirão Preto, de de 2008 


\section{Pesquisa: Nutroterapia Parenteral, Crescimento de microorganismos em Biofilme e Fatores Relacionados à Infecção do Cateter Venoso Central}

A infecção de cateter venoso central é uma complicação freqüente em pacientes que necessitam deste dispositivo médico para terapia nutricional, ou para administração de medicamentos ou qualquer outro tipo de tratamento. Há muito tempo tem sido estudado mecanismo relacionado à etiologia, como também mecanismos que visam prevenir e diminuir a sua incidência no ambiente hospitalar. Até hoje, as intervenções realizadas na maioria dos estudos relacionados à infecção de cateter venoso central não são suficientes para esclarecer todas as dúvidas de como se evitar e controlar a infecção deste dispositivo médico amplamente utilizado do mundo. Por isso são realizadas pesquisas em busca de novas informações.

Sendo assim, esta pesquisa tem como objetivo avaliar os mecanismos relacionados à infecção do cateter venoso central, destacando a formação de biofilmes que estão relacionados com a manutenção do processo infeccioso, como também pode agravar a mesma em pacientes que necessitam deste dispositivo para terapia nutricional parenteral. Será avaliado por meio de microscopia eletrônica de varredura, associado à cultura semiquantitativa a ponta distal do cateter venoso central, além de coleta de hemocultura, sendo este dois últimos procedimento rotina, durante à retirada de todo cateter venoso central no Hospital das Clínicas de Ribeirão Preto. Caberá a equipe que assiste ao paciente a decisão pela retirada do mesmo, sem interferência dos pesquisadores responsáveis pelo projeto. Como a microflora da pele do paciente pode contribuir para migração de microorganismos para o interior do cateter, os pacientes que participarem do projeto serão convidados a coletar swabs da região pericateter, auricular e das mãos.

Como a infecção cruzada é um dos mecanismos que contribuem para contaminação e infecção do cateter venoso central, um dos objetivos da pesquisa é comparar se há relação do microorganismo colonizador do cateter com a flora bacteriana que possa existir na região auricular e nas mãos dos profissionais de saúde que estejam acompanhado o paciente durante a terapia nutricional. A equipe de saúde a ser avaliada será aquele que tenha manipulado o cateter em alguma ocasião (médico residente, enfermeira e auxiliar de enfermagem). Para que esta avaliação seja possível serão coletados swabs da região auricular e das mãos dos profissionais. As amostras serão avaliadas através de culturas semiquantitativas e quando necessário através de microscopia eletrônica de varredura..

Estes procedimentos não oferecerão riscos à saúde ou à moral dos pacientes e aos profissionais de saúde, que poderão concordar ou não em participar da pesquisa, sem sofrer qualquer prejuízo. Como também é direito do participante desistir de participar da pesquisa em qualquer etapa da pesquisa, sem que seja prejudicado.

Os resultados obtidos na pesquisa poderão ser publicados em periódicos especializados, sendo mantidos em sigilo identidade dos participantes e os procedimentos durante a pesquisa.

Dúvidas poderão ser esclarecidas com a responsável pela pesquisa, Juliana de Carvalho Machado, que se coloca à disposição pelo telefone (16) 3964-5644 ou (16) 8121-4620 ou por e-mail: juliana@infonet.com.br. 
Juliana de carvalho Machado

Tendo sido devidamente informado(a) sobre o objetivo da pesquisa "Terapia nutricional parenteral e crescimento de microorganismos em biofilme", eu, procedimentos a serem realizados estou de acordo com os

Assinatura do profissional da saúde

Ribeirão Preto, de de 2008 


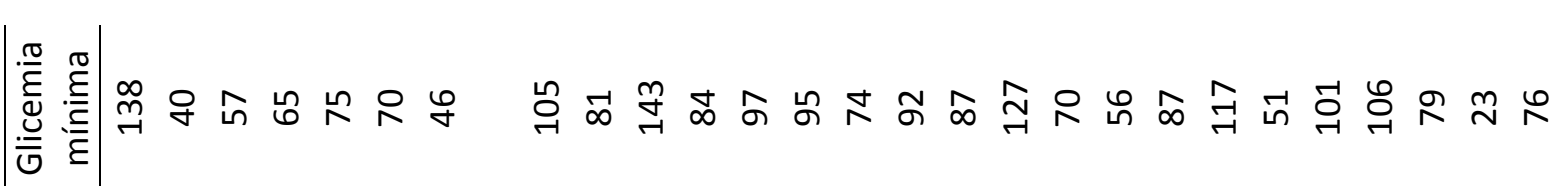

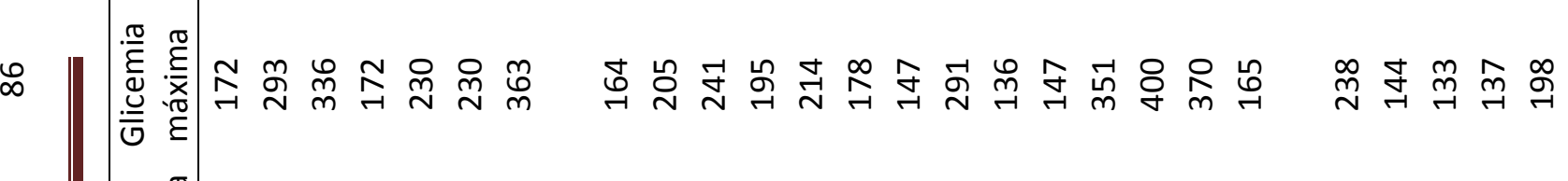

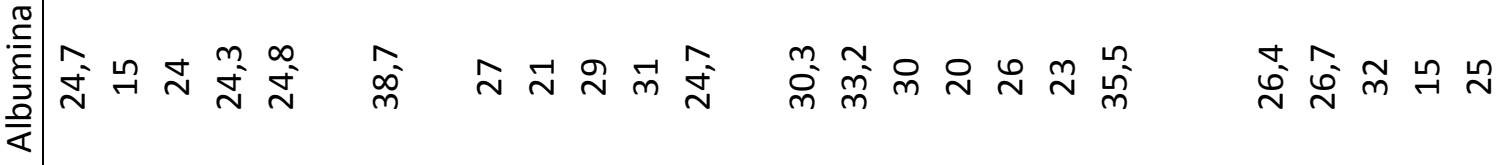

竡

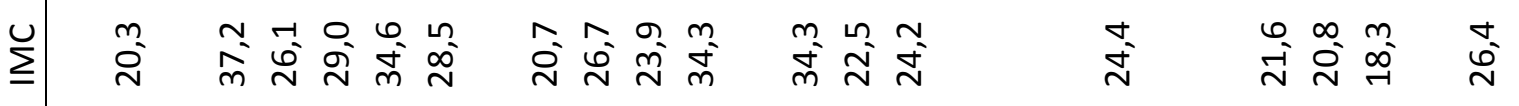

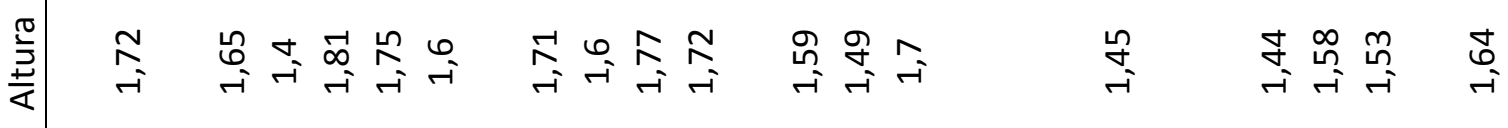

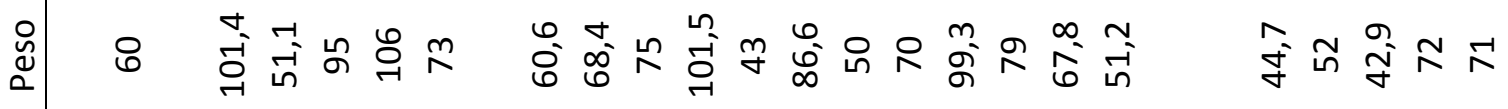

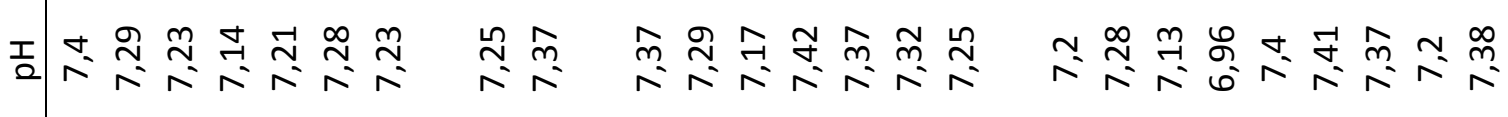

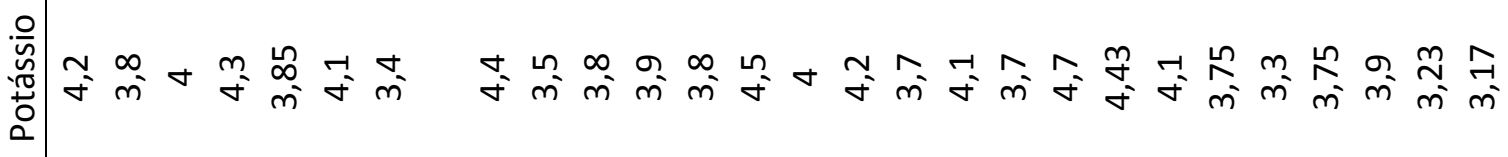

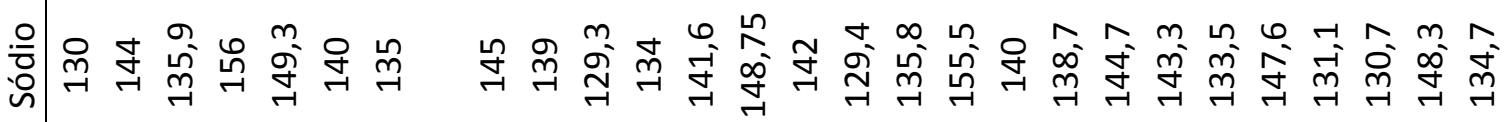

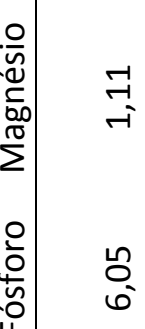

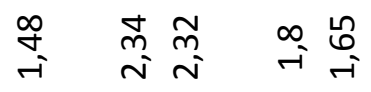

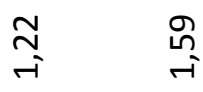

$\stackrel{n}{\sim} \stackrel{\sim}{\sim} \stackrel{n}{\sim} \stackrel{n}{\sim} \stackrel{\sim}{*}$

$\stackrel{\infty}{m} \stackrel{-1}{m}$

尊

㑒욱 


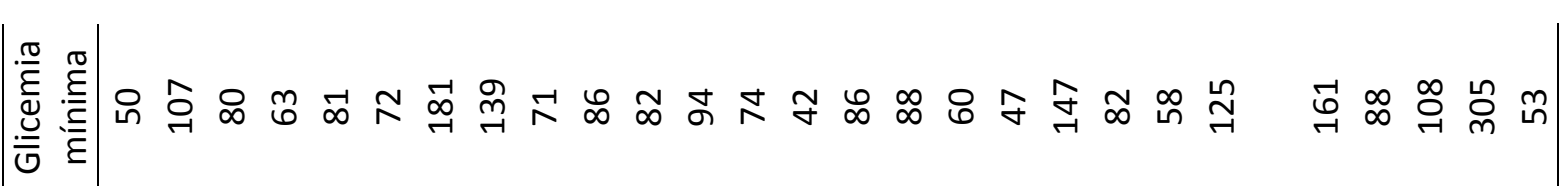

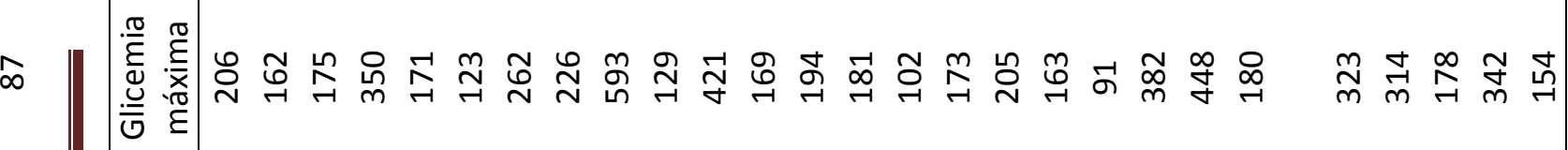
产帝

苟

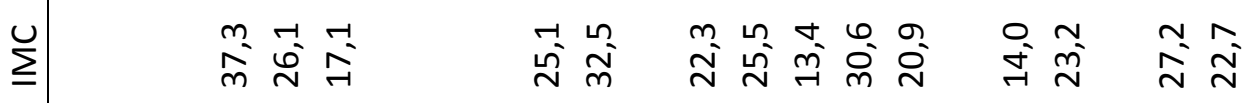

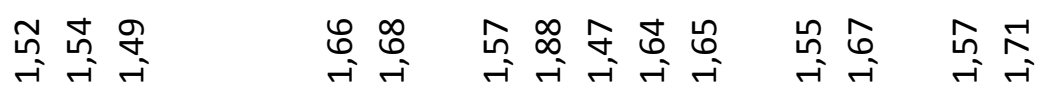

$\stackrel{\circ}{\rightarrow-1}$

훙

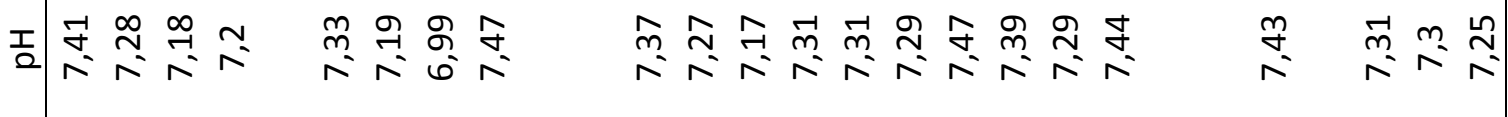

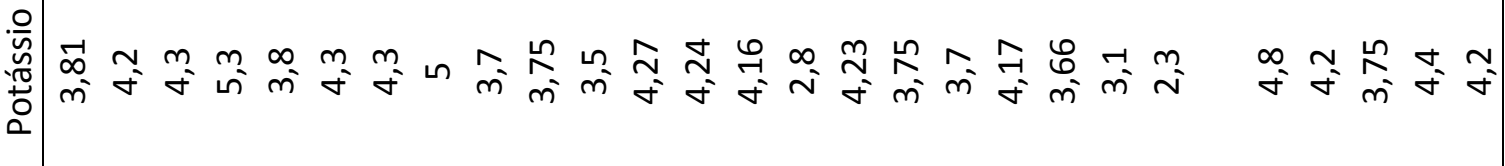

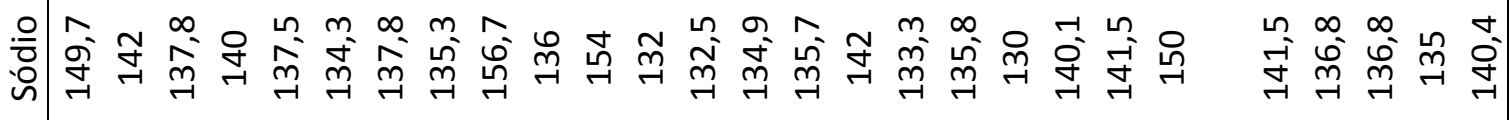

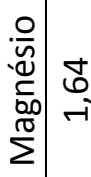

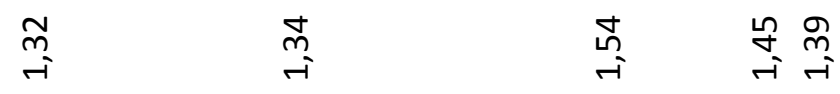

高

$\stackrel{n}{\mathfrak{n}} \quad \stackrel{m}{\sim} \underset{\sim}{\sim} \underset{\sim}{\sim}$

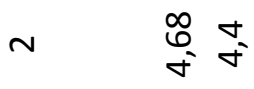

m)

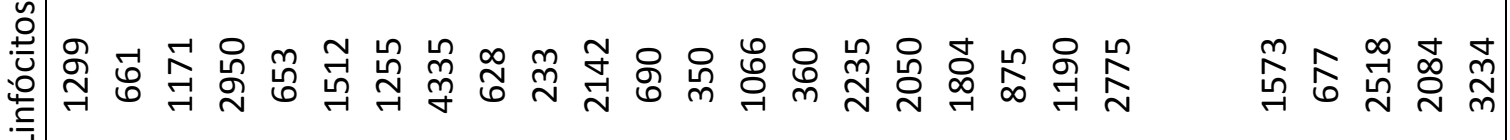

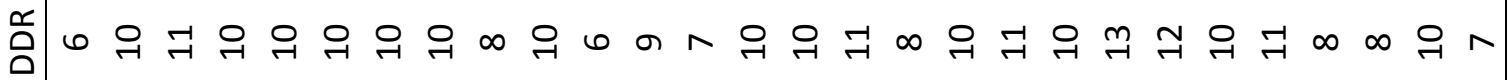




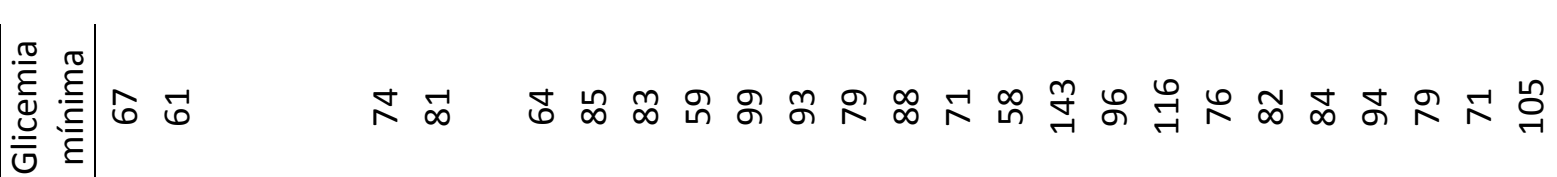

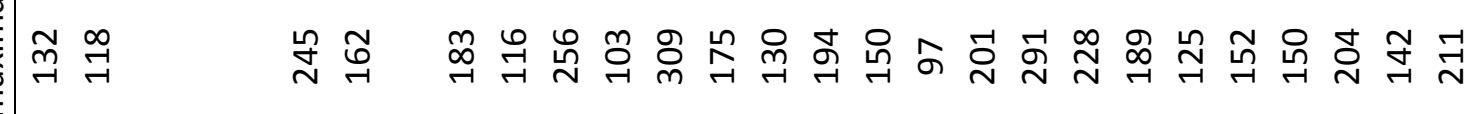

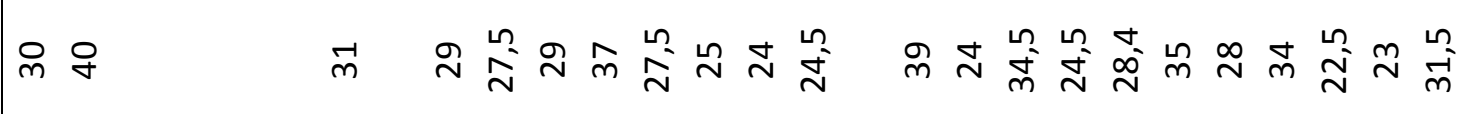

$\frac{3}{\bar{\alpha}}$

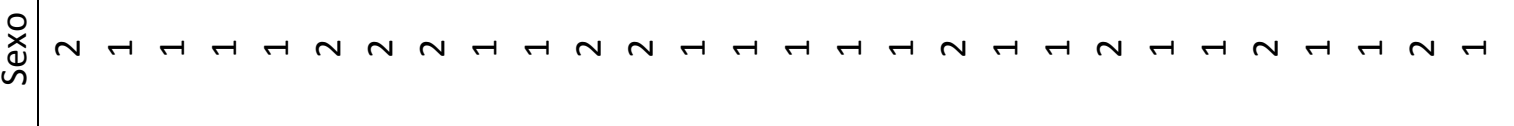

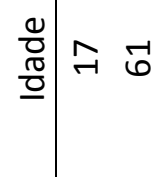

$\stackrel{\cup}{\stackrel{n}{\sim}} \stackrel{\infty}{\stackrel{\infty}{0}}$

ฟ $\stackrel{\infty}{\sim}$ f

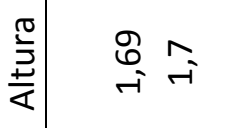

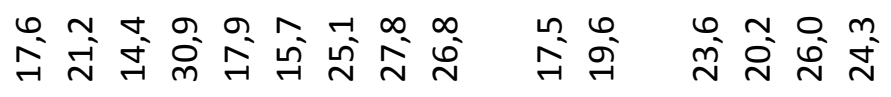

กิ

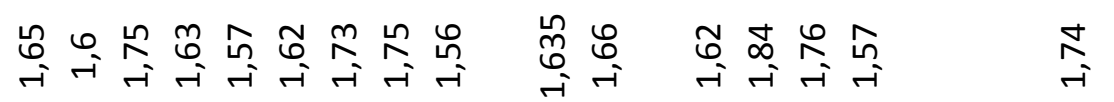

迤

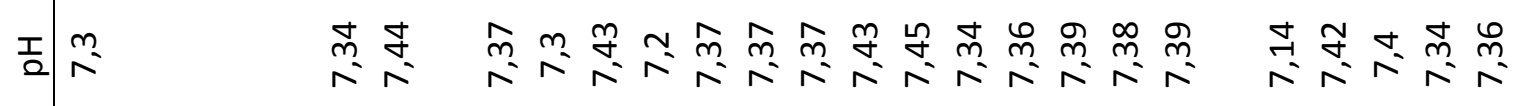

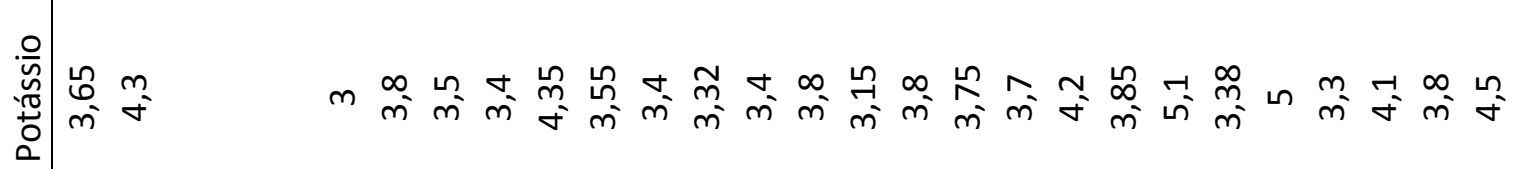

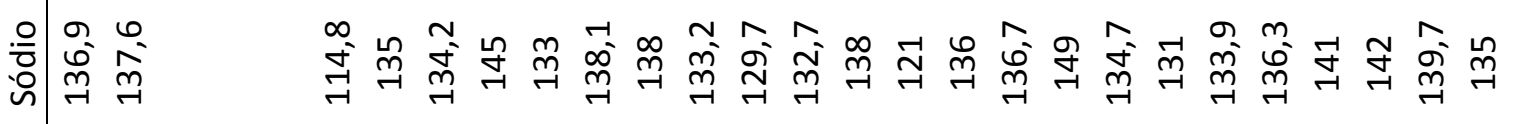

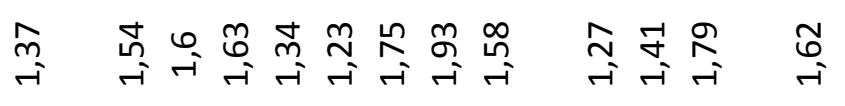

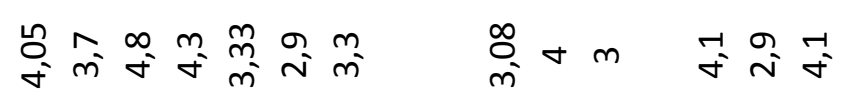

:

覓

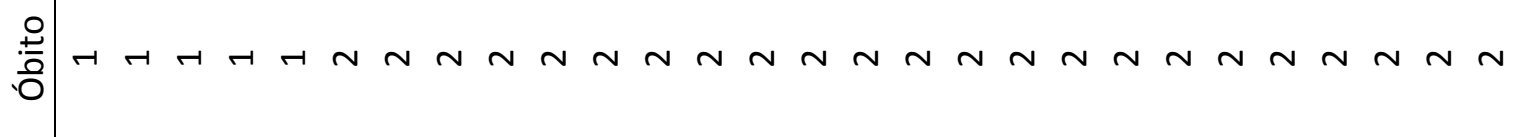

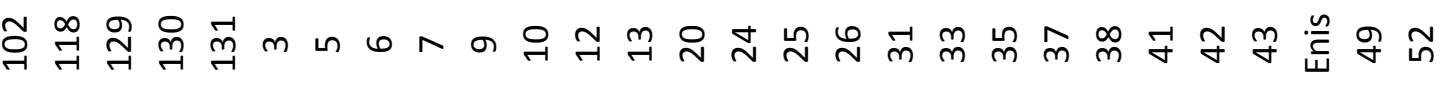




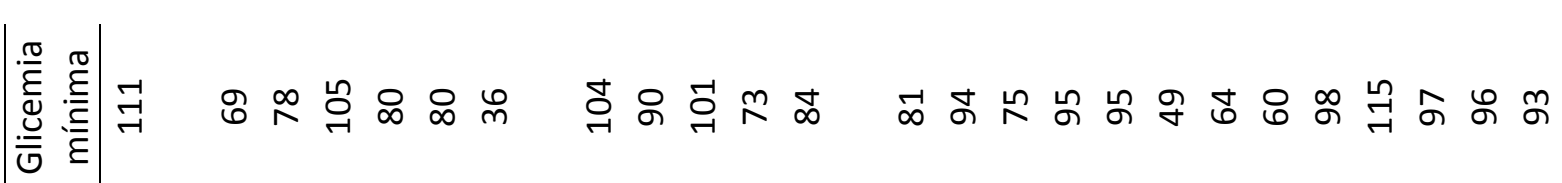
产苛

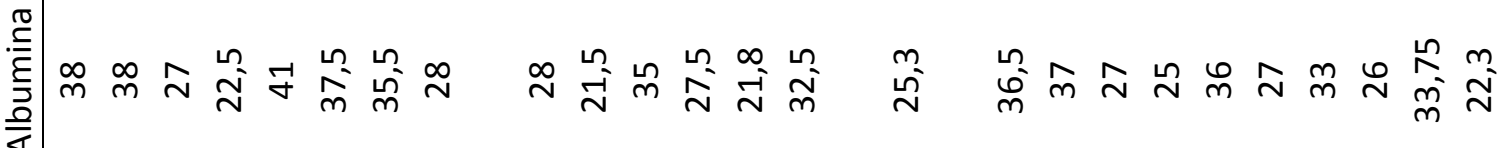

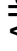

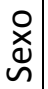

䎡

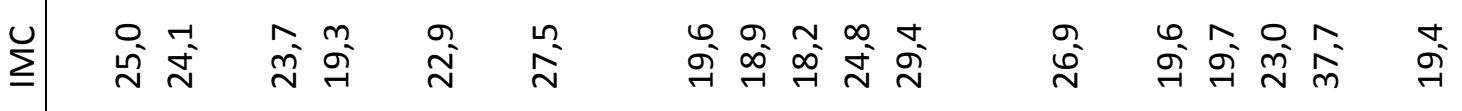

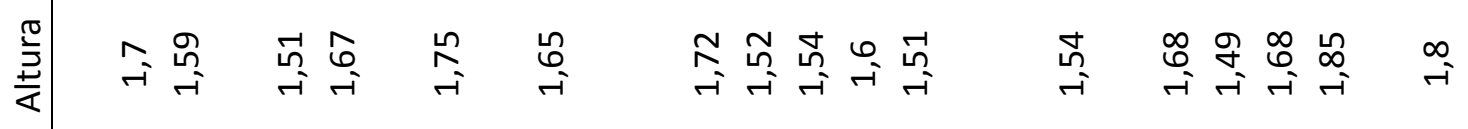

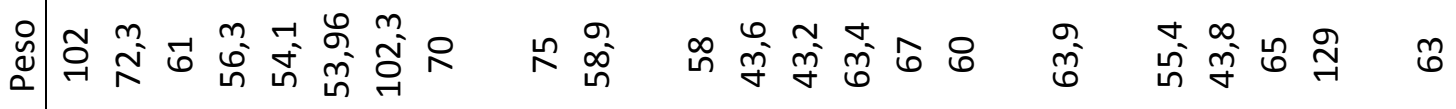

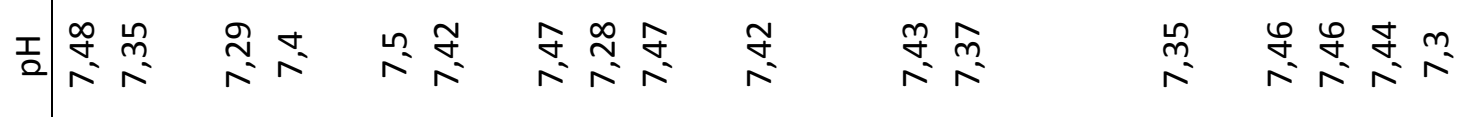

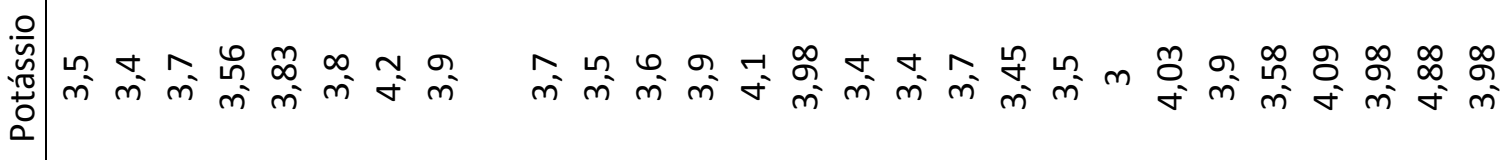

㖣

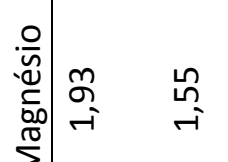

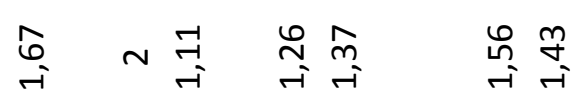

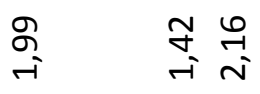

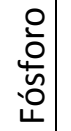

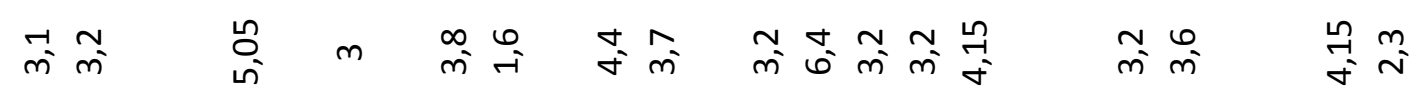

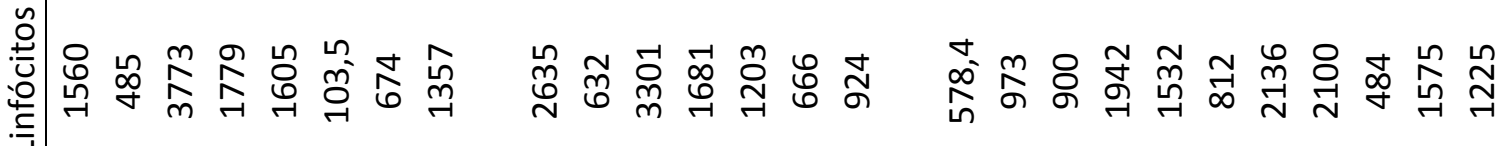

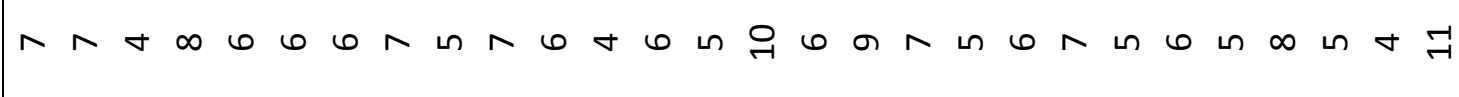




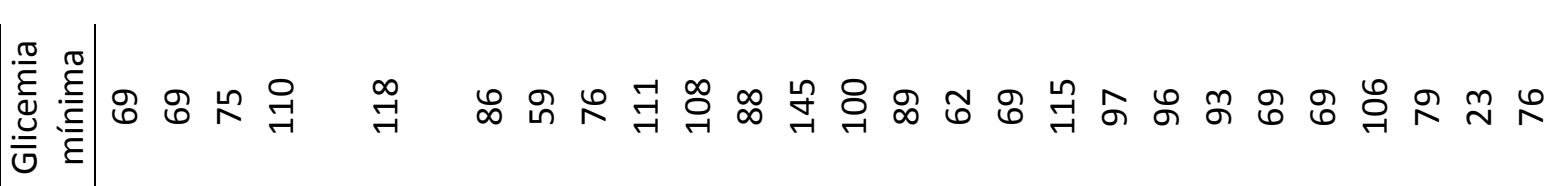

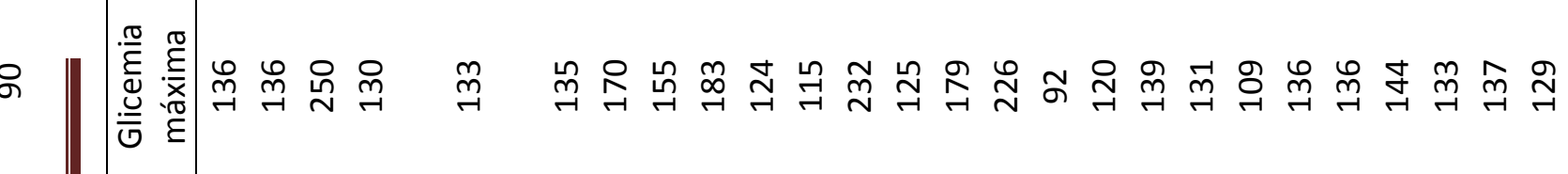
产产帝

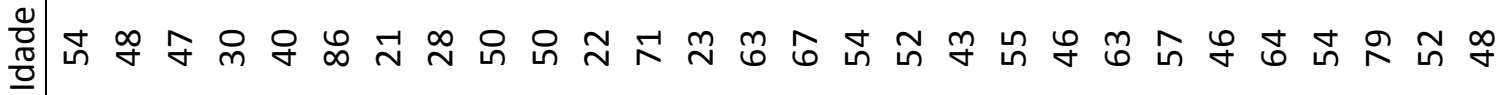

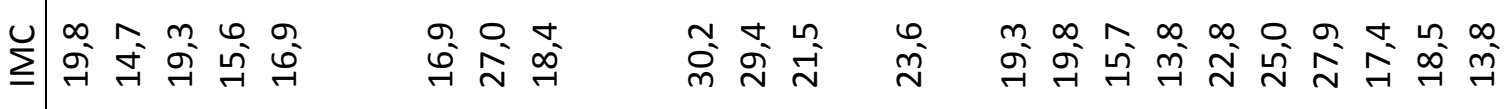

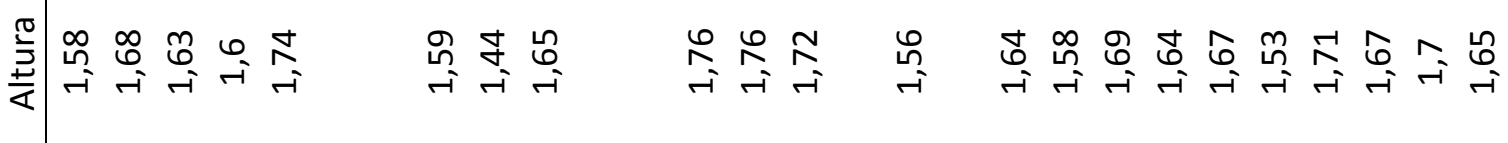

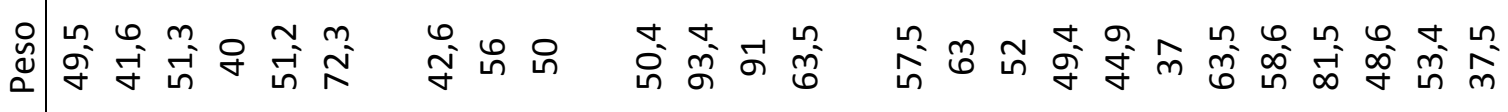

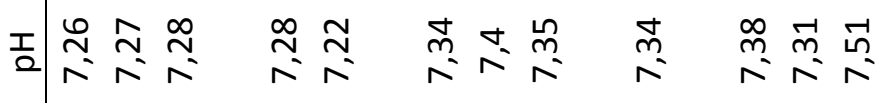

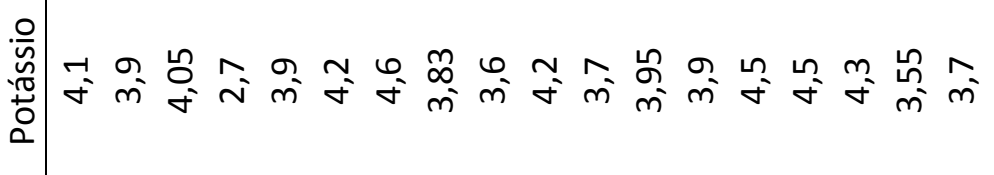

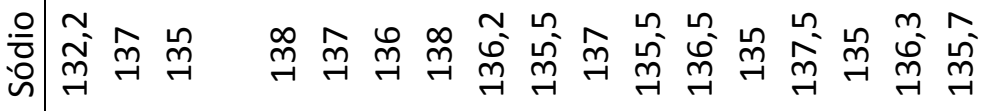

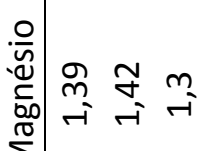

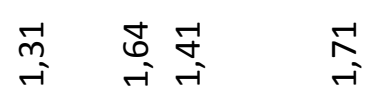

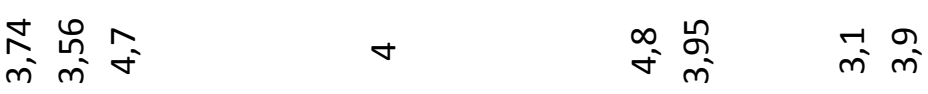

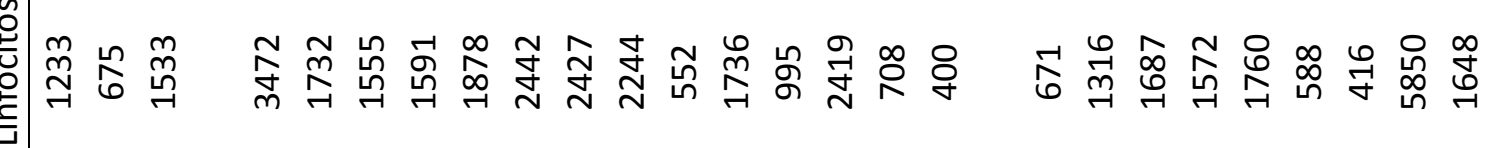

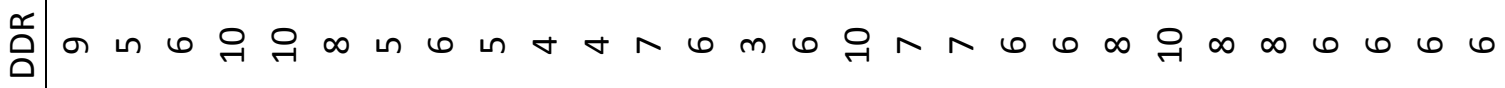

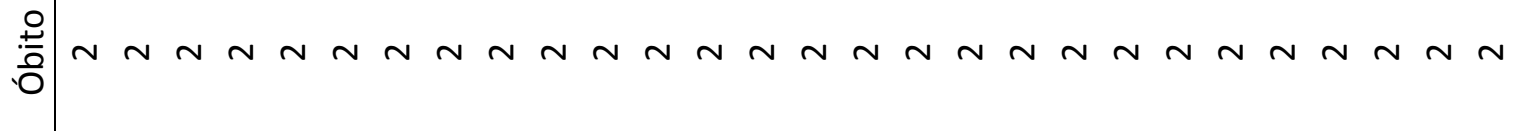

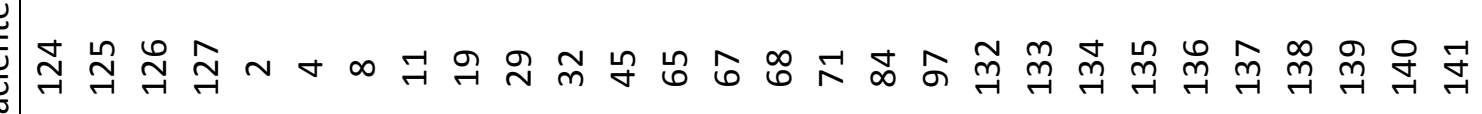


Sexo Óbito Pontuação Contaminação Hemocultura Hemocultura Tipo CVC ( Quantidade Dias de

\begin{tabular}{|c|c|c|c|c|c|c|c|c|}
\hline$(M=1 / F=2)$ & $(S=1 / N=2)$ & DDR & CVC & Periferica & CVC & $\mathrm{F}=1, \mathrm{~J}=2, \mathrm{~S}=3$ ) & Lumens & uso \\
\hline 1 & 1 & 10 & 1 & 1 & 1 & 2 & 3 & 14 \\
\hline 1 & 2 & 10 & 2 & 1 & 2 & 2 & 1 & 3 \\
\hline 2 & 2 & 7 & 2 & 2 & 2 & 2 & 2 & 13 \\
\hline 1 & 2 & 8 & 2 & 1 & 2 & 2 & 2 & 15 \\
\hline 2 & 2 & 8 & 2 & 2 & 2 & 3 & 2 & 11 \\
\hline 2 & 2 & 5 & 2 & 2 & 2 & 2 & 2 & 22 \\
\hline 1 & 2 & 4 & 1 & 1 & 1 & 2 & 2 & 30 \\
\hline 1 & 2 & 4 & 1 & 1 & 1 & 2 & 3 & 7 \\
\hline 1 & 2 & 4 & 1 & 1 & 1 & 2 & 0 & 24 \\
\hline 1 & 2 & 5 & 1 & 1 & 1 & 2 & 2 & 9 \\
\hline 1 & 2 & 9 & 1 & 1 & 1 & 3 & 2 & 10 \\
\hline 2 & 2 & 5 & 2 & 2 & 2 & 3 & 2 & 7 \\
\hline 2 & 2 & 6 & 1 & 2 & 2 & 2 & 2 & 6 \\
\hline 2 & 2 & 6 & 1 & 1 & 1 & 2 & 2 & 14 \\
\hline 2 & 2 & 6 & 1 & 1 & 1 & 2 & 0 & 541 \\
\hline 1 & 2 & 12 & 1 & 2 & 2 & 3 & 2 & 14 \\
\hline 1 & 2 & 12 & 2 & 2 & 2 & 3 & 2 & 14 \\
\hline 1 & 2 & 12 & 2 & 2 & 2 & 3 & 2 & 15 \\
\hline 1 & 1 & 12 & 1 & 1 & 1 & 3 & 2 & 13 \\
\hline 1 & 1 & 9 & 1 & 1 & 1 & 2 & 2 & 11 \\
\hline 1 & 1 & 11 & 1 & 2 & 2 & 3 & 2 & 14 \\
\hline 1 & 1 & 8 & 2 & 1 & 1 & 2 & 2 & 10 \\
\hline 2 & 1 & 6 & 2 & 1 & 2 & 2 & 2 & 10 \\
\hline 1 & 2 & 8 & 2 & 2 & 2 & 2 & 2 & 13 \\
\hline 2 & 1 & 12 & 1 & 1 & 1 & 2 & 2 & 7 \\
\hline 2 & 1 & 12 & 1 & 1 & 1 & 3 & 2 & 18 \\
\hline 1 & 1 & 4 & 1 & 1 & 1 & 2 & 2 & 5 \\
\hline 1 & 1 & 4 & 1 & 1 & 1 & 2 & 2 & 5 \\
\hline 1 & 1 & 9 & 2 & 2 & 2 & 2 & 2 & 5 \\
\hline 1 & 2 & 9 & 2 & 2 & 2 & 3 & 2 & 17 \\
\hline 1 & 2 & 6 & 2 & 2 & 2 & 3 & 2 & 10 \\
\hline 1 & 1 & 15 & 1 & 1 & 1 & 2 & 0 & 1042 \\
\hline 2 & 1 & 6 & 2 & 2 & 2 & 2 & 2 & 8 \\
\hline 1 & 1 & 12 & 1 & 1 & 1 & 3 & 2 & 19 \\
\hline 2 & 2 & 4 & 2 & 2 & 2 & 2 & 2 & 12 \\
\hline 2 & 2 & 2 & 2 & 2 & 2 & 2 & 0 & 300 \\
\hline 1 & 2 & 4 & 1 & 2 & 2 & 2 & 1 & 11 \\
\hline 1 & 2 & 8 & 2 & 2 & 2 & 2 & 2 & 7 \\
\hline 2 & 1 & 8 & 1 & 1 & 1 & 2 & 2 & 10 \\
\hline 1 & 2 & 6 & 1 & 1 & 1 & 2 & 2 & 10 \\
\hline 2 & 1 & 14 & 2 & 2 & 1 & 2 & 2 & 15 \\
\hline 2 & 2 & 4 & 2 & 2 & 2 & 2 & 2 & 8 \\
\hline 1 & 2 & 9 & 1 & 2 & 1 & 2 & 2 & 11 \\
\hline 1 & 2 & 9 & 1 & 2 & 2 & 2 & 2 & 10 \\
\hline
\end{tabular}




\begin{tabular}{|c|c|c|c|c|c|c|c|c|}
\hline $\begin{array}{c}\text { Sexo } \\
(M=1 / F=2)\end{array}$ & $\begin{array}{c}\text { Óbito } \\
(\mathrm{S}=1 / \mathrm{N}=2)\end{array}$ & $\begin{array}{c}\text { Pontuação } \\
\text { DDR }\end{array}$ & $\begin{array}{c}\text { Contaminação } \\
\text { CVC }\end{array}$ & $\begin{array}{l}\text { Hemocultura } \\
\text { Periferica }\end{array}$ & $\begin{array}{l}\text { Hemocultura } \\
\text { CVC }\end{array}$ & $\begin{array}{c}\text { Tipo CVC ( } \\
F=1, J=2, S=3)\end{array}$ & $\begin{array}{l}\text { Quantidade } \\
\text { Lumens }\end{array}$ & $\begin{array}{c}\text { Dias de } \\
\text { uso }\end{array}$ \\
\hline 1 & 1 & 7 & 2 & 1 & 1 & 3 & 1 & 13 \\
\hline 1 & 1 & 7 & 1 & 1 & 1 & 1 & 3 & 14 \\
\hline 1 & 1 & 7 & 2 & 2 & 2 & 2 & 2 & 11 \\
\hline 1 & 1 & 12 & 1 & 1 & 1 & 3 & 1 & 15 \\
\hline 1 & 2 & 6 & 1 & 1 & 1 & 2 & 2 & 16 \\
\hline 1 & 2 & 6 & 2 & 2 & 2 & 2 & 2 & 9 \\
\hline 2 & 2 & 8 & 2 & 2 & 2 & 3 & 2 & 15 \\
\hline 1 & 2 & 6 & 2 & 2 & 2 & 3 & 2 & 13 \\
\hline 2 & 1 & 8 & 2 & 2 & 2 & 3 & 2 & 29 \\
\hline 1 & 2 & 7 & 2 & 2 & 2 & 2 & 2 & 6 \\
\hline 1 & 1 & 12 & 2 & 2 & 2 & 3 & 2 & 6 \\
\hline 1 & 1 & 10 & 2 & 2 & 2 & 2 & 1 & 6 \\
\hline 1 & 2 & 6 & 1 & 2 & 2 & 2 & 2 & 9 \\
\hline 2 & 2 & 6 & 2 & 2 & 2 & 2 & 2 & 2 \\
\hline 2 & 2 & 6 & 2 & 2 & 2 & 2 & 2 & 2 \\
\hline 2 & 2 & 6 & 2 & 2 & 2 & 2 & 2 & 13 \\
\hline 2 & 2 & 6 & 1 & 1 & 2 & 2 & 2 & 11 \\
\hline 2 & 1 & 8 & 1 & 1 & 1 & 2 & 2 & 19 \\
\hline 2 & 1 & 6 & 1 & 1 & 1 & 2 & 2 & 13 \\
\hline 1 & 2 & 9 & 2 & 1 & 1 & 2 & 2 & 7 \\
\hline 1 & 2 & 7 & 2 & 2 & 2 & 2 & 2 & 17 \\
\hline 1 & 2 & 7 & 1 & 2 & 2 & 2 & 2 & 21 \\
\hline 1 & 1 & 8 & 2 & 2 & 2 & 2 & 2 & 5 \\
\hline 2 & 2 & 4 & 2 & 2 & 2 & 2 & 2 & 1 \\
\hline 1 & 1 & 8 & 1 & 1 & 1 & 3 & 2 & 24 \\
\hline 1 & 1 & 10 & 2 & 1 & 1 & 3 & 2 & 30 \\
\hline 1 & 2 & 6 & 1 & 1 & 1 & 3 & 2 & 13 \\
\hline 2 & 1 & 7 & 2 & 2 & 2 & 3 & 2 & 10 \\
\hline 2 & 2 & 6 & 2 & 2 & 1 & 2 & 2 & 15 \\
\hline 1 & 2 & 6 & 1 & 2 & 2 & 2 & 2 & 8 \\
\hline 1 & 1 & 8 & 2 & 2 & 2 & 2 & 3 & 5 \\
\hline 2 & 1 & 10 & 2 & 2 & 2 & 2 & 2 & 7 \\
\hline 1 & 2 & 6 & 2 & 2 & 2 & 3 & 2 & 27 \\
\hline 1 & 1 & 9 & 1 & 1 & 1 & 2 & 2 & 3 \\
\hline 1 & 2 & 3 & 1 & 1 & 1 & 2 & 1 & 11 \\
\hline 1 & 2 & 6 & 1 & 2 & 2 & 3 & 2 & 15 \\
\hline 1 & 1 & 10 & 2 & 2 & 2 & 3 & 3 & 18 \\
\hline 1 & 1 & 9 & 2 & 2 & 2 & 2 & 3 & 15 \\
\hline 1 & 2 & 10 & 2 & 2 & 1 & 2 & 1 & 5 \\
\hline 1 & 1 & 5 & 2 & 2 & 2 & 2 & 2 & 8 \\
\hline 1 & 2 & 7 & 2 & 2 & 2 & 3 & 2 & 21 \\
\hline 1 & 2 & 5 & 2 & 2 & 2 & 2 & 2 & 10 \\
\hline 2 & 1 & 7 & 2 & 2 & 2 & 2 & 2 & 5 \\
\hline 1 & 1 & 9 & 2 & 1 & 1 & 3 & 2 & 11 \\
\hline
\end{tabular}




\begin{tabular}{|c|c|c|c|c|c|c|c|c|}
\hline $\begin{array}{c}\text { Sexo } \\
(M=1 / F=2)\end{array}$ & $\begin{array}{c}\text { Óbito } \\
(\mathrm{S}=1 / \mathrm{N}=2)\end{array}$ & $\begin{array}{l}\text { Pontuação } \\
\text { DDR }\end{array}$ & $\begin{array}{l}\text { Contaminação } \\
\text { CVC }\end{array}$ & $\begin{array}{l}\text { Hemocultura } \\
\text { Periferica }\end{array}$ & $\begin{array}{l}\text { Hemocultura } \\
\text { CVC }\end{array}$ & $\begin{array}{c}\text { Tipo CVC ( } \\
F=1, J=2, S=3)\end{array}$ & $\begin{array}{l}\text { Quantidade } \\
\text { Lumens }\end{array}$ & $\begin{array}{l}\text { Dias de } \\
\text { uso }\end{array}$ \\
\hline 1 & 1 & 12 & 2 & 1 & 2 & 2 & 3 & 11 \\
\hline 2 & 2 & 7 & 1 & 1 & 2 & 2 & 2 & 12 \\
\hline 2 & 1 & 7 & 1 & 2 & 2 & 2 & 2 & 4 \\
\hline 1 & 1 & 6 & 1 & 1 & 1 & 2 & 2 & 20 \\
\hline 1 & 2 & 6 & 1 & 2 & 1 & 3 & 2 & 16 \\
\hline 1 & 2 & 4 & 2 & 2 & 2 & 2 & 2 & 3 \\
\hline 1 & 2 & 6 & 2 & 2 & 2 & 2 & 2 & 14 \\
\hline 2 & 2 & 7 & 1 & 1 & 1 & 2 & 2 & 21 \\
\hline 2 & 2 & 5 & 2 & 2 & 2 & 2 & 2 & 9 \\
\hline 2 & 1 & 10 & 2 & 2 & 2 & 3 & 2 & 9 \\
\hline 2 & 1 & 11 & 2 & 1 & 2 & 2 & 3 & 11 \\
\hline 2 & 1 & 10 & 2 & 1 & 2 & 3 & 2 & 12 \\
\hline 2 & 2 & 10 & 2 & 2 & 2 & 3 & 2 & 4 \\
\hline 2 & 2 & 6 & 2 & 2 & 2 & 1 & 2 & 21 \\
\hline 2 & 2 & 9 & 2 & 1 & 2 & 3 & 2 & 6 \\
\hline 2 & 1 & 10 & 1 & 1 & 1 & 2 & 2 & 11 \\
\hline 2 & 1 & 7 & 1 & 1 & 1 & 2 & 2 & 17 \\
\hline 2 & 1 & 10 & 1 & 1 & 1 & 2 & 2 & 13 \\
\hline 2 & 1 & 10 & 1 & 2 & 1 & 3 & 3 & 10 \\
\hline 2 & 2 & 7 & 2 & 2 & 2 & 2 & 2 & 5 \\
\hline 2 & 2 & 5 & 2 & 2 & 2 & 2 & 2 & 7 \\
\hline 2 & 2 & 6 & 2 & 2 & 2 & 2 & 2 & 12 \\
\hline 2 & 2 & 7 & 2 & 2 & 2 & 2 & 2 & 13 \\
\hline 2 & 1 & 14 & 2 & 1 & 2 & 2 & 2 & 6 \\
\hline 2 & 1 & 6 & 1 & 1 & 1 & 2 & 2 & 13 \\
\hline 2 & 1 & 8 & 2 & 1 & 2 & 2 & 2 & 3 \\
\hline 1 & 2 & 10 & 2 & 2 & 2 & 2 & 1 & 24 \\
\hline 1 & 1 & 6 & 2 & 2 & 2 & 2 & 2 & 26 \\
\hline 2 & 1 & 9 & 1 & 2 & 2 & 2 & 2 & 15 \\
\hline 2 & 1 & 7 & 1 & 1 & 1 & 2 & 2 & 15 \\
\hline 1 & 1 & 9 & 1 & 1 & 1 & 2 & 2 & 4 \\
\hline 1 & 1 & 9 & 2 & 1 & 2 & 2 & 2 & 10 \\
\hline 2 & 2 & 5 & 2 & 2 & 2 & 2 & 2 & 27 \\
\hline 2 & 2 & 6 & 1 & 2 & 2 & 2 & 2 & 25 \\
\hline 2 & 1 & 10 & 2 & 2 & 2 & 3 & 2 & 4 \\
\hline 1 & 1 & 11 & 1 & 2 & 2 & 2 & 2 & 7 \\
\hline 1 & 1 & 11 & 2 & 2 & 2 & 3 & 2 & 8 \\
\hline 1 & 2 & 5 & 2 & 2 & 1 & 2 & 2 & 22 \\
\hline 1 & 2 & 8 & 1 & 1 & 1 & 2 & 2 & 9 \\
\hline 2 & 2 & 5 & 1 & 2 & 2 & 2 & 2 & 8 \\
\hline 1 & 1 & 8 & 1 & 2 & 2 & 2 & 2 & 14 \\
\hline 1 & 1 & 8 & 1 & 1 & 1 & 2 & 2 & 3 \\
\hline 1 & 1 & 10 & 2 & 1 & 2 & 2 & 2 & 5 \\
\hline 1 & 2 & 6 & 2 & 2 & 2 & 2 & 2 & 5 \\
\hline
\end{tabular}




\begin{tabular}{|c|c|c|c|c|c|c|c|c|}
\hline $\begin{array}{c}\text { Sexo } \\
(M=1 / F=2)\end{array}$ & $\begin{array}{c}\text { Óbito } \\
(\mathrm{S}=1 / \mathrm{N}=2)\end{array}$ & $\begin{array}{c}\text { Pontuação } \\
\text { DDR }\end{array}$ & $\begin{array}{c}\text { Contaminação } \\
\text { CVC }\end{array}$ & $\begin{array}{l}\text { Hemocultura } \\
\text { Periferica }\end{array}$ & $\begin{array}{l}\text { Hemocultura } \\
\text { CVC }\end{array}$ & $\begin{array}{c}\text { Tipo CVC ( } \\
F=1, J=2, S=3)\end{array}$ & $\begin{array}{l}\text { Quantidade } \\
\text { Lumens }\end{array}$ & $\begin{array}{c}\text { Dias de } \\
\text { uso }\end{array}$ \\
\hline 2 & 1 & 11 & 1 & 2 & 2 & 2 & 1 & 27 \\
\hline 2 & 1 & 11 & 1 & 1 & 1 & 3 & 1 & 44 \\
\hline 2 & 1 & 11 & 1 & 1 & 1 & 3 & 0 & 79 \\
\hline 2 & 2 & 11 & 1 & 1 & 1 & 2 & 1 & 20 \\
\hline 2 & 2 & 11 & 1 & 1 & 1 & 3 & 1 & 7 \\
\hline 1 & 2 & 4 & 2 & 1 & 1 & 2 & 1 & 8 \\
\hline 1 & 2 & 4 & 1 & 1 & 1 & 3 & 1 & 10 \\
\hline 2 & 2 & 11 & 2 & 2 & 2 & 2 & 2 & 20 \\
\hline 2 & 1 & 13 & 1 & 1 & 2 & 2 & 2 & 5 \\
\hline 2 & 2 & 9 & 1 & 1 & 1 & 2 & 2 & 14 \\
\hline 1 & 2 & 5 & 1 & 1 & 1 & 2 & 0 & 247 \\
\hline 1 & 2 & 5 & 2 & 1 & 1 & 2 & 2 & 6 \\
\hline 2 & 1 & 6 & 2 & 1 & 1 & 3 & 2 & 5 \\
\hline 2 & 1 & 6 & 2 & 2 & 2 & 2 & 1 & 14 \\
\hline 2 & 1 & 6 & 2 & 2 & 2 & 2 & 1 & 28 \\
\hline 2 & 1 & 6 & 1 & 1 & 1 & 2 & 1 & 133 \\
\hline 1 & 1 & 10 & 1 & 1 & 1 & 2 & 3 & 14 \\
\hline 2 & 2 & 10 & 2 & 2 & 2 & 3 & 2 & 21 \\
\hline 1 & 2 & 6 & 1 & 2 & 2 & 2 & 1 & 10 \\
\hline 2 & 1 & 10 & 2 & 2 & 2 & 2 & 1 & 7 \\
\hline 1 & 2 & 7 & 2 & 2 & 2 & 2 & 1 & 15 \\
\hline 2 & 2 & 11 & 1 & 1 & 1 & 2 & 2 & 17 \\
\hline 1 & 2 & 6 & 1 & 1 & 1 & 3 & 0 & 180 \\
\hline 1 & 2 & 6 & 2 & 2 & 2 & 1 & 0 & 180 \\
\hline 2 & 2 & 6 & 1 & 2 & 2 & 2 & 0 & 780 \\
\hline 2 & 2 & 6 & 2 & 2 & 2 & 1 & 0 & 570 \\
\hline 1 & 2 & 8 & 2 & 2 & 2 & 1 & 0 & 225 \\
\hline 1 & 2 & 8 & 1 & 2 & 2 & 3 & 0 & 1500 \\
\hline 1 & 2 & 10 & 1 & 2 & 2 & 2 & 2 & 21 \\
\hline 1 & 2 & 10 & 1 & 2 & 2 & 2 & 2 & 21 \\
\hline 1 & 2 & 10 & 2 & 2 & 2 & 2 & 2 & 21 \\
\hline 1 & 2 & 8 & 1 & 1 & 1 & 2 & 1 & 7 \\
\hline 2 & 2 & 8 & 1 & 2 & 2 & 2 & 1 & 21 \\
\hline 1 & 2 & 6 & 1 & 1 & 1 & 3 & 2 & 21 \\
\hline 1 & 2 & 6 & 2 & 2 & 2 & 2 & 1 & 7 \\
\hline 1 & 2 & 6 & 2 & 2 & 2 & 2 & 1 & 240 \\
\hline 1 & 2 & 6 & 2 & 2 & 2 & 2 & 1 & 7 \\
\hline 2 & 2 & 6 & 1 & 2 & 2 & 3 & 1 & 15 \\
\hline 1 & 2 & 6 & 1 & 2 & 2 & 3 & 1 & 19 \\
\hline 1 & 2 & 10 & 1 & 1 & 1 & 2 & 1 & 21 \\
\hline 1 & 2 & 10 & 1 & 1 & 1 & 3 & 0 & 164 \\
\hline 1 & 2 & 10 & 1 & 1 & 1 & 3 & 2 & 7 \\
\hline 1 & 2 & 10 & 1 & 1 & 1 & 2 & 2 & 2 \\
\hline 1 & 2 & 10 & 1 & 1 & 1 & 2 & 2 & 21 \\
\hline
\end{tabular}




\begin{tabular}{ccccccccc}
\hline $\begin{array}{c}\text { Sexo } \\
(\mathrm{M}=1 / \mathrm{F}=2)\end{array}$ & $\begin{array}{c}\text { Óbito } \\
(\mathrm{S}=1 / \mathrm{N}=2)\end{array}$ & $\begin{array}{c}\text { Pontuação } \\
\text { DDR }\end{array}$ & $\begin{array}{c}\text { Contaminação } \\
\text { CVC }\end{array}$ & $\begin{array}{c}\text { Hemocultura } \\
\text { Periferica }\end{array}$ & $\begin{array}{c}\text { Hemocultura } \\
\text { CVC }\end{array}$ & $\begin{array}{c}\text { Tipo CVC ( } \\
\mathrm{F}=1, \mathrm{~J}=2, \mathrm{~S}=3)\end{array}$ & $\begin{array}{c}\text { Quantidade } \\
\text { Lumens }\end{array}$ & $\begin{array}{c}\text { Dias de } \\
\text { uso }\end{array}$ \\
\hline 1 & 2 & 10 & 1 & 1 & 1 & 2 & 2 & 15 \\
1 & 2 & 8 & 1 & 1 & 1 & 2 & 2 & 15 \\
1 & 2 & 8 & 1 & 2 & 2 & 2 & 2 & 7 \\
\hline
\end{tabular}

M: Masculino; F: Feminino; DDR: DIETAS DENUNCIAM RISCO; CVC: Cateter Venoso Central; F: Femoral;J: Jugular; S: Subclávia 


\title{
Journal of Parenteral and Enteral Nutrition
}

http://pen.sagepub.com

Biofilms, Infection, and Parenteral Nutrition Therapy

Juliana Deh Carvalho Machado, Vivian Miguel Marques Suen, José Fernando de Castro Figueiredo and Júlio Sérgio Marchini

JPEN J Parenter Enteral Nutr 2009; 33; 397 originally published online Apr 28, 2009;

DOI: $10.1177 / 0148607108327526$

The online version of this article can be found at:

http://pen.sagepub.com/cgi/content/abstract/33/4/397

\author{
Published by: \\ @SAGE \\ On behalf of: \\ aspen
}

http://www.sagepublications.com

The American Society for Parenteral \& Enteral Nutrition

Additional services and information for Journal of Parenteral and Enteral Nutrition can be found at:

Email Alerts: http://pen.sagepub.com/cgi/alerts

Subscriptions: http://pen.sagepub.com/subscriptions

Reprints: http://www.sagepub.com/journalsReprints.nav

Permissions: http://www.sagepub.com/journalsPermissions.nav 


\title{
Biofilms, Infection, and Parenteral Nutrition Therapy
}

\author{
Juliana Deh Carvalho Machado, $\mathrm{MD}^{1}$; \\ Vivian Miguel Marques Suen, $\mathrm{MD}, \mathrm{PhD}^{2}$; \\ José Fernando de Castro Figueiredo, $\mathrm{MD}, \mathrm{PhD}^{3}$; and \\ Júlio Sérgio Marchini, $\mathrm{MD}, \mathrm{PhD}^{2}$
}

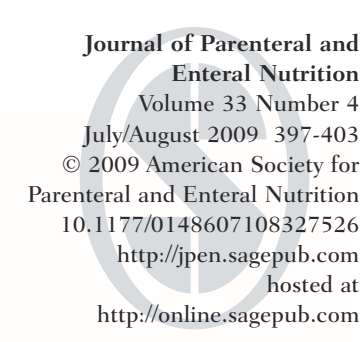

Financial disclosure: none declared.

Parenteral nutrition therapy is used in patients with a contraindication to the use of the gastrointestinal tract, and infection is one of its frequent and severe complications. The objective of the present study was to detect the presence of biofilms and microorganisms adhering to the central venous catheters used for parenteral nutrition therapy by scanning electron microscopy. Thirty-nine central venous catheters belonging to patients with clinical signs of infection (G1) and asymptomatic patients (G2) and patients receiving central venous catheters for clinical monitoring (G3) were analyzed by semiquantitative culture and scanning electron microscopy. The central venous catheters of $\mathrm{Gl}$ presented more positive cultures than those of G2 and G3 (81\% vs $50 \%$ and $0 \%$, respectively). However, biofilms were observed in all catheters used and 55\% of them showed structures that suggested central venous catheters colonization by microorganisms. Approximately $53 \%$ of the catheter infections evolved with systemic infection confirmed by blood culture. The authors conclude that the presence of a biofilm is frequent and is an indicator of predisposition to infection, which may even occur in patients who are still asymptomatic. (JPEN J Parenter Enteral Nutr. 2009;33:397-403)

Keywords: parenteral nutrition; central venous catheter; scanning electron microscopy; biofilms
$\mathrm{T}$ The use of central venous catheters (CVCs) has been growing all over the world, permitting the administration of medications, blood derivatives, and nutrients, as well as the hemodynamic monitoring of critical patients. ${ }^{1,2}$ However, infection related to a catheter is one of the most feared complications, occurring at a frequency of $5 \%-26 \%$ and being related to the site of insertion and to the migration of pathogens along the outer surface of the catheter. ${ }^{3}$

Among the hypotheses raised about catheter colonization is the fact that contaminated connections result in

From the ${ }^{1}$ Department of Clinical Medicine, Hospital of the School of Medicine of Ribeirão Preto; ${ }^{2}$ Nutrology Division, Department of Clinical Medicine, Hospital of the School of Medicine of Ribeirão Preto; ${ }^{3}$ Infectious Disease, Department of Clinical Medicine, Hospital of the School of Medicine of Ribeirão Preto.

Received for publication December 11, 2007; accepted for publication March 13, 2008.

Address correspondence to: Juliana Deh Carvalho Machado, Hospital das Clínicas, Faculdade de Medicina de Ribeirão Preto, Universidade de São Paulo, Departamento de Clínica Médica, Av. Bandeirantes, 3.900 - 14.048-900 - Ribeirão Preto - SP; e-mail: juliana@infonet.com.br. colonization of the catheter itself and of its lumen, followed by blood colonization. ${ }^{3}$ The adherence of these microorganisms to the lumen probably is one of the factors contributing to the formation of biofilms that are associated, for example, with the maintenance and severity of infection in hemodialysis catheters. ${ }^{4}$ In vitro experiments have suggested that bacteria enveloped by a biofilm may become 50-500 times more resistant to antimicrobial therapy than plankton bacteria..$^{5}$ In these cases, the infection does not resolve and can only be treated by removing the infected implants, causing treatment failure and increasing patient morbidity and mortality.

Malnourished, cachectic, and immunocompromised patients are predisposed to CVC infections. As well, some treatment modalities may also predispose patients to a higher risk of CVC infections. Studies have reported parenteral nutrition as an independent risk factor for the development of CVC infection because its macro- and micronutrient composition may facilitate the growth of microorganisms. ${ }^{6}$ In addition, patients with intestinal failure $(<1 \mathrm{~m}$ of functioning small bowel and dependent on parenteral nutrition ${ }^{7}$ ) frequently develop CVC infection. ${ }^{8}$ Several factors are related to CVC infections, among them migration of microorganisms from the patient's skin to the catheter lumen, ${ }^{9} \mathrm{CVC}$ manipulation for the administration 
of medications, ${ }^{10}$ clinical conditions of patients who require central access such as age, ${ }^{11}$ and the use of parenteral nutrition. This last risk factor was confirmed by Beghetto et $\mathrm{al}^{6}$ in a cohort study conducted at the University Hospital of Porto Alegre over a period of 1 year in which the exposure factor (administration of parenteral nutrition) was compared in patients with CVCs. The authors observed a relative risk of 3.30 with a confidence interval of 1.3-8.3 in the exposed population compared with the nonexposed one. In the same study, malnutrition, the time of hospitalization preceding CVC insertion, and sustained hyperglycemia were not risk factors for increased infection. ${ }^{6}$

The hypothesis of the present study was that biofilms formed in the lumen of the CVC facilitate the adherence of microorganisms to the lumen of the central catheter, causing and maintaining infection, not always diagnosed, in patients submitted to long-term parenteral nutrition therapy. Thus, the objective was to demonstrate the presence of biofilms and microorganisms adhering to CVCs used for parenteral nutrition therapy using scanning electron microscopy (SEM).

\section{Material and Methods}

\section{Patients}

This was a prospective study in which removal of the CVC was medically indicated in patients receiving parenteral nutrition therapy due to infectious or mechanical complications, or completion of treatment. The investigators were not involved in the indication of therapy, in the medical care of the patient, or in the decision to remove the catheter. After removal, the CVCs were analyzed by microbiology and by SEM. During a 1-year time period, patients who required central venous access for nutrition therapy or for drug administration were eligible for participation in the study.

The medical records of the patients whose catheter tips were analyzed were reviewed for the collection of data such as sex, age (years), weight $(\mathrm{kg})$, height $(\mathrm{m})$, body mass index (BMI, $\mathrm{m} / \mathrm{kg}^{2}$ ), associated diseases, hypoalbuminemia, and peripheral white blood cell and total lymphocyte counts.

The presence of infection was clinically determined on the basis of hyperemia at the site of catheter implant, pericatheter purulent secretion, tachycardia, fever, shivering, bacteremia, and presumed sepsis without a known infectious source. In this last case, the infectious process was attributed to the catheter.

Thus, CVCs used for parenteral nutrition were analyzed after removal from the patients either due to infection (group 1; G1) or because a clinical indication for their use no longer existed (ie, from patients who had been discharged or who had experienced a mechanical complication related to the catheter such as thrombosis). In this second group (group 2; G2), no infection was clinically diagnosed during their hospitalization. Two control groups were used. Group 3 (G3) consisted of patients who had used a CVC for clinical monitoring during or immediately after cardiothoracic surgery for a maximum period of 48 hours, and group 4 (G4) consisted of catheters that were not used for clinical applications. Group 4 catheters were analyzed separately to determine whether preparation caused any damage to the material studied.

Aseptic technique was used to remove the catheters. ${ }^{12}$ The catheter tips were then analyzed using SEM and semiquantitative culture analysis. Tests were considered positive when the result of the semiquantitative method was $\geq$ 15 colony forming units (CFU), according to Maki's method of analyses. ${ }^{13}$ For visualization of the catheter tip through SEM, all catheters tips were fixed with $2 \%$ glutaraldehyde for 2 hours, transferred to a $0.1 \mathrm{M}$ phosphate buffer solution ( $\mathrm{pH}$ 7.2), and refrigerated. The tips were again fixed with osmium for 2 hours, washed with phosphate buffer, and dehydrated with ethanol. After dehydration, the material was placed in the critical point apparatus Bal-tec ${ }^{\circledR}$ CPD 030 (Boeckeler Instruments, Tucson, AZ). The fixed catheters were stored until the time for analysis with a JSM 5200® (Jeol Datum, Tokyo, Japan) and EVO 50® (Carl Zeiss, Oberkochen, Germany). SEM process was chosen because it is a method that shows morphological features of biofilms (sensitivity range from $84 \%$ to $100 \%$ and specificity range from $97 \%$ to $100 \%) .{ }^{14}$ Biofilm was defined as a community of microorganisms irreversibly attached to a surface, producing extracellular polymeric substances and exhibiting an altered phenotype compared with corresponding plaktonic cells. ${ }^{15}$

The project was approved by the Ethics Committee of the University Hospital, Faculty of Medicine of Ribeirão Preto (process HCRP no. 13050/2006).

\section{Statistical Analysis}

Data were analyzed descriptively. The Students' $t$-test or Fisher's exact test was used to compare population means of G1 and G2. ANOVA was used to compare all groups. The level of significance was set with $\alpha=.05$. A result was considered to be doubtful when the $P$ value was less than .10 or greater than .05 .

\section{Results}

A total of 39 CVCs were analyzed, 16 in G1 (clinically infected), 12 in G2 (no clinical signs of infection), 8 in G3 (monitoring), and 3 in G4 (not utilized).

G4 catheters were the first to be analyzed. We observed that some had irregularities in their internal lumen such as the presence of elevations or indentations (Figure 1A and 1B). 


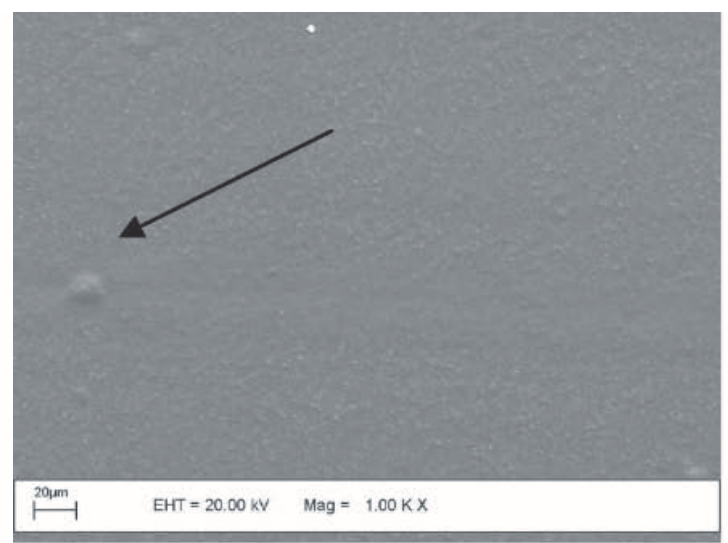

(a)

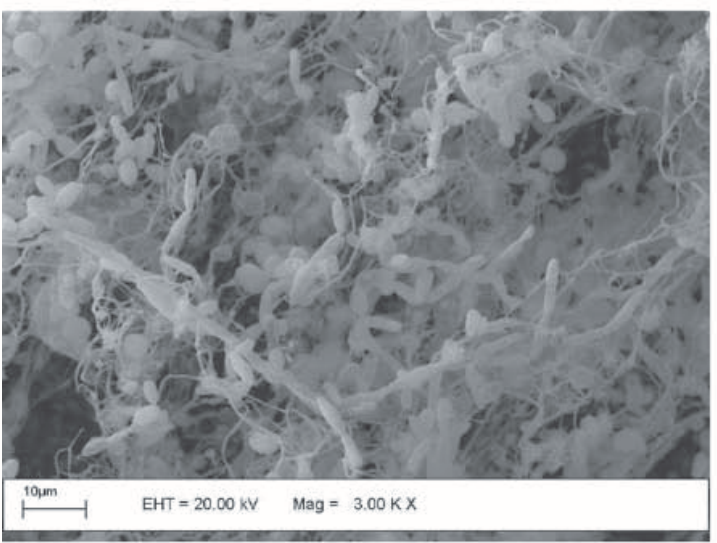

(c)

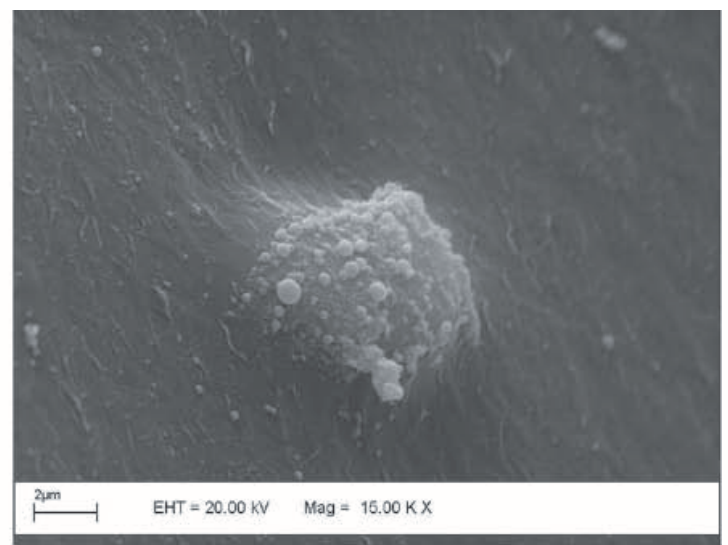

(b)

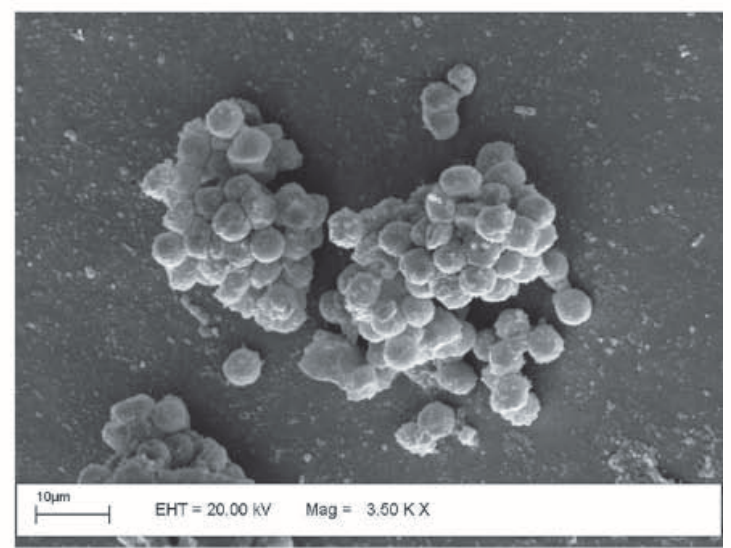

(d)

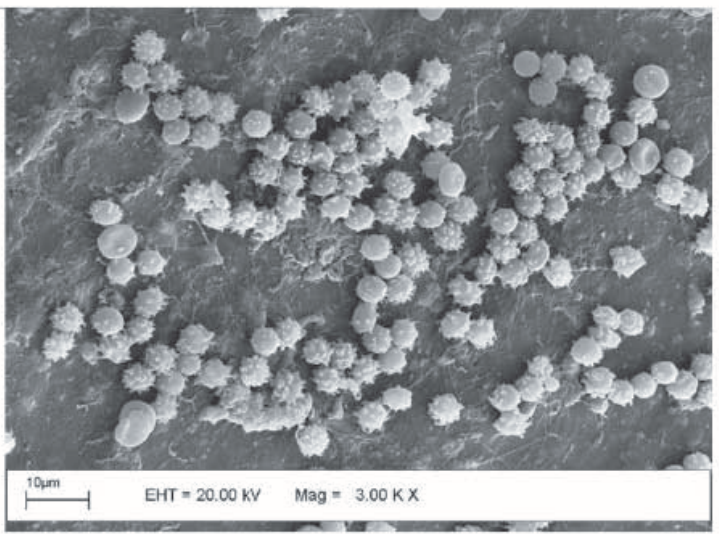

(e)

Figure 1. Scanning electron microscopy of central venous catheters. A: A deformity in an unused catheter (arrowhead) facilitates the adherence of microorganisms to the lumen. B: Coccoid structures adhering to the elevation existing in the lumen of the catheter. Scanning electron microscopy of central venous catheters. C: Hyphae of Candida albicans at 3000× magnification. D: Colonies suggesting the presence of Staphylococcus epidermidis (3500×). E: Fibrin formed in a catheter after less than 48 hours of use and lymphocytes from a patient which may suggest an acute inflammatory response $(3000 \times)$. The dimensions of the structures analyzed, in $\mu \mathrm{m}$, are indicated by the bar $\longmapsto$. EHT, extra-high tension; Mag, magnification. 
Table 1. Patient Demographics

\begin{tabular}{|c|c|c|c|}
\hline & $\begin{array}{l}\text { Group } 1 \text { (Clinical } \\
\text { Infection) }\end{array}$ & $\begin{array}{c}\text { Group } 2 \text { (No Clinical } \\
\text { Infection) }\end{array}$ & $\begin{array}{c}\text { Group } 3 \text { (Clinical } \\
\text { Monitoring) }\end{array}$ \\
\hline Age (years) & $55 \pm 10^{\mathrm{ab}}$ & $52 \pm 20^{\mathrm{b}}$ & $51 \pm 7^{\mathrm{b}}$ \\
\hline \multicolumn{4}{|l|}{ Sex, n (\%) } \\
\hline Male & $9(81)$ & $4(57)$ & $2(50)$ \\
\hline Female & $2(19)$ & $3(43)$ & $2(50)$ \\
\hline Weight (kg) & $46 \pm 17^{\mathrm{ab}}$ & $47 \pm 21^{b}$ & $69 \pm 11^{\mathrm{c}}$ \\
\hline $\operatorname{BMI}\left(\mathrm{kg} / \mathrm{m}^{2}\right)$ & $17 \pm 7^{\mathrm{ab}}$ & $19 \pm 6^{b}$ & $25 \pm 4^{c}$ \\
\hline Albumin $(\mathrm{g} / \mathrm{L})$ & $28 \pm 6^{\mathrm{ab}}$ & $32 \pm 6^{b}$ & - \\
\hline Leukocytes $/ \mathrm{mm}^{3}$ & $8.369 \pm 4.072^{\mathrm{ac}}$ & $8.460 \pm 5.783^{\mathrm{c}}$ & - \\
\hline Lymphocytes $/ \mathrm{mm}^{3}$ & $1.548 \pm 1.342^{\mathrm{ab}}$ & $1.396 \pm 1.204^{\mathrm{b}}$ & - \\
\hline Lymphopenia - n $(\%)$ & $6(38)$ & $5(42)$ & - \\
\hline Associated Diseases & n $(\%)$ & $\mathrm{n}(\%)$ & $\mathrm{n}(\%)$ \\
\hline SBS & $8(73)$ & $4(57)$ & - \\
\hline Diabetes mellitus & $2(18)$ & - & $1(25)$ \\
\hline $\mathrm{AH}$ & $6(55)$ & $1(14)$ & $2(50)$ \\
\hline CAD & $1(9)$ & $1(14)$ & $2(50)$ \\
\hline PCM & $10(91)$ & $5(72)$ & - \\
\hline Cardiac failure & $2(18)$ & $1(14)$ & $2(50)$ \\
\hline Diarrhea & $10(91)$ & $4(57)$ & - \\
\hline Enteric fistula & $1(9)$ & - & - \\
\hline Intestinal occlusion & $1(9)$ & - & - \\
\hline Multiple myeloma & $1(9)$ & - & - \\
\hline Multiple sclerosis & $1(9)$ & - & - \\
\hline \multirow{2}{*}{ Carcinoma } & - & $1(14)$ & - \\
\hline & $3(28)$ & $1(14)$ & - \\
\hline
\end{tabular}

BMI, body mass index; SBS, short bowel syndrome; AH, arterial hypertension; CAD, coronary artery disease; PCM, protein-calorie malnutrition.

${ }^{\mathrm{a}}$ Mean $\pm \mathrm{SD}$.

${ }^{\mathrm{b}} P>.05 \mathrm{NS}$.

${ }^{\mathrm{c}} \mathrm{P} \leq .05$.

All the samples used clinically (G1, G2, and G3) presented the formation of biofilms, even those that had been inserted for only 48 hours (Figure 1C).

Patient demographics are listed in Table 1. A greater percentage of men were observed in G1 and G2, $81 \%$ and $57 \%$ respectively, with an equal distribution observed in G3.

G3 had a significantly higher BMI than G1 $(P=.001)$ and G2 $(P=.01)$, with the latter 2 not differing significantly (mean; $17 \pm 7 \mathrm{~kg} / \mathrm{m}^{2}$ and $19 \pm 6 \mathrm{~kg} / \mathrm{m}^{2}$, respectively). G1 patients also experienced hypoalbuminemia compared with G2 patients, with respective mean values of $28 \pm 6 \mathrm{~g} / \mathrm{L}$ and $32 \pm 6 \mathrm{~g} / \mathrm{L}(P=.08)$. There was no difference in white blood cell count between G1 and G2 $(P=.48)$. G2 had higher lymphopenia $(42 \%)$ than G1 $(38 \% ; P<.05)$. Data are listed in Table 1.

General characteristics of the clinically used catheters submitted for microbiological and SEM analysis are presented on Table 2.

For G1 and G2, CVC implants were indicated for nutrition therapy in $100 \%$ and $92 \%$ of the cases, respectively, and for intravenous hydration in $100 \%$ of the cases in both groups. For G3, the clinical indication was for intravenous hydration and clinical monitoring. The maximum catheterization time for these patients was 48 hours.

The incidence of catheter tip infection was $81 \%$ for G1 and $50 \%$ for G2. However, only $56 \%$ of G1 patients and $8 \%$ of G2 patients, whose catheters were colonized, showed a positive blood culture. The total infection rate was 0.04 patients per year, and when G3 patients were excluded, the rate was 0.049 patients per year.

The internal jugular vein was the site most frequently used in G1 (63\%); in G2 the preference was for the femoral vein (33\%) and the internal jugular vein (33\%), and in G3 access was through the subclavian vein $(100 \%)$. It was not possible to detect whether there was a relation between the site of puncture and the presence of infection.

Patients with no clinical signs of infection had a significantly longer venous access time ranging from 7 to 1500 days (median 101 days; mean $294 \pm 453$ days), whereas the duration of venous access ranged from 2 to 240 days (median 15 days; mean $37 \pm 66$ days) in $\mathrm{G} 1$ and from 1 to 2 days (median 2 days; mean $1.6 \pm 0.5$ days) in G3 $(P=.038)$. 
Table 2. Characteristics of the Central Venous Catheters

\begin{tabular}{|c|c|c|c|}
\hline & $\begin{array}{l}\text { Group } 1 \text { (Clinical } \\
\text { Infection) }\end{array}$ & $\begin{array}{c}\text { Group } 2 \text { (No Clinical } \\
\text { Infection) }\end{array}$ & $\begin{array}{l}\text { Group } 3 \text { (Clinical } \\
\text { Monitoring) }\end{array}$ \\
\hline \multicolumn{4}{|l|}{ Therapeutic indication, n (\%) } \\
\hline Nutrition therapy & $16(100)$ & $11(92)$ & - \\
\hline Hydration & $16(100)$ & $12(100)$ & $8(100)$ \\
\hline Clinical monitoring & - & $1(8)$ & $8(100)$ \\
\hline \multicolumn{4}{|l|}{ Type, n (\%) } \\
\hline Totally implantable & $2(13)$ & $6(50)$ & - \\
\hline Single lumen & $6(37)$ & - & $4(50)$ \\
\hline Double lumen & $8(50)$ & $5(42)$ & $4(50)$ \\
\hline Umbilical & - & $1(8)$ & - \\
\hline Time of access (days) & $37 \pm 66^{\mathrm{a}}$ & $294 \pm 453^{\mathrm{a}}$ & $2 \pm 1^{\mathrm{a}}$ \\
\hline \multicolumn{4}{|l|}{ Reason for catheter removal, n (\%) } \\
\hline Termination of therapy & - & $6(50)$ & $8(100)$ \\
\hline Bacteremia & $1(6)$ & - & - \\
\hline Fever & $13(81)$ & - & - \\
\hline Hyperemia at site of insertion & $2(13)$ & - & - \\
\hline Thrombosis & - & $6(50)$ & - \\
\hline \multicolumn{4}{|l|}{ Tip culture, n (\%) } \\
\hline Positive & $13(81)^{\mathrm{b}}$ & $6(50)^{\mathrm{b}}$ & 0 \\
\hline Negative & $3(19)$ & $6(50)$ & $8(100)$ \\
\hline \multicolumn{4}{|l|}{ Site of implant ${ }^{\mathrm{c}}, \mathrm{n}(\%)$} \\
\hline Jugular & $10(63)$ & $4(33)$ & - \\
\hline Subclavian & $6(37)$ & $3(25)$ & $8(100)$ \\
\hline Femoral & - & $4(33)$ & - \\
\hline Umbilical & - & $1(8)$ & - \\
\hline
\end{tabular}

${ }^{\mathrm{a}}$ mean $\pm \mathrm{SD}$.

${ }^{\mathrm{b}} \chi^{2}=0.09$.

${ }^{\mathrm{c}}$ Fisher's exact test $=0.48$.

In G1, the following pathogens grew in culture in decreasing order of frequency: Staphylococcus epidermidis, 20\%; Staphylococcus aureus, 20\%; Enterococcus faecalis, 20\%; Pseudomonas aeruginosa, 13\%; Candida albicans, 13\%; Escherichia coli, 7\%; and Candida glabrata, 7\%. In G2, the following distribution was observed: Staphylococcus epidermidis, 33\%; Staphylococcus aureus, 33\%; Candida parapsilosis, $17 \%$; and Proteus mirabilis, $17 \%$.

Table 3 shows the quantity of CFU for each microorganism isolated from samples with a positive tip culture. The criterion used to determine the positivity of semiquantitative culture of the catheter tip was a value exceeding $15 \mathrm{CFU} / \mathrm{ml}$. Most samples showed countless CFU after a time of catheter permanence ranging from 2 to 1500 days (median 19 days; mean $149 \pm 342$ days). G1 patients had a positive blood culture in approximately $69 \%$ of cases, whereas in G2, blood cultures were positive in $17 \%$ of the cases.

Biofilms were present in 28 venous catheters analyzed. In G1, the presence of structures with morphology suggesting colonization by microorganisms was confirmed in all catheters with a positive culture (Figures 1C). Structures similar to coccus colonies were observed in only 1 catheter whose culture was negative.
In G2, only 6 catheters had positive semiquantitative cultures and SEM revealed that all of them had some type of microorganism (Figure 1D).

In contrast, in G3 there were no structures denoting the existence of colonization, although there was an important presence of lymphocytes and fibrin (Figure 1E).

\section{Discussion}

In the present study, we observed the formation of a biofilm in the internal and external lumen of almost all of the catheters that were used for more than 48 hours. SEM also revealed the presence of acute inflammatory response in catheters that had been in use for less than 48 hours showing fibrin and the presence of lymphocytes, contributing to microorganisms' adherence to catheter lumen. In vitro studies have demonstrated the formation of biofilms 3-6 hours after inoculation of the microorganism in the material to be analyzed. ${ }^{16,17}$

The biofilm observed in our samples probably consisted of the colonizing microorganism itself and of proteins of the host (such as fibronectin and fibrinogen), as suggested by others. ${ }^{18,19}$ Some microorganisms can also 
Table 3. Relation Between the Microorganism Isolated by Semiquantitative Catheter Tip Culture

\begin{tabular}{|c|c|c|c|c|c|}
\hline $\begin{array}{l}\text { Microorganism Detected } \\
\text { in the Catheter }\end{array}$ & $\begin{array}{l}\text { Colony Forming } \\
\text { Units }(\mathrm{CFU} \times \mathrm{ml})\end{array}$ & $\begin{array}{l}\text { Catheter } \\
\text { Type }\end{array}$ & $\begin{array}{l}\text { Time of Catheter } \\
\text { Permanence (days) }\end{array}$ & $\begin{array}{l}\text { Blood } \\
\text { Culture }\end{array}$ & Group \\
\hline 1. Candida albicans and & 140 & & & & \\
\hline Enterococcus faecalis & 40 & Single lumen & 7 & Positive & 1 \\
\hline 2. Staphylococcus epidermidis & Countless* & Single lumen & 21 & Negative & 1 \\
\hline 3. Enterococcus faecalis & 300 & Double lumen & 21 & Positive & 1 \\
\hline 4. $S$ epidermidis & Countless* & Single lumen & 15 & Negative & 1 \\
\hline 5. $S$ epidermidis & Countless* & Double lumen & 19 & Negative & 1 \\
\hline 6. Candida albicans & ND & Double lumen & 21 & Positive & 1 \\
\hline 7. Candida glabrata & ND & Subcutaneous port & 164 & Positive & 1 \\
\hline $\begin{array}{l}\text { 8. Pseudomonas aeruginosa and } \\
\text { Staphylococcus aureus }\end{array}$ & $\begin{array}{l}\text { Countless* } \\
\text { Countless* }\end{array}$ & Single lumen & 7 & Positive & 1 \\
\hline 9. $S$ aureus & Countless* & Double lumen & 2 & Positive & 1 \\
\hline 10. $S$ aureus & Countless* & Double lumen & 21 & Positive & 1 \\
\hline 11. Escherichia coli & Countless* & Double lumen & 15 & Positive & 1 \\
\hline 12. E faecalis & Countless* & Double lumen & 15 & Positive & 1 \\
\hline 13. P aeruginosa & 26 & Double lumen & 7 & Negative & 1 \\
\hline 14. Candida parapsilosis & ND & Subcutaneous port & 180 & Positive & 2 \\
\hline 15. $S$ aureus & Countless* & Subcutaneous port & 780 & Negative & 2 \\
\hline 16. $S$ epidermidis & Countless* & Subcutaneous port & 1.500 & Negative & 2 \\
\hline 17. Proteus mirabilis & 25 & Double lumen & 21 & Negative & 2 \\
\hline 18. $S$ aureus & Countless* & Umbilical & 7 & Negative & 2 \\
\hline 19. $S$ epidermidis & Countless* & Double lumen & 7 & Negative & 2 \\
\hline
\end{tabular}

Group 1: patients with clinical symptoms of infection; Group 2: patients without clinical symptoms of infection. ND, not determined. *Countless: too numerous to count.

produce a material called glycocalyx, which facilitates the adherence of the microcolonies formed and protects them against the defense cells of the host. In addition, the glycocalyx reduces the sensitivity to antibiotic treatment by preventing antibiotic binding to the bacteria, leading to the occurrence of strains that are more resistant to treatment. ${ }^{20,21}$

Small sample size could be an analytical problem; however, our sample size is similar to other studies. ${ }^{18,19,22,23}$ Only multicenter or large retrospective studies have larger samples. ${ }^{24-26}$

We observed that the site of implant may be related to a greater or lesser predisposition to infection. In our study, the catheters inserted into the internal jugular vein had a higher incidence of infection compared with the subclavian and/or femoral vein, but because of the small sample size, we cannot make further conclusions. Some data from the literature show that the jugular vein is a suitable site related to CVC infection. ${ }^{1,24}$ In a meta-analysis, Ruesch et $\mathrm{al}^{25}$ reviewed 17 prospective studies with the objective of comparing CVC complications through the internal jugular vs the subclavian vein. The authors analyzed 2085 catheters in the internal jugular vein and 2428 in the subclavian vein and observed infection in 707 catheters, with a 9\% incidence in the internal jugular vein and a $4 \%$ incidence in the subclavian vein (relative risk 2.24; confidence interval 0.62-8.09). ${ }^{25}$
When using the Centers for Disease Control and Prevention criteria, we noted that our patients presented catheter colonization confirmed by semiquantitative culture of the CVC tip, as well as systemic infection related to the CVC. ${ }^{12}$ In a study conducted in Ribeirão Preto on patients receiving prolonged parenteral nutrition through catheters of long permanence, Unamuno et $\mathrm{al}^{8}$ detected a lower rate in colonization and infection complications than ours, that is, 0.029 per patient year. Another study conducted by Colomb et $\mathrm{al}^{9}$ detected a 0.78 rate per patient year in a population also requiring prolonged parenteral nutrition in a French pediatric hospital, ${ }^{9}$ which was greater than ours.

Fungal infection was more prevalent than generally reported in the literature, affecting $19 \%$ of our patients as opposed to $3 \%$ to $8 \%$ of patients in other studies. However, a rate similar to the present one $(22 \%)$ was recently reported by Marra et $\mathrm{al}^{26}$ in a study of catheter infections related to the use of parenteral nutrition. Some investigators have suggested that the reason for this greater prevalence of fungal colonization may be explained by parenteral nutrition itself, ${ }^{6}$ in which the glucose- and lipid-rich composition may permit Candida to produce a glycocalyx similar to that of the bacteria, facilitating biofilm formation. ${ }^{27}$ According to literature data, other factors that may explain this increased incidence are the immunosuppression of our 
patients, as well as diseases of the gastrointestinal tract. ${ }^{28,29}$ Most of our patients (55\%) had short bowel syndrome.

Thus, asepsis care is necessary when these catheters are manipulated in order to prevent their contamination. In addition, catheter removal should not be postponed but should occur when there is no longer a therapeutic indication for its use. With this precaution, the incidence of infection is reduced. Finally, in vivo studies are needed to evaluate the characteristics of the biofilms formed, helping to direct treatment that will prevent their formation and reduce the resistance acquired by the strains when they adhere to the biofilm matrix.

\section{Conclusion}

Although we analyzed only a small sample size, because it was not our aim to make an epidemiological study, we observed that the presence of biofilms and of infection of CVC used for parenteral nutrition therapy is frequent even among clinically asymptomatic patients and can contribute to their morbidity and mortality. Further studies are needed to evaluate methods that can control biofilm formation. Biofilms represent a challenge to microbiologists and clinicians because they contribute to antimicrobial resistance. ${ }^{15}$ From the perspective of the hospital environment, bacterial and fungal biofilms are a problem to be recognized and solved, since they could result in infectious complications, especially in immunocompromised patients.

\section{Acknowledgments}

The authors thank Maria do Rosário Del Lama Unamuno and Maria Dolores Ferreira, a "Tuca."

\section{References}

1. Raad I. Intravascular-catheter-related infections. Lancet. 1998; 351:893-898.

2. Galloway $\mathrm{S}$, Bodenham A. A long-term central venous access. $\mathrm{Br} J$ Anaesthesiol. 2004;92(Suppl 5):722-734.

3. Richards MJ, Edwards JR, Culver DH, Gaynes RP. Nosocomial infections in medical intensive care units in the United States. Crit Care Med. 1999;27:887-892.

4. Moyses-Neto M, Vieira-Neto OM, Figueiredo JFC. Bacterial colonization in a hemodyalisis dual lumen temporary catheter. Rev Soc Bras Med Trop. 2003;36:431-432.

5. Kumar A, Prasad R. Biofilms. J K Science. 2006;8:14-17.

6. Beghetto MG, Victorino J, Teixeira L, Azevedo MJ. Parenteral nutrition as a risk factor for central venous catheter-related infection. JPEN J Parenter Enteral Nutr. 2005;29:367-373.

7. O'Keefe SJD, Buchman A, Fishbein T, Jeejeebhoy K, Jeppesen P, Shaffer J. Short bowel syndrome and intestinal failure: consensus definitions and overview. Clin Gastroenterol Hepatol. 2005;4:6-10.

8. Unamuno MRDL, Carneiro JJ, Chueire FB, Marchini JS, Suen VMM. Uso de cateteres venosos totalmente implantados para parenteral nutrition: cuidados, tempo de permanência e ocorrência de complicações infecciosas [Totally implantable venous catheter for parenteral nutrition care: Use of totally implanted catheters for intravenous parenteral nutrition care, length of stay, and occurrence of infectious complications]. Rev Nutr. 2005;18:261-269.

9. Colomb V, Fabeiro M, Dabbas M, Goulet O, Merckx J, Ricour C. Central venous catheter-related infections in children on longterm home parenteral nutrition: incidence and risk factors. Clin Nutr. 2000;19:355-359.

10. Sherertz RJ. Update on vascular catheter infections. Curr Opin Infect Dis. 2004;17:303-307.

11. Veenstra DL, Saint S, Saha S, Lumley T, Sullivan SD. Efficacy of antiseptic-impregnated central venous catheter in preventing catheter-related bloodstream infection: a meta-analysis. JAMA. 1999;281:261-267.

12. Centers for Disease Control and Prevention. Guidelines for the prevention of intravascular catheter-related infections. MMWR Morb Mortal Wkly Rep. 2002;51(No. RR-10):1-34.

13. Maki DG, Weise CE, Sarafin HW. A semiquantitative culture method for identifying intravenous catheter-related infection. $N$ Engl J Med. 1977;296:305-309.

14. Raad I, Hanna H, Maki D. Intravascular catheter-related infections: advances in diagnosis, prevention, and management. Lancet Infect Dis. 2007;7:645-657.

15. Lindsay D, Von Holy A. Bacterial biofilms with the clinical setting: what healthcare professionals should know. J Hosp Infect. 2006;64:313-325.

16. Ramage G, Saville SP, Thomas DP, López-Ribot JL. Candida biofilms: an update. Eukaryot Cell. 2005;4:633-638.

17. García-Sánchez S, Albert S, Iraqui I, Janbon G, Ghigo JM, D'Enferti C. Candida albicans Biofilms: a developmental state associated with specific and table gene expression patterns. Eukaryot Cell. 2004;3:536-545.

18. Marie TJ, Noble MA, Costerton JW. Examination of the morphology of bacteria adhering to peritoneal dialysis catheters by scanning and transmission electron microscopy. J Clin Microbiol. 1983; 18:1388-1398.

19. Marie TJ, Costerton JW. Scanning and transmission electron microscopy of in situ bacterial colonization of intravenous and intraarterial catheters. J Clin Microbiol. 1984;19:687-693.

20. Donlan RM, Costerton JW. Biofilms: survival mechanisms of clinically relevant microorganisms. Clin Microbiol Rev. 2002;15:167-193.

21. Costerton JW, Stewart P, Greenberg E. Bacterial biofilms: a common cause of persistent infections. Science. 1999;284:1318-1322.

22. Aoki EE, Pizzolitto AC, Garcia LB, Pizzolitto EL. Staphylococcus aureus biofilms on central venous haemodialysis catheters. Bras J Microbiol. 2005;36:342-346.

23. Storti A, Pizzolitto AC, Pizzolitto EL. Detection of mixed microbial biofilms on central venous catheters removed from intensive care unit patients. Bras J Microbiol. 2005;36:275-280.

24. Nagashima G, Kikuchi T, Tsuyuzaki H, et al. To reduce catheter bloodstream infections: is the subclavian route better than the jugular route for central venous catheterization? J Infect Chemother. 2006;12:363-365.

25. Ruesch S, Walder B, Tramer MR. Complications of central venous catheters: internal jugular versus subclavian access-a systematic review. Crit Care Med. 2002;30:454-460.

26. Marra AR, Opilla M, Edmond AB, Kirby F. Epidemiology of bloodstream infections in patients receiving long-term total parenteral nutrition. J Clin Gastroenterol. 2007;41:19-28.

27. Sherertz RJ. Pathogenesis of vascular catheter infections. In: Waldvogel FA, Bisno AL, eds. Infections Associated With Indwelling Medical Devices. Washington, DC: ASM Press; 2000:111-125.

28. Wey SB, Mori M, Pfaller MA, Woolson RF, Wenzel RP. Risk factors for hospital-acquired candidemia. A matched case-control study. Arch Intern Med. 1989;149:2349-2353.

29. Kojic EM, Darouiche RO. Candida infections of medical devices. Clin Microbiol Rev. 2004;17:255-267. 


\title{
Pacientes assintomáticos apresentam
} infecção relacionada ao cateter venoso utilizado para terapia nutricional parenteral

\author{
Asymptomatic patients present infection related \\ to the central venous catheter used \\ for total parenteral nutrition
}

Juliana Deh Carvalho MACHADO'

Vivian Marques Miguel SUEN²

José Fernando de Castro FIGUEIREDO ${ }^{3}$

Júlio Sérgio MARCHINI ${ }^{3}$

\section{R E S U M O}

\section{Objetivo}

Avaliar a freqüência de infecção relacionada ao cateter venoso central em pacientes submetidos a terapia nutricional parenteral.

\section{Métodos}

Foram analisados os cateteres venosos centrais de pacientes em terapia nutricional parenteral que tiveram a indicação de retirada do cateter venoso central por infecção, alta hospitalar, ou trombose. Os pacientes com infecção foram denominados de grupo 1 e os demais de grupo 2.

\section{Resultados}

Não houve diferença estatisticamente significante quanto ao estado nutricional dos 18 pacientes analisados. Foram analisados 28 cateteres e, destes $68 \%$ estavam infectados, sendo $72 \%$ do grupo 1 e $28 \%$ do grupo 2 (assintomáticos). No grupo 1, houve infecção sistêmica em 70\% dos casos, já no grupo 2 a hemocultura foi positiva em $17 \%$ dos casos. A colonização por Staphylococcus sp. ocorreu em $48 \%$ dos casos, seguida de Candida sp. (21\%), Enterococcus faecalis (16\%), Pseudomonas aerurginosa (10\%) e Proteus sp. (5\%).

\footnotetext{
1 Universidade de São Paulo, Faculdade de Medicina de Ribeirão Preto, Departamento de Clínica Médica, Hospital das Clínicas. Av. Bandeirantes, 3900, 14048-900, Ribeirão Preto, SP, Brasil. Correspondência para/Correspondence to: J.D.C. MACHADO. E-mail: <juliana@infonet.com.br>.

2 Universidade de São Paulo, Faculdade de Medicina de Ribeirão Preto, Departamento de Clínica Médica do Hospital das Clínicas, Divisão de Nutrologia. Ribeirão Preto, SP, Brasil.

3 Universidade de São Paulo, Faculdade de Medicina de Ribeirão Preto, Departamento de Clínica Médica do Hospital das Clínicas, Divisão Moléstias Infecciosas. Ribeirão Preto, SP, Brasil.
} 
788 | J.D.C. MACHADO et al.

\section{Conclusão}

A contaminação de cateter venoso central utilizados para terapia nutricional parenteral é freqüente. Mesmo pacientes assintomáticos e pacientes recebendo nutrição parenteral têm uma incidência maior de infecção por Candida sp. Portanto, sendo necessária a criação de barreiras que impeçam a colonização destes cateteres venosos centrais, a fim de diminuir a morbimortalidade de pacientes dependentes deste tipo de terapia.

Termos de indexação: Infecção. Infecções relacionadas a catéter. Nutrição parenteral total.

\section{A B S T R A C T}

\section{Objective}

The aim of this study was to evaluate the frequency of central venous catheter-related infections in hospitalized patients receiving total parenteral nutrition.

\section{Methods}

Central venous catheters were analyzed immediately after removal due to infection, hospital discharge or thrombosis. The patients with catheter-related infection were named group 1 and the other patients were named group 2.

\section{Results}

Eighteen patients were studied. There was no statistically significant difference in nutritional status between the two groups. A total of 28 catheters were analyzed. Sixty-eight percent of the catheters were infected: $72 \%$ of them were from group 1 and 28\% from group 2 (asymptomatic patients). Systemic infection was diagnosed in $70 \%$ of the patients from group 1. Positive blood culture was found in $17 \%$ of the patients from group 2. The microorganisms found were: Staphylococcus sp. (48\%), Candida sp. (21\%), Enterococcus faecalis (16\%), Pseudomonas aerurginosa (10\%) and Proteus sp. (5\%).

\section{Conclusion}

Central venous catheter infection is common in hospitalized asymptomatic patients. Patients receiving total parenteral nutrition are most frequently infected with Candida sp. Therefore, the creation of barriers that block colonization in the central venous catheter is essential to decrease the morbidity and mortality among patients that depend on total parenteral nutrition.

Indexing terms: Infection. Catheter-related infections. Parenteral nutrition total.

\section{N T R O D U Ç Ã O}

EM 1968, Dudrick et al. ${ }^{1}$ relataram, em estudo experimental, a curva de crescimento normal em cachorros alimentados exclusivamente por nutrição parenteral. Ainda nesta década, Shils et $a^{2}$. conseguiram acompanhar pacientes com necessidade de terapia nutricional parenteral domiciliar. A partir desta época a mortalidade de pacientes sem trato disgetivo funcionante diminuiu drasticamente ${ }^{3}$.

A indicação para terapia nutricional parenteral ocorre quando pacientes possuem falência intestinal, seja decorrente de processos obstrutivos, de não motilidade, de ressecções intestinais intensas, defeitos congênitos e doenças que comprometem a absorção, caracterizadas pela incapa- cidade de manter o equilíbrio de energia, proteína, hidroeletrolítico e de micronutrientes ${ }^{4}$. Porém, como todo tratamento clínico, a nutrição parenteral não está isenta de complicações clínicas e a infecção relacionada com cateter venoso central é uma das mais temidas e freqüentes ${ }^{5}$.

O objetivo deste estudo é comparar a incidência de infecção relacionada ao cateter venoso central em pacientes com e sem clínica de infecção, que estavam sendo submetidos à terapia nutricional parenteral.

\section{M É TO D OS}

Este foi um estudo prospectivo de cateteres venosos centrais retirados de pacientes internados 
no Hospital das Clínicas da Faculdade de Medicina de Ribeirão Preto da Universidade de São Paulo. Todos os cateteres foram retirados por indicação médica, tais como complicação infecciosa ou mecânica, ou pelo término da terapia que indicou sua utilização. Os pesquisadores responsáveis pela pesquisa não tiveram qualquer participação na indicação da terapia, na evolução do paciente ou na indicação da retirada do cateter. O projeto foi aprovado pelo Comitê de Ética do Hospital das Clínicas da Faculdade de Medicina de Ribeirão Preto (processo HCRP n 13050/2006).

Participaram do estudo pacientes do Hospital das Clínicas da Faculdade de Medicina de Ribeirão Preto que necessitaram de acesso venoso central para terapia nutricional parenteral, em algumas situações os cateteres de duplo lúmen também foram utilizados para administração de medicamentos.

Todos os pacientes que tiveram indicação da retirada do cateter venoso central foram acompanhados e avaliados clinicamente, a fim de diagnosticar sinais clínicos que sugerissem infecção como: hiperemia no local de inserção do cateter, secreção purulenta pericateter, taquicardia, febre, calafrios, bacteremia e sepse sem foco infeccioso conhecido, neste caso o processo infeccioso foi atribuído ao cateter.

Dessa maneira, foram avaliados cateteres venosos centrais utilizados para nutrição parenteral, que foram retirados dos pacientes por indicação médica: seja por infecção (Grupo 1), ou então por não ter mais indicação clínica para sua utilização, ou seja, pacientes que receberam alta médica, ou então tiveram complicação mecânica relacionada ao cateter, como trombose, neste último grupo durante a evolução não foi clinicamente diagnosticada infecção (Grupo 2).

As pontas dos cateteres foram submetidas à cultura semiquantitativa utilizando técnicas classicamente descritas, sendo considerado o teste positivo quando o resultado do método semi- quantitativo fosse $\geq 15$ Unidades Formadoras de Colônia (UFC).

Foi realizada uma análise descritiva. Utilizou-se o teste $t$ de Student para comparar médias populacionais, além do teste exato de Fisher. Em todas as situações, considerou-se um nível de significância estatística de 5\%. Os resultados foram considerados duvidosos quando o $p$ valor foi menor que 0,10 ou maior do que 0,05 .

\section{RES U LTADOS}

Foram analisados 18 pacientes submetidos à Terapia Nutricional Parenteral (TNP), que utilizaram um total de 28 cateteres venosos centrais. Destes 16 pertenciam ao grupo 1 (clinicamente infectados) e 12 ao grupo 2 (sem sinal clínico de infecção).

As indicações para TNP e as principais características dos pacientes divididos por grupo estão descritas na Tabela 1, sendo a síndrome do intestino curto (68\%) a mais freqüente. Embora os pacientes do grupo 1 fossem mais hipoalbuninêmicos e mais emagrecidos do que os do grupo 2, não houve diferença entre o estado nutricional dos pacientes dos dois grupos, quanto ao índice de massa corporal, albumina sérica e glóbulos brancos (Tabela 1). Observou-se que $61 \%$ dos pacientes eram linfopênicos e o grupo 2 apresentava maior incidência de linfopenia (42\%) do que os pacientes do grupo 1 (38\%).

A Figura 1 mostra a curva térmica axilar média dos dois grupos. Observou-se que os pacientes com infecção clínica sintomática (grupo 1) apresentavam temperatura axilar superior à do grupo 2. A Figura 2 exibe os resultados das temperaturas axilares individualizadas de cada grupo.

As características dos cateteres utilizados e o seu sítio de inserção estão resumidos na Tabela 2. O cateter mais utilizado no grupo 1 foi o de duplo-lúmen (Arrow International ${ }^{\circledR}$, Estados Unidos da América) com 50\% das cateterizações, No grupo 2, o mais utilizado foi o totalmente implantável (Port-cath ${ }^{\circledR}$, Arrow International ${ }^{\circledR}$, Estados 
790 | J.D.C. MACHADO et al.

Tabela 1. Características gerais de pacientes submetidos à terapia nutricional parenteral. Ribeirão Preto (SP), 2006.

\begin{tabular}{|c|c|c|c|c|c|}
\hline \multirow[t]{2}{*}{ Características } & \multicolumn{2}{|c|}{$\begin{array}{c}\text { Grupo } 1 \\
\text { (Infecção clínica) }\end{array}$} & \multicolumn{2}{|c|}{$\begin{array}{c}\text { Grupo } 2 \\
\text { (Sem infecção clínica) }\end{array}$} & \multirow[t]{2}{*}{$p$} \\
\hline & $M$ & $D P$ & $M$ & $D P$ & \\
\hline Idade (anos) & 55 & $10^{*}$ & 52 & $20^{*}$ & \\
\hline Sexo & $n$ & $\%$ & $n$ & $\%$ & - \\
\hline Masculino & 9 & 81 & 4 & 57 & \\
\hline \multirow[t]{2}{*}{ Feminino } & 2 & 19 & 3 & 43 & \\
\hline & $M$ & $D P$ & $M$ & $D P$ & - \\
\hline Peso $(k g)$ & 46 & 17 & 47 & 21 & \\
\hline IMC $\left(\mathrm{kg} \cdot \mathrm{m}^{-2}\right)$ & 17 & $7^{*}$ & 19 & $6^{*}$ & 0,01 \\
\hline Albumina $\left(g \cdot L^{-1}\right)$ & 28 & $6^{*}$ & 32 & $6^{*}$ & 0,08 \\
\hline Leucócitos $\left(\mathrm{mm}^{-3}\right)$ & 8369 & $4072^{*}$ & 8460 & $5783^{*}$ & 0,48 \\
\hline Linfócitos. $\mathrm{mm}^{-3}$ & 1548 & 1342 & 1396 & 1204 & 0,38 \\
\hline Linfopenia n (\%) & 6 & 38 & 5 & 42 & \\
\hline Doenças Associadas & $n$ & $\%$ & $n$ & $\%$ & - \\
\hline SIC & 8 & 73 & 4 & 57 & \\
\hline DM & 2 & 18 & - & - & \\
\hline HA & 6 & 55 & 1 & 14 & \\
\hline DAC & 1 & 9 & 1 & 14 & \\
\hline DPC & 10 & 9 & 5 & 72 & \\
\hline Insuficiência cardíaca & 2 & 18 & 1 & 14 & \\
\hline Diarréia intratável & 1 & 91 & 4 & 57 & \\
\hline Fístula entérica & 1 & 9 & - & - & \\
\hline Oclusão intestinal & 1 & 9 & - & - & \\
\hline Mieloma múltiplo & 1 & 9 & - & - & \\
\hline Esclerose múltipla & - & - & 1 & 14 & \\
\hline Carcinoma & 3 & 28 & 1 & 14 & \\
\hline
\end{tabular}

IMC: índice de massa corporal; SIC: síndrome do intestino curto; HA: hipertensão arterial; DAC: doença aterosclerótica. DPC: desnutrição protéico-energética; DP: desvio-padrão; M: média.

*Média e Desvio-Padrão

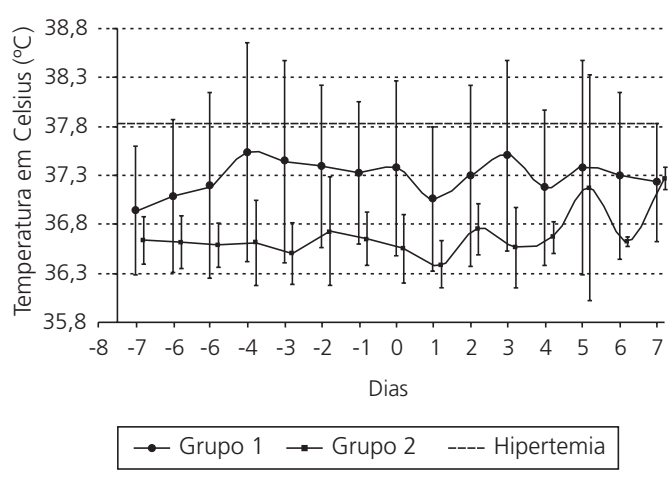

Figura 1. Curva térmica axilar média de pacientes submetidos à terapia nutricional parenteral. Ribeirão Preto (SP), 2006. Notas: ${ }^{*} p<0.005 ;{ }^{* *} p<0.03,{ }^{* * *} p<0.05$

O grupo 1 representa pacientes com sintomas clínicos de infecção. O grupo 2 representa os pacientes sem sintomas e sinais de infecção relacionada ao cateter. A linha pontilhada representa o ponto de corte de hipertermia e febre. Dia 0 representa o dia da retirada do cateter.
Unidos da América), representando 50\% dos casos. A jugular interna foi o local de inserção mais utilizado pela equipe médica (63\%).

A incidência de colonização da ponta dos cateteres do grupo 1 foi de $81 \%$ e a do grupo 2 de $50 \%$, porém, dos cateteres que estavam colonizados apenas $56 \%$ da amostra do grupo 1 tiveram hemoculturas positivas, ou seja tiveram infecção na corrente sanguínea relacionada com o cateter (Tabela 2). Já no grupo 2, esta relação só ocorreu em $8 \%$ do casos. A taxa de infecção total foi de 0,049 pacientes por ano. No grupo 1 foi de 0,51 pacientes por ano, enquanto no grupo 2 foi de 0,015 pacientes por ano.

Os pacientes sem sinais clínicos de infecção permaneceram por mais tempo com o acesso venoso (294, Desvio-Padrão - DP=453 dias), versus 


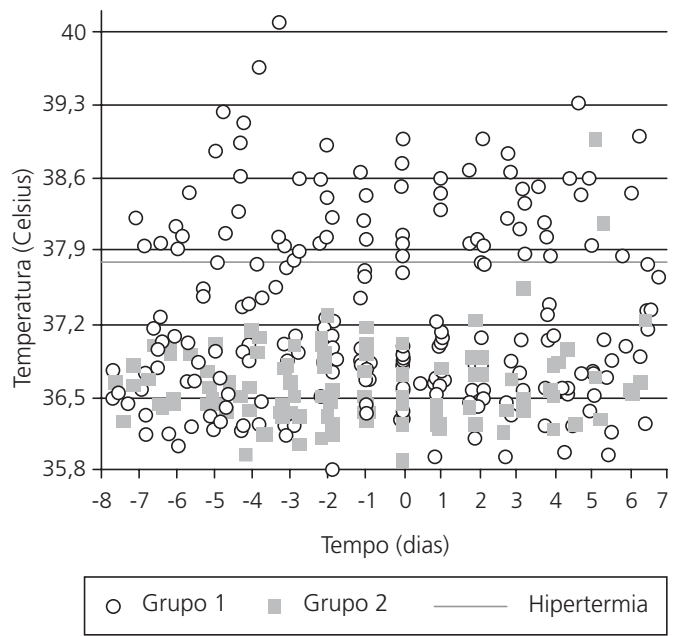

Figura 2. Temperatura axilar de pacientes submetidos à terapia nutricional parenteral.. Ribeirão Preto (SP), 2006.

Notas: O grupo 1 representa pacientes com sintomas clínicos de infecção. O grupo 2 representa os pacientes sem sintomas e sinais de infecção relacionada ao cateter. A linha pontilhada representa o ponto de corte de hipertermia e febre. $\mathrm{O}$ dia 0 representa o dia da retirada do cateter.

$37(\mathrm{DP}=66)$ dias do grupo com infecção clínica $(p=0,038)$.

Ao serem submetidas à cultura semiquantitativa observou-se que $81 \%$ das pontas analisadas no grupo 1 foram positivas, enquanto que no grupo 2 a positividade ocorreu em 50\% dos casos. Os cateteres inseridos na veia jugular foram os que apresentaram a maior freqüência de colonização ou de infecção relacionada ao cateter, sendo esta de $64 \%$, seguida da femoral $50 \%$ e da subclávia $47 \%$.

O staphylococcus sp. foi o microorganismo mais freqüente encontrado nos CVC, seguido por: cândida sp., enterococcussp., proteus, pseudomonas e escherichia coli.

\section{I S C USS Ã O}

Um processo infeccioso nem sempre é diagnosticado clinicamente, alguns pacientes, principalmente os imunodeprimidos, podem evoluir clinicamente sem os sintomas clássicos de
Tabela 2. Características dos cateteres venosos centrais de pacientes submetidos à terapia nutricional parenteral. Ribeirão Preto (SP), 2006.

\begin{tabular}{|c|c|c|c|c|}
\hline \multirow[b]{2}{*}{ Indicação terapêutica } & \multicolumn{2}{|c|}{$\begin{array}{c}\text { Grupo } 1 \\
\text { (Infecção } \\
\text { clínica) }\end{array}$} & \multicolumn{2}{|c|}{$\begin{array}{c}\text { Grupo } 2 \\
\text { (Sem infecção } \\
\text { clínica) }\end{array}$} \\
\hline & $n$ & $\%$ & $n$ & $\%$ \\
\hline Terapia Nutricional & 16 & 100 & 12 & 92 \\
\hline Hidratação & 16 & 100 & 12 & 100 \\
\hline Monitorização clínica & - & - & 1 & 8 \\
\hline Tipos & $n$ & $\%$ & $n$ & $\%$ \\
\hline Totalmente Implantável & 2 & 13 & 6 & 50 \\
\hline Lúmen simples & 6 & 37 & - & - \\
\hline Duplo-lúmen & 8 & 50 & 5 & 42 \\
\hline Umbilical & - & - & 1 & 8 \\
\hline Tempo de acesso (dias) & $37^{1}$ & $66^{1}$ & $294^{1}$ & $453^{1}$ \\
\hline Motivo da retirada do cateter & $n$ & $\%$ & $n$ & $\%$ \\
\hline Suspensão da Terapêutica & - & - & 6 & 50 \\
\hline Bacteremia & 1 & 6 & - & - \\
\hline Febre & 13 & 81 & - & - \\
\hline Hiperemia local inserção & 2 & 13 & - & - \\
\hline Trombose & - & - & 6 & 50 \\
\hline Cultura da ponta & $n$ & $\%$ & $n$ & $\%$ \\
\hline Positiva & 13 & $81^{2}$ & 6 & $50^{2}$ \\
\hline Negativa & 3 & 19 & 6 & 50 \\
\hline Hemocultura $^{3}$ & $n$ & $\%$ & $n$ & $\%$ \\
\hline Positiva & 9 & $69^{2}$ & 1 & $17^{2}$ \\
\hline Negativa & 13 & 31 & 5 & 83 \\
\hline
\end{tabular}

${ }^{1} \mathrm{M}$ : média; $\mathrm{DP}=$ desvio-padrão; \# $c h{ }^{2}: 0,09 ;{ }^{2}$ teste exato de Fisher: 0,$48 ;{ }^{3}$ incluem somente pacientes com cultura da ponta positiva.

infecção, fato que pode dificultar o diagnóstico precoce e o tratamento do processo infeccioso, além de aumentar a morbimortalidade desta população. A subnutrição produz alterações morfológicas em, virtualmente, todos os órgãos. A gravidade da disfunção depende, em parte, do gasto energético e da taxa de renovação celular de determinado tecido ou órgão. Neste aspecto, o sistema imune e o gastrointestinal são os mais vulneráveis ${ }^{6}$. A maioria dos pacientes em TNP avaliados era desnutrida e a maioria era linfopênica, fato que pode sugerir imunodepressão e justificar que, mesmos pacientes assintomáticos cursassem com colonização do cateter, ou infecção sistêmica relacionada ao cateter. Neste estudo a linfopenia foi mais freqüente nos pacientes do grupo 2. 
A fim de combater a desnutrição em pacientes com falência intestinal, ou naqueles em que há contra-indicação de utilizar o trato gastrointestinal, a TNP está indicada, sendo necessário acesso venoso para iniciar a terapia nutricional ${ }^{4}$. Porém, apesar de indispensável para manutenção da vida da maioria de pacientes com insuficiência intestinal, a TNP não está isenta de complicações clínicas, sendo a infecção relacionada ao cateter venoso freqüente ${ }^{5}$. Em estudo com pacientes que recebiam Nutrição Parenteral Prolongada (NPP) por cateteres de longa permanência, Unamuno et al. ${ }^{7}$, em estudo em Ribeirão Preto, obtiveram uma taxa relacionada ao cateter inferior à deste estudo, de 0,029 paciente. Colomb et al. ${ }^{8}$, em um hospital pediátrico francês, obtiveram taxas de 0,78 por paciente ano em população que também necessitava de NPP.

Vários são os fatores relacionados às infecções de CVC dentre os quais citam-se a migração de microorganismos da pele do paciente para o lúmen do cateter ${ }^{9}$, a manipulação do CVC para administração de medicamentos ${ }^{10}$, as condições clínicas dos pacientes que necessitam do acesso central, como idade, ${ }^{11}$ e o uso de nutrição parenteral. Tal fator de risco foi confirmado por Beghetto et al. ${ }^{12}$, em estudo de coorte realizado no Hospital das Clínicas de Porto Alegre durante o período de um ano, comparando o fator de exposição (administração de nutrição parenteral) em pacientes com CVC, no qual os autores observaram um risco relativo de 3,30 , com intervalo de confiança de 1,3-8,3 da população exposta comparada à não exposta. Ainda neste estudo, a desnutrição, o tempo de internação que antecedeu a inserção do CVC e a hiperglicemia sustentada não foram fatores de risco para aumento de infecção ${ }^{12}$.

Quanto à epidemiologia dos microorganismos mais freqüentes nesta população, observou-se que a maioria dos cateteres foi colonizada por Staphylococcus coagulase negativo (24\%) e Staphylococcus aureus (24\%), que, somados perfazem, $48 \%$ dos casos, semelhantes a resultados do Centers for Disease Control and Prevention ${ }^{11}$, que apresentam taxas de $50 \%$ de colonização de CVC por estes microorganismos.

\section{O N C L U S Ã O}

A infecção relacionada ao CVC em pacientes submetidos à terapia nutricional parenteral é freqüente, mesmo em população assintomática, sendo necessário cuidado ao manipular estes cateteres venosos centrais, além de desenvolver técnicas de assepsia eficientes que bloqueiem ou impeçam a colonização destes dispositivos médicos.

\section{REFER Ê NCIAS}

1. Dudrick SJ, Wilmore DW, Vars HM, Rhoads JE. Long-term total parenteral nutrition with growth, development, and positive nitrogen balance. Surgery. 1968; 64(1):134-42.

2. Shils ME, Wright WL, Turnbull A, Brescia F. Long term parenteral nutrition through external arteriovenous shunt. N Engl J Med. 1970; 283(7): 341-4.

3. Ireton-Jones C, DeLegge M. Home parenteral nutrition registry: a five-year retrospective evaluation of outcomes of patients receiving home parenteral nutrition support. Nutrition. 2005; 21(2):156-60. doi:10.1016/j.nut.2004.04.024.

4. O'Keefe SJ, Buchman A, Fishbein T, Jeejeebhoy K, Jeppesen P, Shaffer J. Short bowel syndrome and intestinal failure: Consensus definitions and overview. Clin Gastroenterol Hepatol. 2006; 4(1): 6-10. doi:10.1016/j.cgh.2005.10.002.

5. O'Keefe SJ, Burnes JU, Thompson RL. Recurrent sepsis in home parenteral nutrition patients: an analysis of risk factors. J Parenter Enteral Nutr. 1994; 18(3): 256-63. doi: 10.1177/01486071940 18003256.

6. Caballero B. Global patterns of child health: the role of nutrition. Ann Nutr Metab. 2002; 46(1): S3-S7. doi: 10.1159/000066400.

7. Unamuno MRDL, Carneiro JJ, Chueire FB, Marchini JS, Suen VMM. Uso de cateteres venosos totalmente implantados para nutrição parenteral: cuidados, tempo de permanência e ocorrência de complicações infecciosas. Rev Nutr. 2005; 18(2): 261-9. doi: 10.1590/S1415-527320050002000 10. 
8. Colomb V, Fabeiro M, Dabbas M, Goulet O, Merckx J, Ricour C. Central venous catheter-related infections in children on long-term home parenteral nutrition: incidence and risk factors. Clin Nutr. 2000; 19(5):355-9. doi: 10.1054/clnu.2000. 0132.

9. Veenstra DL, Saint S, Saha S, Lumley T, Sullivan SD. Efficacy of antiseptic-impregnated central venous catheter in preventing catheter-related bloodstream infection: a meta-analysis. JAMA. 1999; 281(3):261-7.

10. Sherertz RJ. Update on vascular catheter infections. Curr Opin Infect Dis. 2004; 17(4):303-7. doi: 10.1097/01.qco.0000136925.52673.16.
11. Centers for Disease Control and Prevention. Guidelines for the prevention of intravascular catheter-related infections. MMWR. 2002; 51(10): 1-34.

12. Beghetto MG, Victorino J, Teixeira L, Azevedo MJ. Parenteral nutrition as a risk factor for central venous catheter: related infection. J Parenter Enteral Nutr. 2005; 29(5):367-73. doi: 10.1177/014860 7105029005367.

Recebido em: 5/12/2007

Versão final reapresentada em: 22/8/2008 Aprovado em: 9/9/2009 



\section{$\mathrm{BMI}$ Case Reports}

Published 5 March 2009

Cite this as: BMJ Case Reports 2009 [doi:10.1136/bcr.07.2008.0521]

Copyright $\odot 2009$ by the BMJ Publishing Group Ltd.

\section{Reminder of important clinical lesson}

\section{Refeeding syndrome, an undiagnosed and forgotten potentially fatal condition}

Juliana Deh Carvalho Machado ${ }^{1,2}$, Vivian Marques Miguel Suen ${ }^{1}$, Fernando Bahdur Chueire ${ }^{1}$, Julio Flávio Meirelles Marchini ${ }^{3}$, Julio Sérgio Marchini ${ }^{3}$

${ }^{1}$ Faculdade de Medicina de Ribeirão Preto da Universidade de São Paulo, Clínica Medica Divisão de Nutrologia, 6 Andar Hospital das Clínicas, Avenida Bandeirantes, 3900, Monte Alegre, Ribeirão Preto, São Paulo 14049-900, Brazil

2 Universidade Estadual Paulista Júlio de Mesquita Filho, Faculdade de Medicina de Botucatu, Clínica Medica, Rubiao Jr, Sem número, Botucatu 18600-000, Brazil

${ }^{3}$ Faculdade de Medicina de Ribeirão Preto da Universidade de São Paulo, Clínica Medica, 6 Andar Hospital das Clínicas, Avenida Bandeirantes, 3900, Monte Alegre, Ribeirão Preto, São Paulo 14049-900, Brazil

Correspondence to:

Juliana Deh Carvalho Machado, juliana@infonet.com.br

\section{SUMMARY}

Refeeding syndrome (RFS) has been well described but is also a frequently forgotten and undiagnosed complication in clinical practice, which, if untreated, may lead to death. Patients who are more prone to developing RFS are those with at least one of the following conditions: $\mathrm{BMI}<16 \mathrm{~kg} / \mathrm{m}^{2}$, a recent unintentional weight loss $>15 \%$, very little nutritional intake for $>10$ days, and/or low plasma concentrations of potassium, phosphate or magnesium before feeding; and those with at least two of the following conditions: $\mathrm{BMI}<18.5 \mathrm{~kg} / \mathrm{m}^{2}$, a recent weight loss $>10 \%$, very little nutritional intake for $>5$ day, and/or a history of alcohol abuse or drug use, including insulin, chemotherapy or diuretics. We report here a patient who, after undergoing intestinal resection (short gut syndrome), presented diarrhoea, weight loss and protein-energy malnutrition. After nutritional assessment, the nutritional support team decided to feed the patient by the parenteral route. After $16 \mathrm{~h}$ of parenteral nutrition, the patient developed supraventricular tachycardia, hypomagnesaemia and hypocalcaemia, and RFS was diagnosed and managed. After intestinal adaptation, the patient is currently able to maintain his nutritional status with nutrition therapy by the oral route. 
Refeeding syndrome (RFS) was first reported during World War II, when starved occupants of Leningrad and prisoners of war were refed and developed oedema, dyspnoea and heart failure, often leading to death. ${ }^{1}$ Although RFS has been well described, it is also a frequently overlooked and undiagnosed complication in clinical practice. ${ }^{2-5}$ It is considered to be a potentially fatal condition that occurs in patients with starvation due to any cause, including anorexia nervosa, diarrhoea, vomiting and alcoholism, and after operations. ${ }^{6}$

\section{CASE PRESENTATION}

A 51-year-old man presented with acute abdominal pain initially characterised as cramping pain, followed by a continuous dull pain. He became unstable and was admitted for an urgent open laparotomy. Acute mesenteric ischaemia was diagnosed and intestinal resection was performed, with about $70 \mathrm{~cm}$ of small bowel being left and immediately reconnected to caecum. As he had been admitted to a hospital without the support of a nutritional team, he was fed by the enteral route, with some complications related to nutritional therapy soon becoming apparent, such as diarrhoea (up to 14 times daily) and weight loss ( $>5 \%$ of body weight). Because of these clinical complications, 20 days after surgery he was referred to the Division of Clinical Nutrition of the Ribeirão Preto School of Medicine for clinical evaluation. On admission, physical examination showed faded mucosa, scaling skin, atrophic lingual papillae, glossitis and depressive oedema. Laboratory examinations showed hypoalbuminaemia, anaemia, hypocalcaemia and hypomagnesaemia (table 1). As the patient had short gut syndrome and was losing weight, with severe diarrhoea, our institutional support team decided to introduce a central venous line via the subclavian vein and parenteral nutrition was prescribed. Because he was at risk for RFS we decided to offer about $50 \%$ of his energy requirements (table 2 ).

Table 2 Composition of the parenteral nutrition delivered to the patient

Sixteen hours after the beginning of nutritional support, the patient developed sinus tachycardia (fig 1) without haemodynamic instability, associated with hypocalcaemia (ionised calcium: 1.02 $\mathrm{mmol} / \mathrm{l})$, hypomagnesaemia $(1.08 \mathrm{mEq} / \mathrm{l})$ and hyperlactataemia $(3.3 \mathrm{mmol} / \mathrm{l}$, normal range: $0.9-1.7 \mathrm{mmol} / \mathrm{l})$. We decided to withdraw parenteral nutrition until cardiac rhythm could be 
controlled.

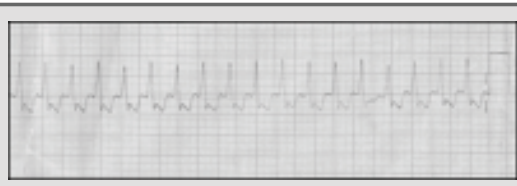

View this figure $(61 \mathrm{~K})$ :

in this window | in a new window | PowerPoint for Teaching

Figure 1 Chest electrocardiogram (derivation D II, 25 mm/s) showing sinus tachycardia (approximately 200-250 bpm), probably secondary to electrolyte disturbances due refeeding syndrome.

\section{TREATMENT}

After treatment with intravenous amiodarone, the patient's tachycardia was controlled. He was found to have Wolf-Parkinson-White syndrome that might have contributed to the development of arrhythmia.

All electrolyte disturbances were corrected and thiamine was supplemented (100 mg per day) before restarting nutritional support. The patient started to receive about $40 \%$ of his energy requirements and after 4 days he was able to receive his full energy requirements without any metabolic complication.

\section{OUTCOME AND FOLLOW-UP}

One month later, the patient was discharged and continued to receive parenteral nutrition for 6 months due to short gut syndrome. After intestinal adaptation, he is able to maintain nutritional status with nutrition therapy by the oral route.

\section{DISCUSSION}

RFS can be defined as the potentially fatal shifts in fluids and electrolytes that may occur in malnourished patients receiving artificial refeeding (whether orally, enterally or parenterally). ${ }^{2,7}$ These shifts result from hormonal and metabolic changes and may cause serious clinical complications. The hallmark biochemical feature of RFS is hypophosphataemia. However, the syndrome is complex and may also feature an abnormal sodium and fluid balance; changes in glucose, protein and fat metabolism; thiamine deficiency; hypokalaemia; and hypomagnesaemia. ${ }^{5,6}$

Mechanisms of RFS can be explained by metabolic complications related to the refeeding process. Patients who are submitted to long starvation periods or who are in catabolic states often develop protein, fat, electrolyte, mineral and vitamin depletion as well as water and salt intolerance. A too rapid refeeding, particularly with carbohydrates, may precipitate a number of metabolic and 
pathophysiological complications, which may adversely affect the cardiac, respiratory, haematological, hepatic and neuromuscular systems, leading to clinical complications and even death. ${ }^{5}$ When we start the refeeding process we promote an anabolic stimulus as we offer nutrients, mainly in the form of carbohydrate. A glucose load stimulates insulin release, causing increased cellular uptake of glucose, phosphate, potassium, magnesium and water, and protein synthesis. This cellular uptake of electrolytes is responsible for the reduction of blood concentrations of phosphate, potassium and magnesium. Decreased levels of such important minerals can lead to altered myocardial function, cardiac arrhythmias, haemolytic anaemia, liver dysfunction, neuromuscular abnormalities, acute respiratory failure, gastrointestinal and renal disorders, and death. ${ }^{6-8}$

To prevent RFS, some steps should be followed, including awareness of the condition and close monitoring of patients at risk, particular regarding their vital functions, fluid balance and plasma electrolytes, such as phosphate and magnesium. ${ }^{8,9}$ Serum phosphate, magnesium, calcium, potassium, urea and creatinine concentrations should be measured before feeding and the measurements should be repeated daily for at least 4 days after feeding is started. ${ }^{9}$

Some authors' suggestions are to refeed slowly and to build up the macronutrient content of the feed over several days (some of them suggest beginning with $25-50 \%$ of the energy requirement, $20 \mathrm{kcal} / \mathrm{kg}$ per day, or not to exceed $1000 \mathrm{kcal}$ ). ${ }^{2,3,8-10}$ Although we followed this guideline and started nutritional support with $50 \%$ of energy requirements, the patient reported here developed RSF, which means that nutritional therapy should be tailored to individual needs. So far, there is no consensus regarding the prevention of RFS and no guidelines are available. Most recommendations are made by experts in clinical nutrition. ${ }^{7}$

To prevent electrolyte imbalance, some experts suggest to anticipate the additional requirements, particularly of phosphate, potassium, magnesium ${ }^{7-9}$ and thiamine ${ }^{5}$ and to minimise salt intake, unless the patient is salt depleted. ${ }^{5,7}$ Fluid intake should also be minimised to that required to replace any deficit or to allow normal renal function. ${ }^{5,7,9}$

Although there is no consensus, some authors recommend correcting vitamin and trace-element deficiencies as well as supplementing them, specifically thiamine, which should be given at least $30 \mathrm{~min}$ before feeding because it is required for carbohydrate metabolism and its deficiency may be related to metabolic acidosis and may predispose to heart failure.

The patient reported here received the recommend daily allowance (RDA) of vitamins and trace elements. Before 2005, most of the parenteral multivitamin preparations offered about $3 \mathrm{mg}$ of thiamine, which might be insufficient for malnourished patients or for patients at nutritional risk. Today, parenteral multivitamin requirements have been modified, with some of the vitamins being increased in relation to the RDA reference (eg, thiamine from 3 to $6 \mathrm{mg}$, folic acid from 400 to 600 $\mu \mathrm{g}$, and ascorbic acid from 100 to $200 \mathrm{mg}$ ). Thiamine deficiency may have been one of the 
mechanisms explaining the RFS of the patient reported here because RFS was no longer present when the patient received thiamine supplementation (100 mg/day).

In summary, RFS may be frequent in clinical practice, mainly among critical ill and malnourished patients. Physicians, dieticians, nurses and the nutritional support team should be ready to prevent, recognise, diagnose and treat RFS. Aggressive refeeding should be avoided to prevent this clinical condition that may lead to death, and all patients at risk of developing RFS should be submitted to clinical and laboratory monitoring.

\section{LEARNING POINTS}

- RFS is a potentially fatal condition caused by rapid initiation of refeeding after a period of undernutrition.

- Awareness of RFS and identification of patients at risk is crucial as the condition is preventable and the metabolic complications are avoidable.

- Nutritional support should be started with caution and slowly.

- Serum electrolytes should be monitored daily during the first week of refeeding, mainly in patients at risk, and all electrolyte deficiencies should first be corrected before total parenteral nutrition is commenced.

Competing interests: None.

Patient consent: Patient/guardian consent was obtained for publication.

\section{REFERENCES}

1. Brozek, J, Chapman, CB, \& Keys, A. Drastic food restriction: effect on cardiovascular dynamics in normotensive and hypertensive conditions. JAMA 1948; 137: 1569-74. [Abstract/Free Full Text]

2. Solomon, SM, \& Kirby, DF. The refeeding syndrome: a review. JPEN J Parenter Enteral Nutr 1990; 14: 90-7.[Abstract]

3. Crook, MA, Hallyy, V, \& Panteli, JV. The importance of refeeding syndrome. Nutrition 2001; 17: 632-7.[CrossRef][Medline]

4. Marinella, MA. Refeeding syndrome: implications for the inpatient rehabilitation unit. Am Phys Med Rehabil 2004; 83: 65-8.[CrossRef]

5. Stanga, Z, Brunner, A, Leuenberger, M, et al. Nutrition in clinical practice-the refeeding syndrome: illustrative cases and guidelines for prevention and treatment. Eur J Clin Nutr 2008; 62: 687-94.[CrossRef][Medline]

6. Gariballa, S. Refeeding syndrome: a potentially fatal condition but remains underdiagnosed 
and undertreated. Nutrition 2008; 24: 604-6.[CrossRef][Medline]

7. Mehanna, HM, Moledina, J, \& Travis, J. Refeeding syndrome: what it is, and how to prevent and treat it. BMJ 2008; 336: 1495-8.[Free Full Text]

8. Miller, SJ. Death resulting from overzealous total parenteral nutrition: the refeeding syndrome revisited. Nutr Clin Pract 2008; 23: 166-71.[Abstract/Free Full Text]

9. National Institute for Health and Clinical Excellence. Nutrition support in adults. Clinical guideline CG32. 2006. http://www.nice.org.uk/page.aspx?o=cg032 (accessed 22 May 2008).

10. Kraft, MD, Btaiche, IF, \& Sacks, GS. Review of the refeeding syndrome. Nutr Clin Pract 2005; 20: 625-33.[Abstract/Free Full Text]

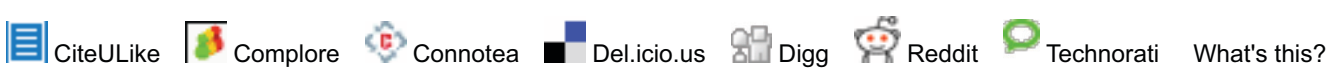


Table 1 Patient's anthropometric measurements and clinical-laboratory parameters on admission

\begin{tabular}{|l|c|c|} 
& Patient & Reference value \\
\hline Weight $(\mathrm{kg})$ & 56 & \\
\hline Height $(\mathrm{cm})$ & 170.5 & \\
\hline Body mass index $\left(\mathrm{kg} / \mathrm{m}^{2}\right)$ & 19.3 & \\
\hline Basal energy expenditure: Harris-Benedict $(\mathrm{kcal})$ & 1.339 & \\
\hline Total energy expenditure: Harris-Benedict x1.2 (kcal) & 1607 & \\
\hline Albumin $(\mathrm{g} / \mathrm{l})$ & 24 & $35-48$ \\
\hline Potassium $(\mathrm{mmol} / \mathrm{l})$ & 3.5 & $3.5-5.0$ \\
\hline Magnesium $(\mathrm{mEq} / \mathrm{l})$ & 1.16 & $1.6-2.5$ \\
\hline Phosphate $(\mathrm{mg} / \mathrm{dl})$ & 2.4 & $2.5-5.6$ \\
\hline lonised calcium $(\mathrm{mmol} / \mathrm{l})$ & 0.98 & $1.14-1.29$ \\
\hline
\end{tabular}


Table 2 Composition of the parenteral nutrition delivered to the patient

\begin{tabular}{|l|c|}
\hline Nutrient & Amount delivered \\
\hline Amino acids, $10 \%$ & $50 \mathrm{~g}$ \\
\hline Glucose, $50 \%$ & $112.5 \mathrm{~g}$ \\
\hline Lipids, $20 \%$ & $20 \mathrm{~g}$ \\
\hline Twice-distilled water & $180 \mathrm{ml}$ \\
\hline Total energy (kcal) & 830 \\
\hline Non-protein energy (kcal) & 630 \\
\hline Glucose infusion rate (mg/kg per min) & 1.4 \\
\hline Potassium & $50 \mathrm{mEq}$ \\
\hline Sodium & $64 \mathrm{mEq}$ \\
\hline Calcium & $15 \mathrm{mEq}$ \\
\hline Phosphate & $20 \mathrm{mEq}$ \\
\hline Magnesium & $12 \mathrm{mEq}$ \\
\hline Thiamine & $3 \mathrm{mg}$ \\
\hline Riboflavin & $3.6 \mathrm{mg}$ \\
\hline Niacin & $40 \mathrm{mg}$ \\
\hline Pyridoxine & $4 \mathrm{mg}$ \\
\hline Folate & $400 \mu \mathrm{gg}$ \\
\hline Biotin & $60 \mu \mathrm{g}$ \\
\hline Pantothenic acid & $15 \mathrm{mg}$ \\
\hline Cyanocobalamin & $5 \mu \mathrm{g}$ \\
\hline Vitamin C & $100 \mathrm{mg}$ \\
\hline Vitamin A & $3300 \mathrm{IU}$ \\
\hline Vitamin D & $200 \mathrm{IU}$ \\
\hline Vitamin E & $10 \mathrm{mg}$ \\
\hline Zinc & $5 \mathrm{mg}$ \\
\hline Copper & $1.6 \mathrm{mg}$ \\
\hline Chromium & $20 \mu \mathrm{gg}$ \\
\hline Manganese & $800 \mathrm{mg}$ \\
\hline
\end{tabular}




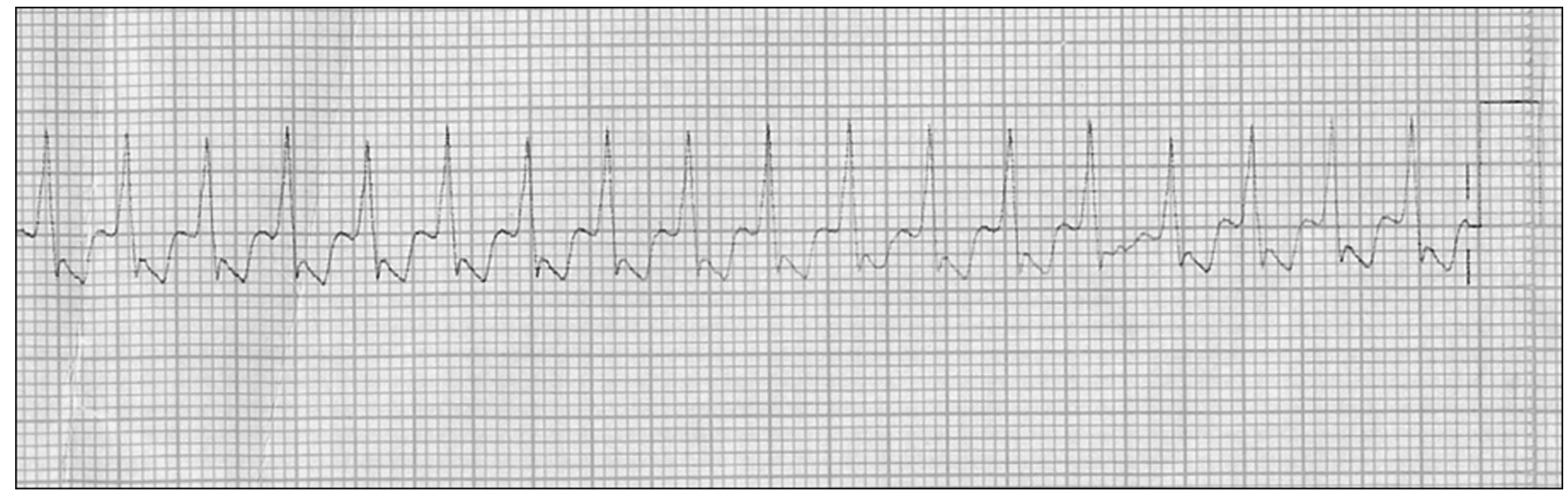




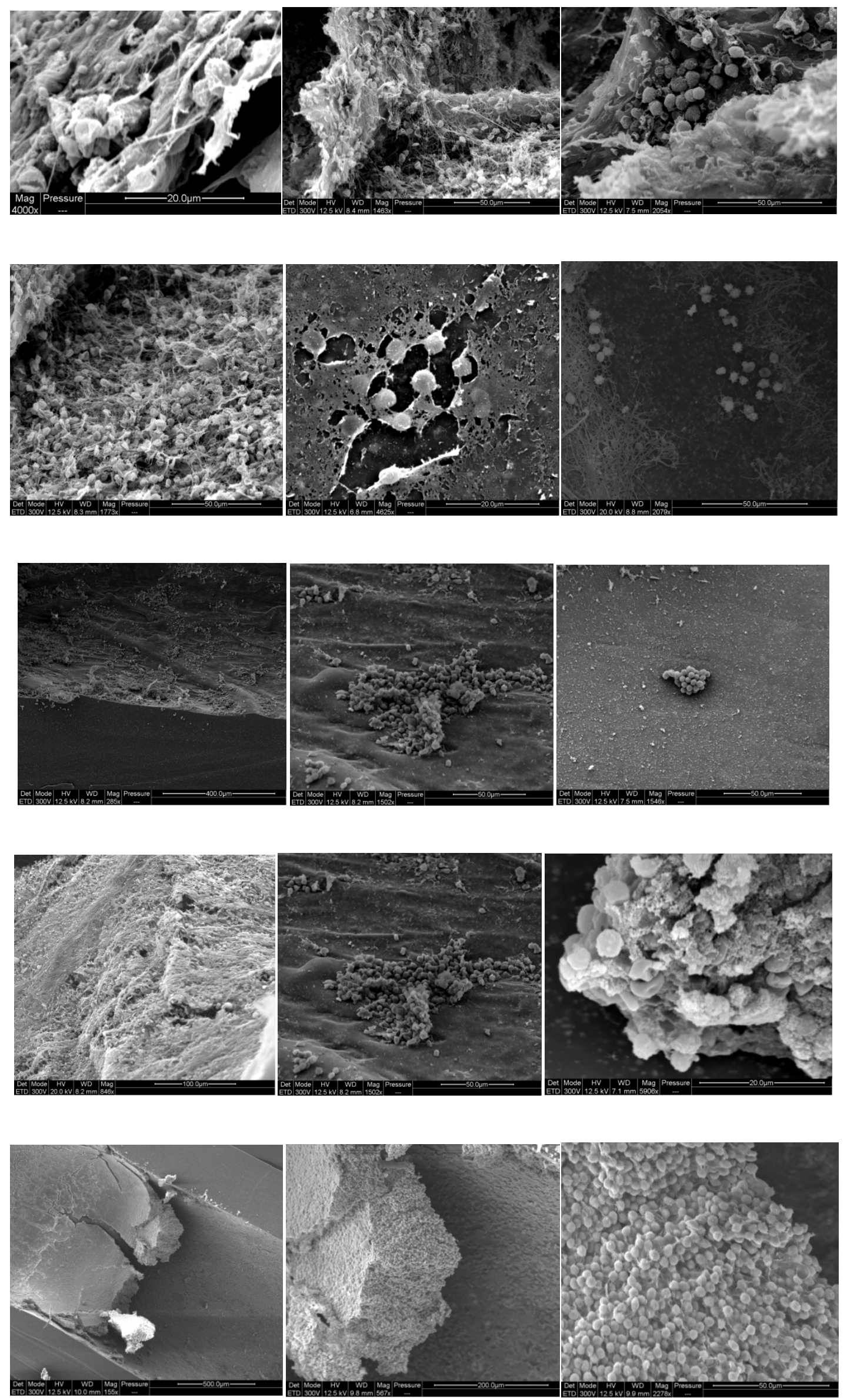

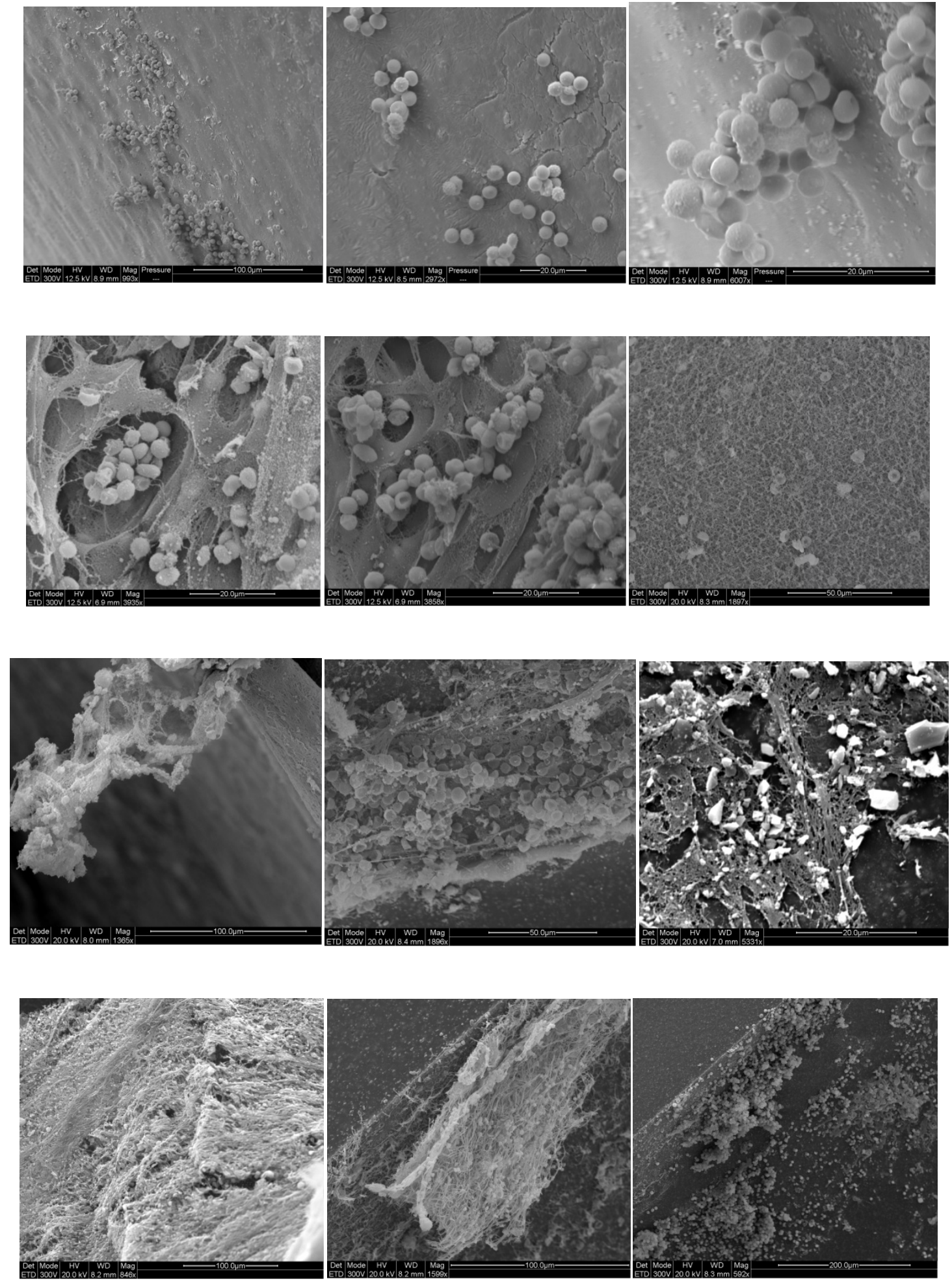

Microfotrografias de cateteres venosos centrais onde observam-se a matriz dos biofilmes. Supõe se que estas estrutura além de permitirem a proliferação bacteriana, dificultam a ação dos agentes antimicrobianos, além de permitirem o comensalismo ou simbiose de micro-organismos. 